\title{
International Journal of Thermal Sciences
}

\section{Droplet entrainment within the evaporator to the suitable volume-filling ratio of a vertical two-phase closed thermosyphon

\author{
--Manuscript Draft--
}

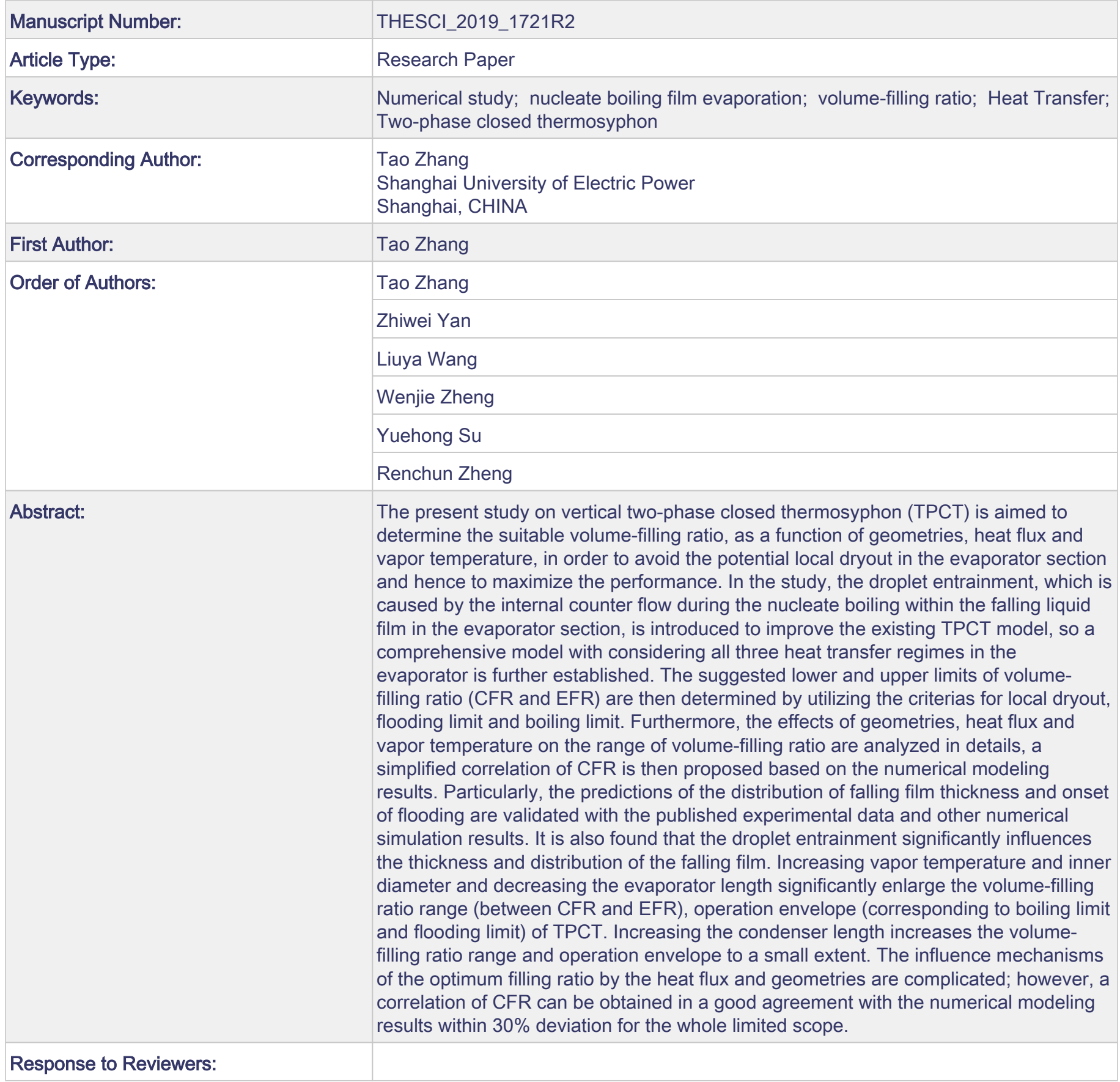




\section{Dear Editor:}

We submit our manuscript entitled "Droplet entrainment within the evaporator to the suitable volume-filling ratio of a vertical two-phase closed thermosyphon" to International Journal of Thermal Science for publication.

We believe the paper may be of particular interest to the readers of your journal as it is an original research paper to determine the volume-filling ratio of a two-phase closed thermosyphon. The droplet entrainment, which is caused by the internal counter flow during the nucleate boiling within the falling liquid film in the evaporator section, is introduced to improve the existing TPCT model, so a comprehensive model with considering all three heat transfer regimes in the evaporator is further established. The suggested lower and upper limits of the volume-filling ratio are then determined by utilizing the criteria for local dryout, flooding, and boiling limits. Furthermore, a parametric analysis is implemented and a simplified correlation of CFR is then proposed based on the numerical modeling results.

The manuscript has not been previously published, nor is it currently submitted for review to any other journal, and will not be submitted elsewhere before a decision is made by this journal.

Thank you very much for your attention and consideration.

Sincerely, T. Zhang, Z.W. Yan, L.Y. Wang, W.J. Zheng, Y.H. Su, R.C. Zheng 


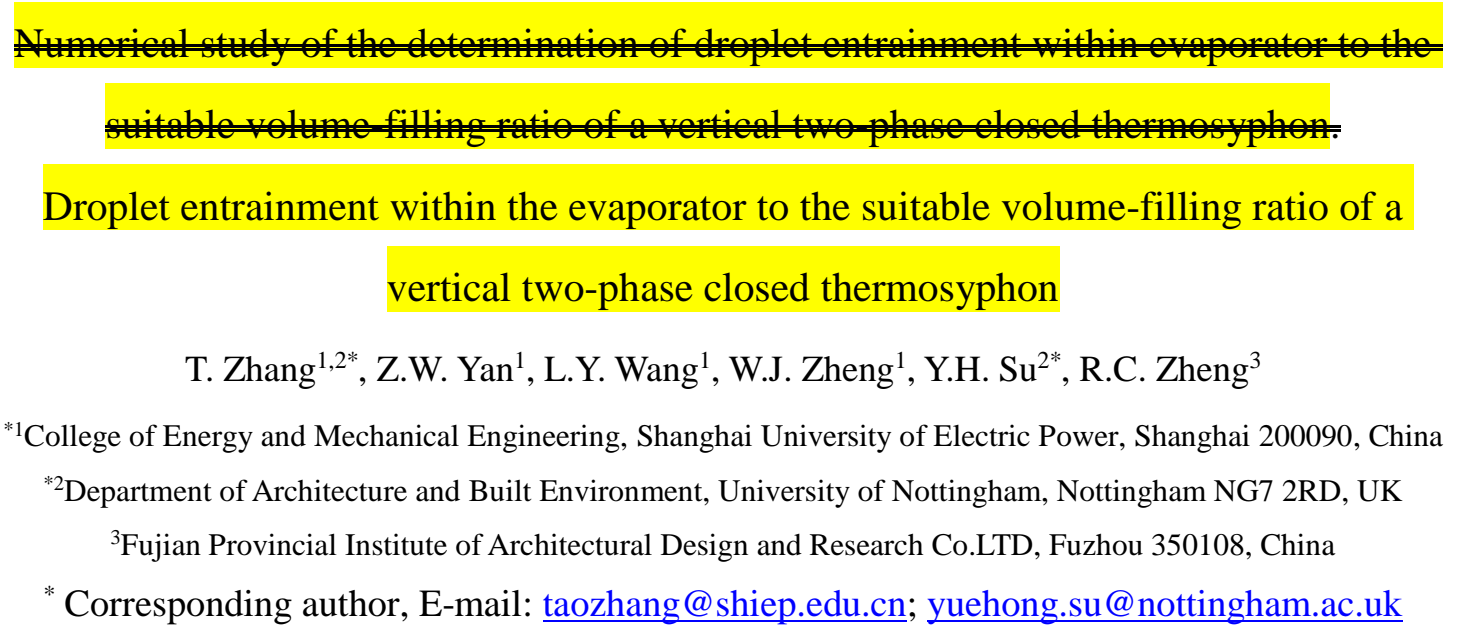

Abstract: The present study on vertical two-phase closed thermosyphon (TPCT) is aimed to determine the suitable volume-filling ratio, as a function of geometries, heat flux and vapor temperature, in order to avoid the potential local dryout in the evaporator section and hence to maximize the performance. In the study, the droplet entrainment, which is caused by the internal counter flow during the nucleate boiling within the falling liquid film in the evaporator section, is introduced to improve the existing TPCT model, so a comprehensive model with considering all three heat transfer regimes in the evaporator is further established. The suggested lower and upper limits of volume-filling ratio (CFR and EFR) are then determined by utilizing the criterias for local dryout, flooding limit and boiling limit. Furthermore, the effects of geometries, heat flux and vapor temperature on the range of volume-filling ratio are analyzed in details, a simplified correlation of CFR is then proposed based on the numerical modeling results. Particularly, the predictions of the distribution of falling film thickness and onset of flooding are validated with the published experimental data and other numerical simulation results. It is also found that the droplet entrainment significantly influences the thickness and distribution of the falling film. Increasing vapor temperature and inner diameter and decreasing the evaporator length significantly enlarge the volume-filling ratio range (between CFR and EFR), operation envelope (corresponding to boiling limit and flooding limit) of TPCT. Increasing the condenser length increases the volume-filling ratio range and operation envelope to a small extent. The influence mechanisms of the optimum filling ratio by 
the heat flux and geometries are complicated; however, a correlation of CFR can be obtained in a good agreement with the numerical modeling results within $\pm 30 \%$ deviation for the whole limited scope.

Keywords: two-phase closed thermosyphon; volume-filling ratio; numerical study; heat transfer; nucleate boiling film evaporation.

\begin{tabular}{|c|c|c|c|}
\hline Nomenclature & & & \\
\hline$C_{p}$ & Specific heat, $\mathrm{J} /(\mathrm{kg} \cdot \mathrm{K})$ & $b$ & Boiling \\
\hline$D$ & Diameter, $\mathrm{m}$ & $b l$ & Boiling limit \\
\hline$g$ & Acceleration of gravity, $\mathrm{m} / \mathrm{s}^{2}$ & con & Condenser section \\
\hline$h$ & $\begin{array}{l}\text { Convective heat transfer coefficient, } \\
\mathrm{W} /\left(\mathrm{m}^{2} \cdot \mathrm{K}\right)\end{array}$ & $C C-F$ & $\begin{array}{lll}\text { Combined } & \text { convection } & \text { film } \\
\text { evaporation } & & \\
\end{array}$ \\
\hline$h_{f g}$ & Latent heat, $\mathrm{kJ} / \mathrm{kg}$ & eva & Evaporator section \\
\hline$k$ & Heat conductivity coefficient, $\mathrm{W} /(\mathrm{m} \bullet \mathrm{K})$ & ef & Flim of Evaporator \\
\hline$L$ & Length, $\mathrm{m}$ & $e p$ & Pool of Evaporator \\
\hline$m$ & Mass,kg & $i$ & Interfacial or inner \\
\hline $\mathrm{Nu}$ & Nusselt number,- & $l$ & Liquid \\
\hline$P$ & Pressure, $\mathrm{Pa}$ & $L C-F$ & $\begin{array}{lll}\text { Laminar convection } & \text { film } \\
\text { evaporation } & & \end{array}$ \\
\hline $\operatorname{Pr}$ & Prandtl number, - & $N B-F$ & Nucleate boiling film evaporation \\
\hline$q$ & Heat flux, W/m ${ }^{2}$ & $p$ & Pool \\
\hline$R$ & Heat transfer resistance, ${ }^{\circ} \mathrm{C} / \mathrm{W}$ & $s$ & Saturated vapor \\
\hline$R e$ & Reynolds number, - & $v$ & Vapor \\
\hline$R e_{x}$ & Liquid film local Reynolds number, - & $w$ & Wall \\
\hline$R e_{l}$ & Liquid film Reynolds number, - & $x$ & Local \\
\hline $\operatorname{Re}_{f}$ & $\begin{array}{l}\text { Liquid film Reynolds number at the onset } \\
\text { of flooding, - }\end{array}$ & & \\
\hline$T$ & Temperature, ${ }^{\circ} \mathrm{C}$ or $\mathrm{K}$ & Greek symbol & \\
\hline$u$ & Velocity of $x$-axis, m/s & $\mu$ & Dynamic viscosity, $\mathrm{Pa} \bullet \mathrm{s}$ \\
\hline$v$ & Velocity of $y$-axis, $\mathrm{m} / \mathrm{s}$ & $\rho$ & Density, $\mathrm{kg} / \mathrm{m}^{3}$ \\
\hline V & Volume, $\mathrm{m}^{3}$ & $v$ & kinematic viscosity, $\mathrm{m}^{2} / \mathrm{s}$ \\
\hline$x$ & $x$-axis or distance from zero of $x$-axis & $\tau$ & Shear stress, N/m² \\
\hline \multirow[t]{2}{*}{$y$} & $y$-axis or distance from zero of $y$-axis & $\delta$ & Thickness, m \\
\hline & & $\Gamma$ & $\begin{array}{l}\text { Mass flow rate per unit perimeter, } \\
\mathrm{kg} /(\mathrm{m} \bullet \mathrm{s})\end{array}$ \\
\hline Abbreviations & & $\alpha$ & Void fraction,- \\
\hline$C F R$ & Critical volume-filling ratio & $\sigma$ & Surface tension, N/m \\
\hline$E F R$ & $\begin{array}{l}\text { Volume-filling ratio when evaporator is } \\
\text { fulfilled replenished }\end{array}$ & $\Phi$ & Power throughput, $\mathrm{W}$ \\
\hline$T P C T$ & Two-phase closed thermosyphon & & \\
\hline \multirow[t]{2}{*}{ VFR } & Volume-filling ratio & superscript & \\
\hline & & $*$ & Dimensionless \\
\hline
\end{tabular}




\begin{tabular}{|l|l|l|l|}
\hline Subscripts & & - & Average \\
\hline$a$ & Adiabatic section & & \\
\hline
\end{tabular}

\section{Introduction}

The two-phase closed thermosyphon (TPCT), which is essentially a gravity-assisted wickless heat pipe, has emerged as the most appropriate thermal control solution due to their low cost and excellent heat transfer capabilities [1]. The internal flow of TPCT is normally assumed as an annular, countercurrent and two-phase flow, which consists of many complex physical processes.

Performance of a TPCT is significantly affected by geometries, temperature, volume-filling ratio, inclination angle and working fluid. Among these factors, the volume-filling ratio (VFR) is deemed of great important, because it can directly determine whether the TPCT functioning well [2-4]. An operation and design concern, however, is determining the VFR of the working fluid, as a function of TPCT dimensions, the power or heat flux throughput, type and vapor temperature of the working fluid, to maximize the TPCT performance.

The suggested filling ranges for the TPCT are mostly obtained through experiments. Imura et al [5] suggested that the optimum VFR ranged between 1/5-1/3 of the evaporation volume, while $1 / 5$ should be taken for a tube with a smaller diameter and $1 / 3$ for a larger diameter. The results of Imura et al [5] were similar to that of Harada et al [6], in whose work the optimum VFR between 0.25-0.30 was suggested. However, the results from Feldman et al [7] suggested that the optimum VFR should be $18 \%-20 \%$ of the whole volume of TPCT. Negishi and Sawada [8] suggested that the optimum VFR ranged between $25 \%-60 \%$ and $40 \%-75 \%$ of the evaporation volume for water and ethanol, respectively. There are also many other experiments involve the influences of VFR to the thermal performances [9-11], however, the results vary from each other.

The numerical models employed to explore the optimum VFR and heat transfer characteristic of TPCT are usually assumed that the heat transfer process within TPCT can be divided into three sub-processes, namely pool boiling, filmwise evaporation and filmwise reflux condensation $[12,13]$. For different heat transfer regimes and 
VFRs, three flow patterns and two transitions were introduced by Jiao et al [14]. To ensure functional operation, a potential dryout within the falling liquid film, namely local dryout, in the evaporator section should be avoided. The local dryout will result in the temperature rising within the evaporator and thereby decreases the thermal performance. On the other hand, a high VFR, although can avoid liquid film dryout in the evaporator, should be also avoided because of two reasons. Firstly, it significantly degrades the TPCT performance, because the heat transfer coefficient of the liquid film is significantly (more than an order of magnitude) higher than that of the pool boiling [15]. Secondly, the two-phase mixture could be extended into the condenser under high VFR, which leads to the heat transfer deterioration within the condenser and the periodic burst boiling within the evaporator.

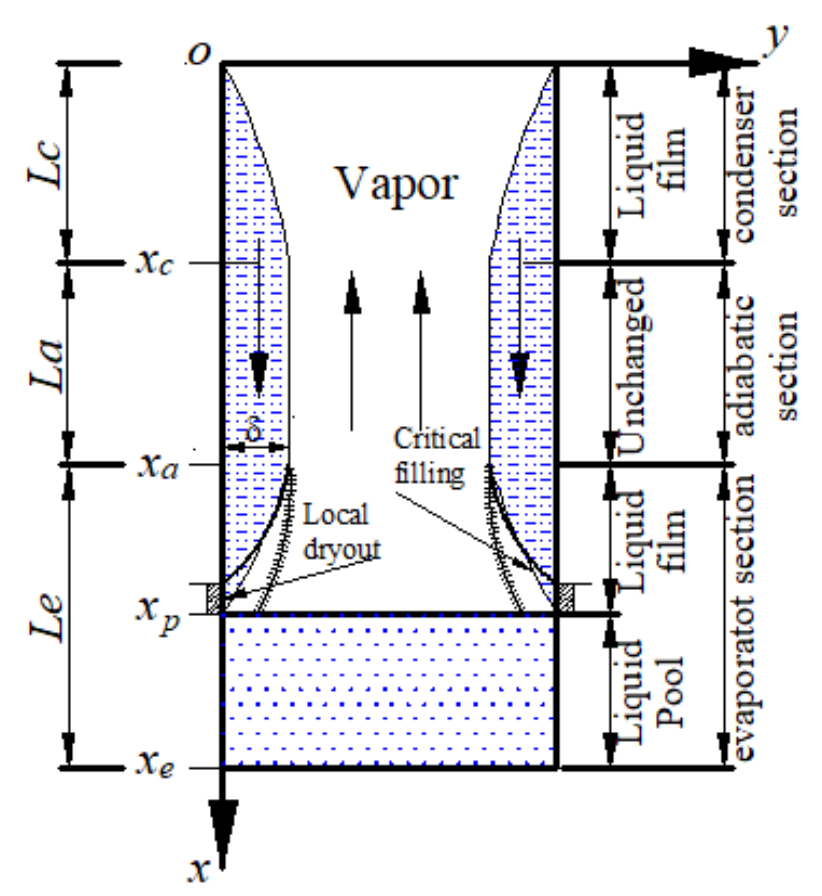

Fig.1 A schematic of TPCT

However, as suggested in [15], one should lengthen the liquid film length to achieve a better heat transfer performance. As shown in Fig.1, the liquid film length takes the highest value when the liquid film thickness in the evaporator taking the minimum value, below which the liquid film will dryout. Correspondingly, the VFR takes the smallest value while the heat transfer coefficient takes the highest value under this condition. VFR under this condition is also defined as the lower boundary 
of the filling envelope and CFR by El-Genk et al [16] and Jiao et al [14,17], respectively. While the liquid film length takes the smallest value, that is zero, when the evaporator is full of working liquid. VFR under this condition is defined as the upper boundary of the operation envelope and EFR, respectively, by above two researchers. It is also identified as the maximum VFR for stable operation. Correspondingly, the heat transfer coefficient takes the smallest value under this condition. In conclusion, a satisfactory state of VFR is situated between CFR and EFR.

Based on the three sub-processes, El-Genk et al [16] and Jiao et al [14,17] numerically studied the filling ranges of TPCTs; while Shabgard et al[18] numerically studied the thermal characteristics of TPCT under different VFRs. According to the results of El-Genk et al [16] and Jiao et al [14,17], CFR and EFR of TPCT are affected simultaneously by geometries of TPCT and vapor temperature. This is also the reason why the experimental results vary from each other.

However, as shown in Fig.2, Cerza et al $[19,20]$ found bubble growing and boiling in the falling liquid films in evaporator, and El-Genk et al [15] then sorted the heat transfer regimes within the falling liquid film into three patterns. In particular, under the high heat flux, the growing vapor bubbles burst at the liquid-vapor interface, dispersing tiny droplets of liquid into the vapor flow. Bubble nucleation at the wall and entrainment of tiny liquid droplets in the vapor flow lead to the enhancement of heat transfer and decrement of film thickness in the evaporator at the same time.
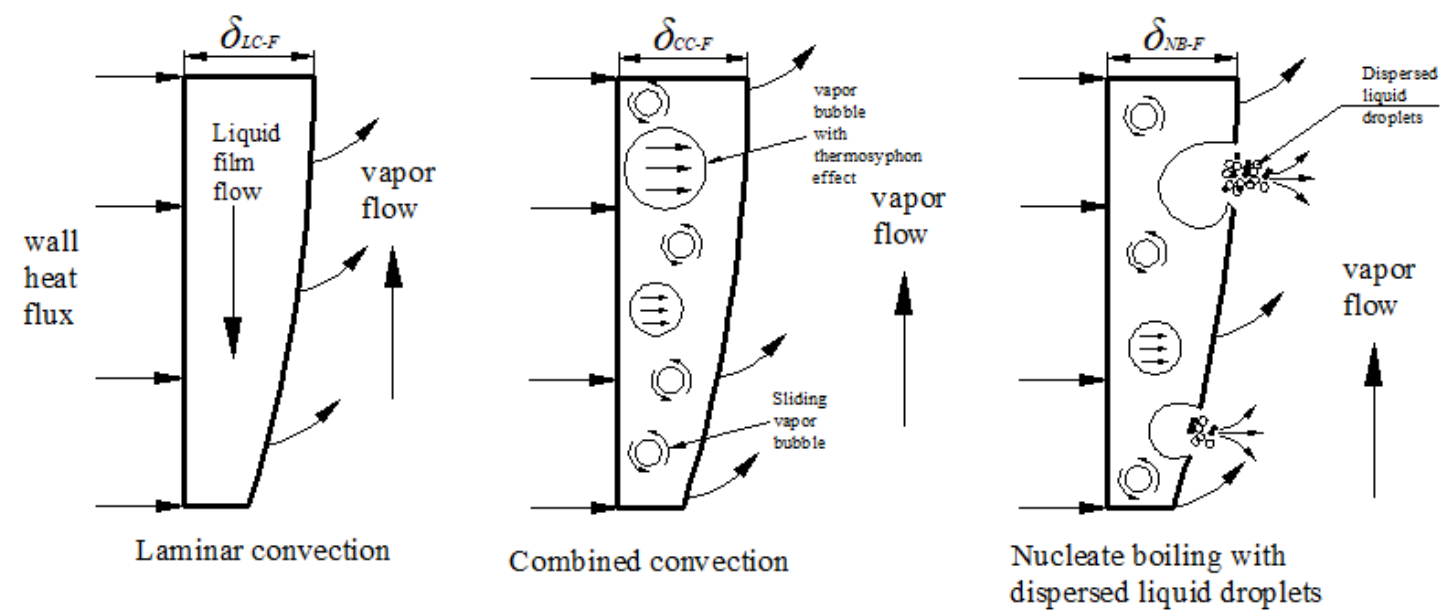

Fig.2 A schematic of the different heat transfer regimes of falling liquid film in a TPCT (reprint 
from El-Genk et al [15])

To the authors' best knowledge, as illustrated on the left side of Fig.2, most of the previous numerical models were established on the basis that the heat transfer regime of the falling liquid film in the evaporator is laminar convection film evaporation. However, the droplet entrainment from the falling liquid film, which is caused by nucleate boiling, will shorten the length of the liquid film under some circumstances and further significantly influences the CFR of TPCT. Further efforts are required to discover the certain impacts. Therefore, in the present study, the entrainment rate, which is caused by the countercurrent vapor flow during the nucleate boiling within the falling liquid film, is introduced to improve the previous TPCT models. A governing equation is developed for the nucleate boiling filmwise evaporation; based on that, a comprehensive model with considering all the three heat transfer regimes in the evaporator is further established. The suggested CFR and EFR are then determined and updated by utilizing the criterias for local dryout, flooding limit and boiling limit; and the effects of geometries and temperature on the filling range are further analyzed in detail. Finally, a simplified correlation for CFR, based on the predicted data from the present model, is proposed.

\section{Mathematical model}

The physical model for the TPCT, as shown in Fig.1, can be divided into three sections: a condenser, an evaporator and an adiabatic section. Normally, changes of mass and momentum are ignored within the adiabatic section. The governing equations, therefore, mainly consist of the liquid film and the liquid pool. Modeling of the TPCT is established on the basis of following assumptions that have been well-accepted: (1) temperature within the liquid film is uniform in the $y$-axis, physical properties are therefore uniform too; (2) Since the film thickness is much less than the tube radius, the curvature effect is negligible and the effects of convective term in momentum and energy equations are negligible; (3) compressibility of the vapor is negligible.

2.1 Reflux film condensation and laminar convection film evaporation

Fig. 3 shows the energy balance of a segment of falling film in the condenser. 
Based on the above assumptions, the governing equations of mass, momentum and energy for a representative elemental volume within the liquid film are (It is noted that energy transfer in $y$ direction in the evaporator is opposite to the condenser):

$\frac{\partial u}{\partial x}+\frac{\partial v}{\partial y}=0$

$\mu_{l} \frac{\partial^{2} u}{\partial y^{2}}+\left(\rho_{l}-\rho_{v}\right) g=0$

$$
\frac{\partial^{2} T}{\partial y^{2}}=0
$$

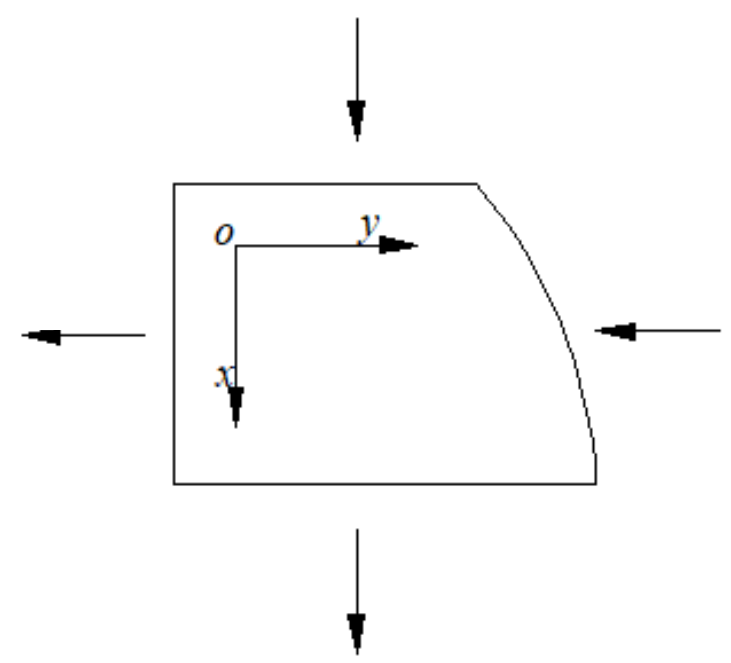

Fig.3 The energy balance of representative elemental volume in the laminar liquid film of the condenser

According to simulation results of Shabgard et al[18], the vapor pressure and the vapor temperature vary little along the falling film, especially under the CFR conditions. Meanwhile, simulation results of different variables were very close when pressure gradient was considered or not. Therefore, the axial pressure gradient is also ignored in the governing equations.

The associated boundary conditions (constant heat flux boundary condition ) are:

$$
\begin{aligned}
& y=0: u=v=0, \mu_{l} \frac{\partial u}{\partial y}=\tau_{w} \\
& y=\delta: \mu_{l} \frac{\partial u}{\partial y}=\tau_{i}, k_{l} \frac{\partial T}{\partial y}=\frac{\partial \Gamma}{\partial x} h_{f g}, T=T_{s}
\end{aligned}
$$


$x=0: u=0, \delta=0, u_{v}=0$

Integrating the governing equations and boundary conditions yields:

$u_{l}(y)=\left(\frac{\left(\rho_{l}-\rho_{v}\right) g \delta-\tau_{i}}{\mu_{l}}\right) y-\left(\frac{\left(\rho_{l}-\rho_{v}\right) g}{2 \mu_{l}}\right) y^{2}$

$\Gamma=\int_{0}^{\delta} \rho_{l} u_{l} d y=\frac{\rho_{l}\left(\rho_{l}-\rho_{v}\right) g}{3 \mu_{l}} \delta^{3}-\frac{\rho_{l} \tau_{i}}{2 \mu_{l}} \delta^{2}$

$h_{f g} d \Gamma=q d x+d\left[\int_{o}^{\delta} \rho_{l} u_{l} h_{l} d y\right]$

$\frac{3 C_{2} C_{3}}{32} \delta^{4}+\left(\frac{C_{1} C_{3}}{3}-\frac{C_{2} \tau_{i}}{9}\right) \delta^{3}-\frac{C_{1} \tau_{i}}{2} \delta^{2}=x$

$\frac{3 C_{2} C_{3}}{32}\left(\delta^{4}-\delta_{a}^{4}\right)+\left(\frac{C_{1} C_{3}}{3}-\frac{C_{2} \tau_{i}}{9}\right)\left(\delta^{3}-\delta_{a}^{3}\right)-\frac{C_{1} \tau_{i}}{2}\left(\delta^{2}-\delta_{a}^{2}\right)=x-x_{a}$

Where $C_{1}=\frac{h_{f g} \rho_{l}}{q \mu_{l}}, C_{2}=\frac{\rho_{l} C_{p}}{\mu_{l} k_{l}}, C_{3}=\left(\rho_{l}-\rho_{v}\right) g$.

The shear stress at the liquid-vapor interface, $\tau_{i}$, which consists of viscous shear stress, $\tau_{f}$, and dynamic shear stress, $\tau_{m}$, can generally be calculated as:

$\tau_{i}=\tau_{f} \pm \tau_{m}=0.5 C_{f i} \rho_{v}\left(u_{l(\delta)}+u_{v}\right)^{2} \pm \frac{q_{e v a}\left(u_{l(\delta)}+u_{v}\right)}{h_{f g}}$

$u_{v}=4 \Gamma /\left(\rho_{l} D_{i}\right)$

where $C_{f i}$ is the friction coefficient and its value can be referenced to Yang [21]. The plus and minus signs on the right-hand-side of Eq.(9) account for the effect of condenser and evaporator at the liquid-vapor interface, respectively [22].

The heat transfer coefficients of the film condensation and laminar convection film evaporation are defined as $[12,13]$ :

$$
\begin{array}{ll}
h=\frac{k_{l}}{\delta} & \text { (Laminar liquid film, } \left.\operatorname{Re}_{l} \leq 2040 ;\right) \\
h=\frac{0.056 \operatorname{Re}_{l}^{-0.2} \operatorname{Pr}^{1 / 3} k_{l}}{\left(v_{l}^{2} / g\right)^{1 / 3}} & \left(\text { Turbulent liquid film, } \operatorname{Re}_{l} \geq 2040\right)
\end{array}
$$




$$
\operatorname{Re}_{l}=\frac{u_{l} \delta}{v_{l}}=\frac{4 \Gamma_{x}}{\mu_{l}}
$$

2.2 Nucleate boiling film evaporation and combined convection film evaporation

As shown in Fig. 2, laminar convection film evaporation occurs under the low heat fluxes. In this regime, the liquid film has a progressively decreasing thickness along the evaporator under the interaction of vaporization and interfacial shear stress. However, under the high heat fluxes, nucleate boiling occurs within the falling liquid film. Bubbles grow in the falling liquid film and continue to grow as they are swept from their nucleation sites until they burst at the liquid-vapor interface and disperse tiny droplets into the vapor flow. The bubbles are continuously growing, sliding and dispersing during the nucleate boiling film evaporation. Heat transfer regime situated between laminar convection and nucleate boiling is named combined convection, in which bubbles are growing and sliding but not splashing.

The vapor bubbles bursting at the liquid-vapor interface disturbs the shear stress at the liquid-vapor interface and further weaken the decisive effect of shear stress on the thickness of the liquid film. The authors assume that the decisive effect is replaced by the droplet entrainment under this condition. Besides, bubbles growing and sliding within the liquid film must also muss up the falling flow pattern of the liquid film; thus, additional with the last assumption, the change of the flow velocity of the liquid film, along the evaporator, is further neglected in the present study; furthermore, since the liquid film thickness is much less than tube inner diameter, influences of bubbles to the mass and thickness of the liquid film are negligible. For the nucleate boiling film evaporation, the equations can be expressed as:

$$
\begin{aligned}
& \frac{d \Gamma}{d x}+\frac{q_{e v a}}{h_{f g}}\left(1+e_{b}\right)=0 \\
& \frac{d \delta}{d x}=\frac{1}{\rho_{l} \overline{u_{l(\delta)}}} \frac{d \Gamma}{d x}
\end{aligned}
$$

where $e_{b}$ is the entrainment rate caused by the internal countercurrent flow, it can be calculated as [23]: 
$\frac{e_{b}}{1-e_{b}}=10^{-2.52} \rho_{l}^{1.08} \rho_{v}^{0.18} \mu_{l}^{0.27} \mu_{v}^{0.28} \sigma^{-1.8} D_{i}^{1.72} u_{l(\delta)}^{0.70} u_{v}^{1.44} g^{0.46}$

The thickness of liquid film under the combined convection film evaporation is assumed as the average value of laminar convection film evaporation and nucleate boiling film evaporation, that is:

$$
\delta_{C C-F}=\frac{\delta_{L C-F}+\delta_{N B-F}}{2}
$$

The heat transfer regimes and heat transfer coefficients within the liquid film are respectively classified and calculated by El-Genk et al [15]:

$$
\begin{aligned}
& N u_{L C-F}=(4 / 3)^{1 / 3}\left(\operatorname{Re}_{x}\right) \quad\left(X_{F} \leq 10^{9}\right) \\
& N u_{N B-F}=1.155 \times 10^{-3} N_{u f}^{0.33} \operatorname{Pr}_{l}^{0.35}\left(\frac{p I_{m}}{\sigma}\right)^{0.7}\left(\frac{q_{\text {eva }} I_{m}}{\rho_{v} h_{f g} \nu_{l}}\right)^{0.7} \quad\left(X_{F} \geq 2.7 \times 10^{10}\right) \\
& N u_{C C-F}=\left(N u_{L C-F}^{3}+N u_{N B-F}^{3}\right)^{1 / 3} \quad\left(10^{9}<X_{F}<2.7 \times 10^{10}\right)
\end{aligned}
$$

where $I_{m}$ is the bubble length scale, $\mathrm{m} ; N_{\mu f}$ is the viscosity number. The film Nusselt number is based on the film thickness scale $l_{l}$, and $X_{F}$ is the discriminant parameter.

$$
\begin{aligned}
& I_{m}=\sqrt{\frac{\sigma}{g\left(\rho_{l}-\rho_{v}\right)}} \\
& N_{u f}=\mu_{l} / \sqrt{I_{m} \sigma \rho_{l}} \\
& l_{l}=\left(\frac{\mu_{l}^{2}}{g \rho_{l}\left(\rho_{l}-\rho_{v}\right)}\right)^{1 / 3} \\
& X_{F}=\left(\frac{q_{e v a} I_{m}}{\rho_{v} h_{f g} v_{l}}\right)^{2}\left(\frac{p I_{m}}{\sigma}\right)^{2} \frac{\operatorname{Re}_{x}}{\operatorname{Pr}_{l}} \\
& \operatorname{Re}_{x}=\frac{4 \Gamma_{x}}{\mu_{l}}=\frac{4 q_{e v a}\left(x_{e}-x\right)}{\mu_{l} h_{f g}}
\end{aligned}
$$

Introducing the droplet entrainment to improve the existing TPCT model and further to modify the existing CFR and the thermal resistance of TPCT are firstly attempted by the present study. Therefore, simplifications and assumptions are set to 
enable the implementation of the present model. The limitation and rationality are suggested as following:

Firstly, one can make certain the heat transfer regime within the falling film according to Eqs.(21-23). Under the fully developed entrainment region, that is under the relatively high heat flux, the bubbles growing in the falling liquid film influence the mass of the liquid film like that in the pool boiling and influence the thickness of liquid film at the same time. However, the bubbles burst at the liquid-vapor interface and disperse tiny droplets into the vapor flow. Meanwhile, considering that the liquid film thickness is much less than the tube inner diameter and the bubbles burst rapidly. The influences have been diminished when the entrainment rate is included in the governing equations (see Eqs.(17-18)). Therefore, under the fully developed entrainment region, the assumptions are relatively reasonable.

However, the present model has limitations under the low heat flux conditions, especially under the combined convection film evaporation. For conditions with very small entrainment rate or the developing entrainment regions (transition regime), Ishii and Kataoka [24] and Kataoka et al [25] proposed the correction factors which were smaller than 1 to amend the influence. But the correction factor is ignored in the present study on the premise that firstly, the entrainment rates are already small in these cases. Furthermore, droplet entrainment captured by equation (19) has a relatively large uncertainty under low heat fluxes. For the combined convection film evaporation, the bubbles are growing and sliding but not splashing. Like that in pool boiling, their influences to the mass and thickness of liquid film can not be ignored. However, to the authors' best knowledge, theoretical models or semi-empirical correlations to estimate the geometries and amount of the bubbles are rare. Therefore, thickness of liquid film under the combined convection film evaporation is assumed as the average value of that under the laminar convection film evaporation and nucleate boiling film evaporation (see Eq.(20)). The latter is employed to reflect the mass reduction caused by bubbles. In a word, as validated by the simulation results, results under the developing entrainment regions and the combined convection film evaporation are close to the laminar convection film evaporation and the previous 
studies.

\subsection{Liquid pool}

The heat transfer regime within the liquid pool is usually perceived as nucleate boiling. However, based on the variation of wall heat flux, there are also three heat transfer regimes in liquid pool, namely natural convection, combined convection and nucleate boiling. Owing to the complexity of heat transfer in the liquid pool, well-accepted empirical correlations for the heat transfer coefficients, which were also proposed by El-Genk et al [26], are employed in the present study. However, the equations are not listed in this paper.

Plenty of bubbles generate in the liquid pool during the pool boiling, their influences on calculating the liquid mass within the elemental volume, as well as on calculating the height of liquid pool, cannot be ignored. Void fraction is introduced to take this effect into account. The local void fraction, given by the drift flux model [27], can be expressed as:

$$
\alpha_{b}(x)=\frac{j_{v}(x)}{C_{0} j_{v}(x)+\overline{V_{v j}}}
$$

where $C_{0}$ is the distribution coefficient; $j_{v}(x)$ is the local superficial velocity of vapor, $\mathrm{m} / \mathrm{s} ; \overline{V_{v j}}$ is the area average local drift velocity, $\mathrm{m} / \mathrm{s}$. These three variables can be expressed as:

$$
\begin{aligned}
& C_{0}=1.2-0.2 \sqrt{\rho_{v} / \rho_{l}} \\
& j_{v}(x)=\frac{4 q_{\text {eva }} L_{p}}{\rho_{v} D_{i} h_{f g}}\left(1-\frac{x-x_{a}}{L_{p}}\right) \\
& \overline{V_{v j}}=V_{v j}^{+}\left(\frac{\sigma g\left(\rho_{l}-\rho_{v}\right)}{\rho_{l}^{2}}\right)^{0.25}
\end{aligned}
$$

The dimensionless vapor drift velocity in Eq.(32), $V_{v j}^{+}$, is in terms of the liquid viscosity number, $N_{u f}$, and the hydraulic diameter of the pool, $D_{i}^{+}$: 


$$
\begin{aligned}
& V_{v j}^{+}=0.03\left(\frac{\rho_{l}}{\rho_{v}}\right)^{0.157} N_{u f}^{-0.562} \quad\left(D_{i}^{+} \leq 30, N_{u f}<2.25 \times 10^{-3}\right) \\
& V_{v j}^{+}=0.0019\left(D_{i}^{+}\right)^{0.809}\left(\frac{\rho_{l}}{\rho_{v}}\right)^{0.157} N_{u f}^{-0.562} \quad\left(D_{i}^{+}>30, \quad N_{u f}<2.25 \times 10^{-3}\right) \\
& V_{v j}^{+}=0.92\left(\frac{\rho_{l}}{\rho_{v}}\right)^{0.157} \quad\left(N_{u f} \geq 2.25 \times 10^{-3}\right) \\
& D_{i}^{+}=D_{i} \sqrt{\frac{g\left(\rho_{l}-\rho_{v}\right)}{\sigma}}
\end{aligned}
$$

The mean void fraction of the liquid pool is expressed as follow:

$$
\alpha_{b}=\frac{1}{L_{p}} \int_{x_{p}}^{x_{\text {eva }}} \alpha_{b}(x) d x
$$

\subsection{Criterias}

In the numerical models of El-Genk et al [16] and Jiao et al [17], the critical film thickness was introduced, beyond which a film dryout could occur. The length of the liquid film in the evaporator is thus determined on the basis of that. However, in the present study, since the liquid film has a probability to burst during the nucleate boiling film evaporation. Therefore, the critical mass flow rate is used instead. It is hypothesized that if the mass flow rate decreases to $1 \%$ of its initial value (exit of condenser), the bubbles are certain to burst [28]:

$$
\Gamma_{x, e v a}=0.01 \Gamma_{x_{c o n}} \text { or } \sum_{j=1}^{M} \frac{d \Gamma_{x}}{d x}=0.99 \Gamma_{x_{c o n}}
$$

The flooding limit and boiling limit also preclude a TPCT from operating well. The boiling limit in thermosyphon is due to the film boiling, which occurs when a vapor film forming between the pipe wall and the liquid in the evaporator [29]. Correspondingly, the onset of boiling is assumed as the flow regime turns from churn flow to annular within the pool. Therefore, the criterion of flow pattern rather than the empirical equations is employed to predicate the onset of boiling, which can be expressed as [30]: 
$V_{v j}^{*}=J_{v}(x) \sqrt{\frac{\rho_{v}}{g D_{i}\left(\rho_{l}-\rho_{v}\right)}} \geq 1$

where $V_{v j}^{*}$ is the modified Froude number.

Flooding occurs when the upward velocity of the vapor is high enough to prevent the liquid film from flowing back to the evaporator due to the shear stress at the interface of the countercurrent liquid-vapor flow. It has been confirmed by visualization experiments [31] and numerical studies [22] that the onset of flooding occurs first at the exit of the condenser. Therefore, the onset of flooding, based on the numerical model, can be expressed as:

$$
\Gamma_{x_{\text {con }}}=0
$$

Based on the governing equations and criterias, the distribution of the thickness of the liquid film, as well as the void fraction and the height of the liquid pool, can be finally determined. The CFR, EFR and thermal resistance can also be further determined. The total mass of working fluid, which consists of the liquid films in the condenser and evaporator, the liquid pool in the evaporator and the vapor in the whole TPCT, can be expressed as:

$$
\begin{aligned}
& m_{c o n}=\pi \int_{0}^{x_{c o n}}\left\{\left[\left(\frac{D_{i}}{2}\right)^{2}-\left(\frac{D_{i}}{2}-\delta\right)^{2}\right] \rho_{l}+\left(\frac{D_{i}}{2}-\delta\right)^{2} \rho_{v}\right\} d x \\
& m_{e f}=\pi \int_{x_{a}}^{x_{e f}}\left\{\left[\left(\frac{D_{i}}{2}\right)^{2}-\left(\frac{D_{i}}{2}-\delta\right)^{2}\right] \rho_{l}+\left(\frac{D_{i}}{2}-\delta\right)^{2} \rho_{v}\right\} d x \\
& m_{e p}=\frac{\pi D_{i}^{2}}{4} L_{p}\left[\alpha_{b} \rho_{v}+\left(1-\alpha_{b}\right) \rho_{l}\right] \\
& m_{a}=\pi \int_{x_{c o n}}^{x_{a}}\left\{\left[\left(\frac{D_{i}}{2}\right)^{2}-\left(\frac{D_{i}}{2}-\delta_{a}\right)^{2}\right] \rho_{l}+\left(\frac{D_{i}}{2}-\delta_{a}\right)^{2} \rho_{v}\right\} d x
\end{aligned}
$$

The VFR of TPCT is expressed as:

$$
V F R=\left(m_{c}+m_{e f}+m_{e p}+m_{a}\right) / \rho_{v} V_{e v a}
$$

The effective heat transfer coefficient of the evaporator is expressed as El-Genk et al [16] and Jiao et al [17]: 
$h_{e v a}=h_{e f} \frac{L_{e f}}{L_{e v a}}+h_{e p} \frac{L_{p}}{L_{e v a}}$

The overall thermal resistance of the TPCT is expressed as:

$$
R=\frac{1}{h_{\text {eva }} \pi D_{i} L_{\text {eva }}}+\frac{1}{h_{c o n} \pi D_{i} L_{c o n}}
$$

TPCT operates unstably when boiling limit and flooding limit occurs. According to Jiao et al [17], heat flux corresponding to the onset of boiling is smaller than that of the flooding limit. The VFR and the operation envelope between that interval, therefore, is not recommended, correspondingly.

\section{Model validation}

Based on the numerical model of TPCT, one can conclude that the VFR and the thermal resistance are mainly determined by liquid film thickness, liquid film length, height of liquid pool, heat flux throughput, void fraction of liquid pool and the heat transfer coefficients of liquid film and liquid pool. The latter three are calculated through empirical correlations in the present study, while the height of the liquid pool can be easily obtained based on the length of the liquid film. Therefore, the liquid film thickness along the TPCT and the heat flux play the most important roles. In the following, the liquid film thickness along the TPCT and the onset of flooding are compared and validated with the published literatures, respectively.

Fig.4 shows the comparisons of the distributions of liquid film thickness along the TPCT with the same thermal boundary conditions. In the present study, two simulated results are compared with Shabgard et al [18]. The first one is based on the normal processing mode. That is, assuming that the heat transfer pattern within the falling liquid film in the evaporator is laminar convection film evaporation, and film thickness is mainly determined by interfacial shear stress. The other one is based on developed model on section 2.1 and 2.2, droplet entrainment is additionally considered in nucleate boiling film evaporation. 


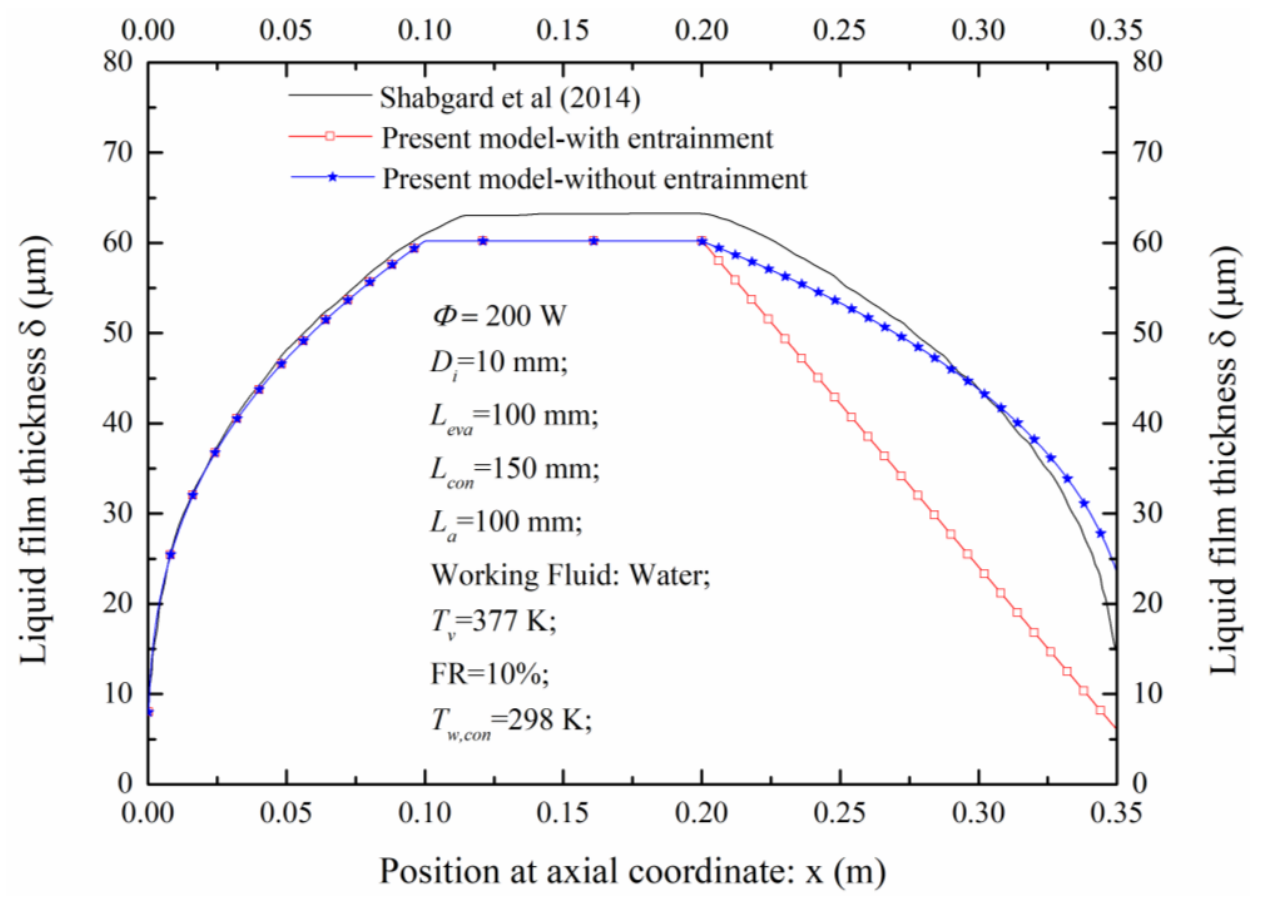

Fig.4 Comparisons of liquid film thickness with Shabgard et al [18]

According to Eqs. (21-28), the heat transfer regime of the falling liquid film within the evaporator in Shabgard et al [18] is nucleate boiling film evaporation. Fig.4 shows that the curve without considering the droplet entrainment agrees well with that of Shabgard et al [18], except the points at the very end of evaporator. The film thickness increases and decreases like a parabola along both the condenser and evaporator. However, when considering the droplet entrainment, the film thickness linearly decreases in the evaporator.

Fig.5 compares the numerical calculated dimensionless liquid film thickness $\left(2 \delta / D_{i}\right)$, as a function of the Reynolds number, with the experimental data. The maximum film Reynolds number indicates the onset of flooding. The results show that the predictions of the present model are in excellent agreement with the experimental data of Reed et al [32]. At the same time, the maximum value of the Reynolds number, which is 129.9 predicted by the present model, agrees well with the values predicted by the models of El-Genk et al [22] and Reed et al [12] ( 125 and $\sim 145$, respectively). According to the analysis of El-Genk et al [22], the higher value from Reed et al [12] is due to the neglecting contribution of the dynamic shear stress. 


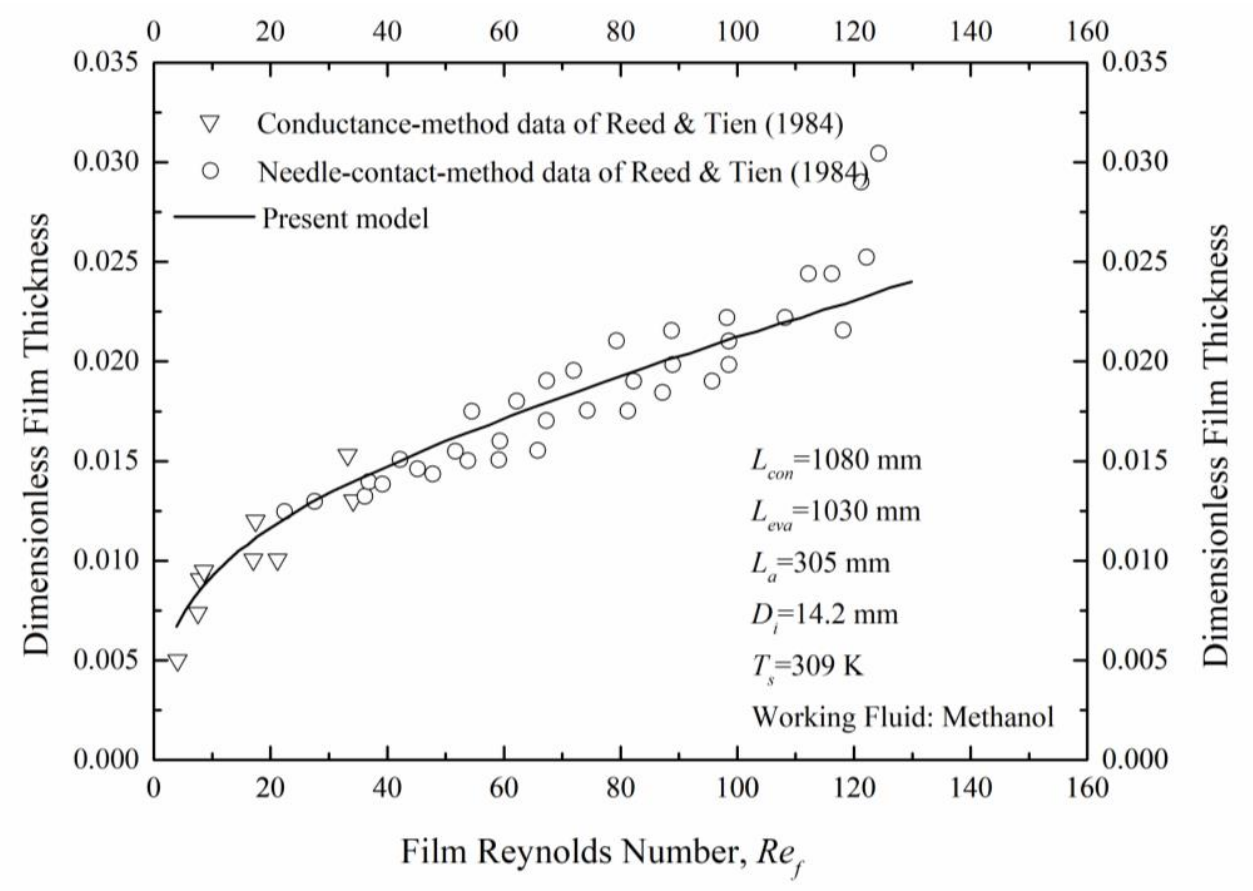

Fig.5 Comparison of present and Reed et al's experimental data [30] for the CCFL at the exit of the condenser

In Fig.5, the mean error of the film thickness between the present model and the Shabgard et al's model [18] is 4.58\%. From Fig.5, the error of the Reynolds number at the onset of flooding between the present model and the El-Genk et al's model [22] is $3.92 \%$. Hence, the predictions of the two most important variables in determining the VFR and thermal resistance, which are heat flux at the onset of flooding and thickness distribution of the liquid film, are reasonable; the deprecated region, which is the heat flux interval between onset of boiling and the onset of flooding, is also reliable.

\section{Results and Discussion}

For the numerical simulation of the CFR, EFR and thermal resistance of TPCT under various heat fluxes, a copper-water TPCT with the dimensions similar to authors' previous work [33] is selected. The sealed filling range of a vertical TPCT under various heat fluxes is shown in Fig.6. As labeled in Fig.6, CFR and EFR are the lower and upper boundaries of the envelope, respectively. Since the relative position of CFR and EFR is stable, the labels are omitted in the subsequent paragraphs. The curves of CFR and EFR are confined by the minimum and the maximum heat fluxes. The maximum heat flux corresponds to the onset of the flooding. The minimum heat 
flux is set as $2500 \mathrm{~W} / \mathrm{m}^{2}$ in the present study. And then the envelope is diced by the boiling limit. The semi-trapezoid region between the boiling limit and the flooding limit is the deprecated region for practical operation.

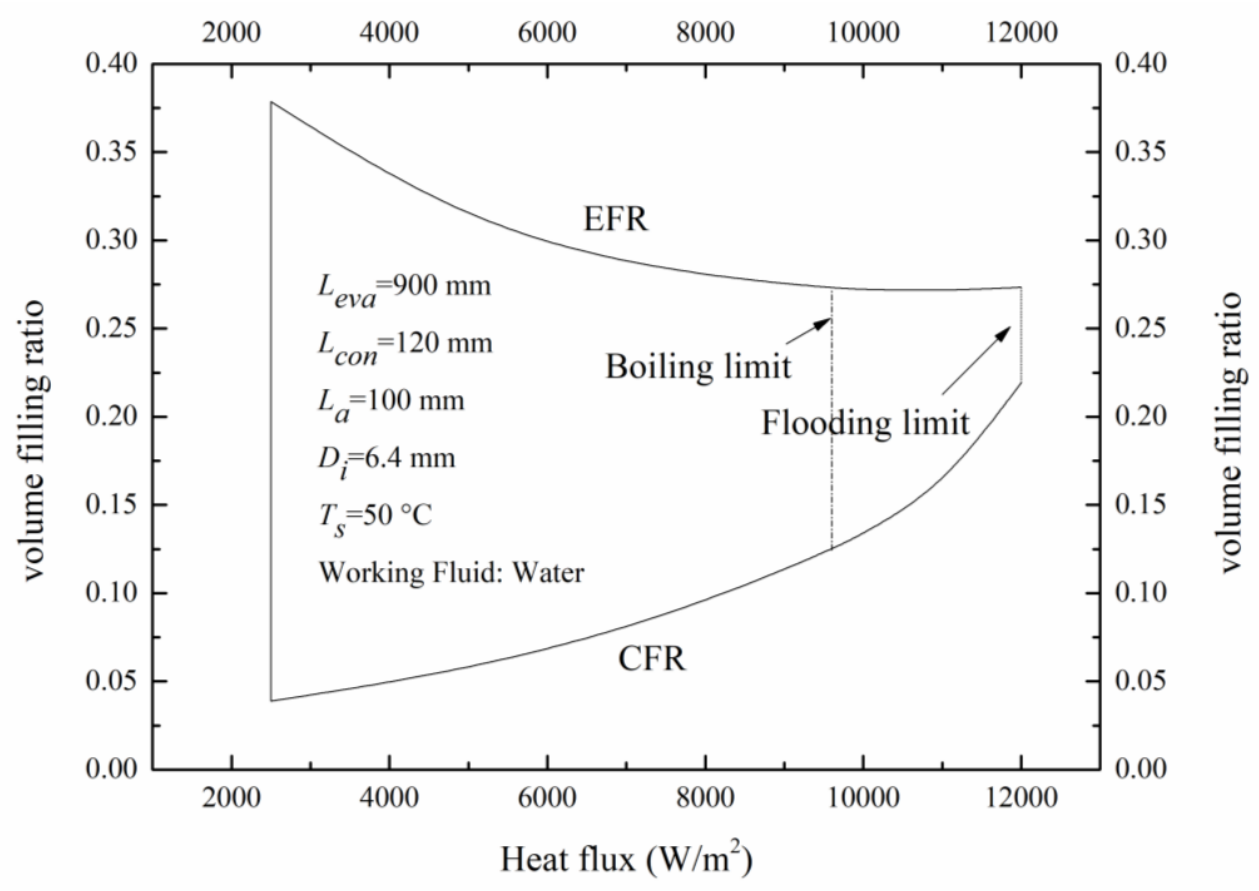

Fig.6 The sealed filling range of a vertical TPCT

As shown in Fig.6, firstly, the EFR decreases while the CFR increases, with increasing the heat flux; secondly, the difference between EFR and CFR decreases with increasing the heat flux; the trends agree well with Jiao et al [14]. The decrease of EFR is resulting from the increase of void fraction in the liquid pool. However, the determining of CFR is relatively complex, which have to be expected with additional evidences, see Fig.7.

Under the conditions of CFR and EFR, variations of the liquid film thickness at the exit of the condenser, the height of the liquid pool and the thermal resistance are presented in detail in Fig.7. It illustrates that the liquid film thickness and the thermal resistance gradually increase with increasing the heat flux; while the height of the liquid pool slightly increases as heat fluxes below $7500 \mathrm{~W} / \mathrm{m}^{2}$ and sharply increases after that. 


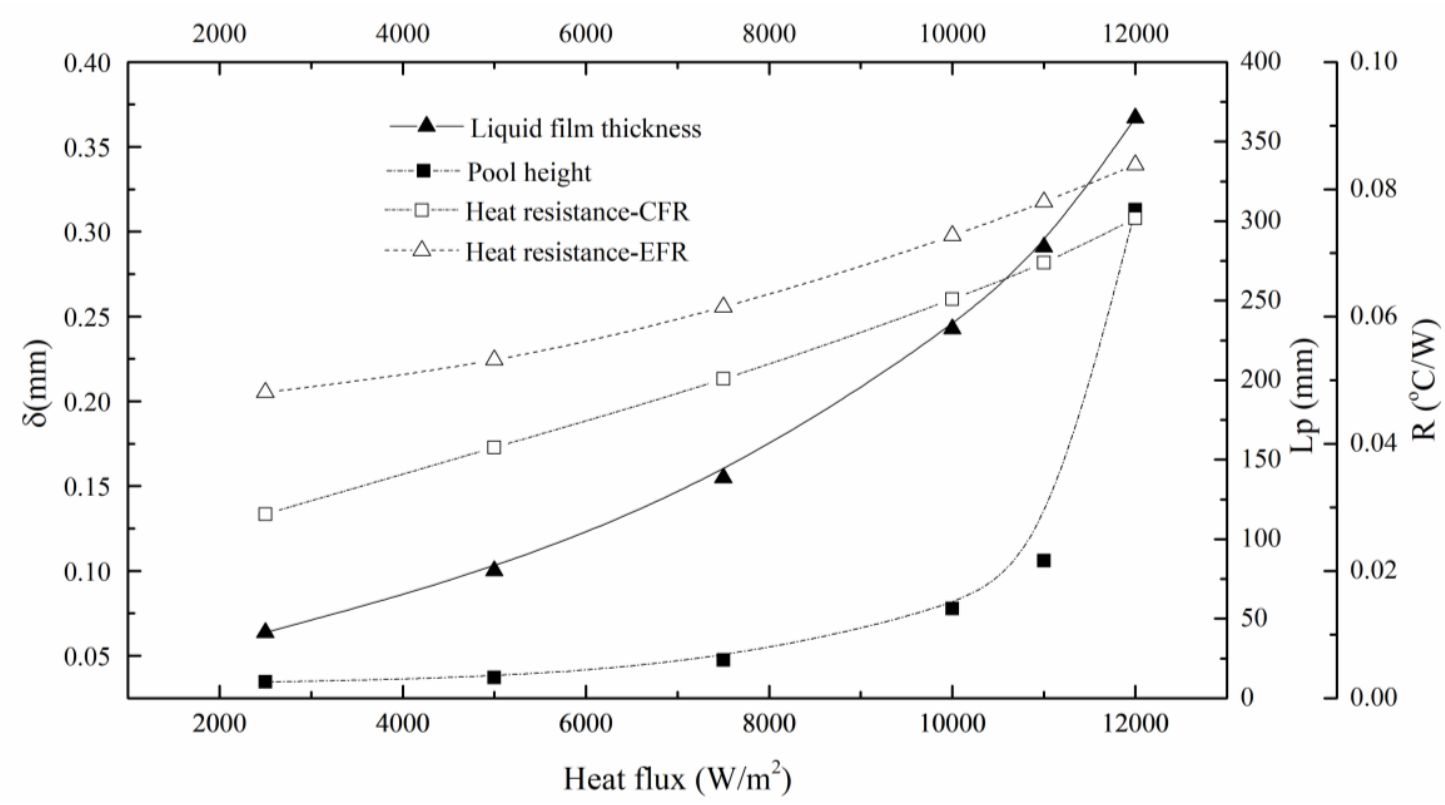

Fig.7 Variations of liquid film thickness, the height of liquid pool and the thermal resistance of

TPCT with increasing the heat flux

The increase of liquid film thickness is dominantly responsible for the increase of thermal resistance. Increasing the heat flux increases the liquid film thickness in the condenser but also increases the attenuation of liquid film thickness in the evaporator. The interaction of above inhibiting effect is responsible for the slight increase in the height of the liquid pool when heat flux below $7500 \mathrm{~W} / \mathrm{m}^{2}$. When under the high heat flux, the heat transfer regime within the falling liquid film in evaporator turns from the combined convection to the nucleate boiling. The droplet entrainment participates the decrease of film thickness. Meanwhile, the entrainment rate increases with increasing the heat flux, which drastically decreases the film thickness and thereby sharply increases the height of the liquid pool. The latter is responsible for the increase of CFR in Fig.6 and also responsible for the decrease of thermal resistance difference between CFR and EFR.

\subsection{Effect of condenser length}

Fig.8 shows the effect of condenser length on the filling range of TPCT, it indicates that increasing the condenser length: (1) increases EFR; (2) the value of heat flux corresponding to the onset of boiling, however, is constant; (3) increases the value of heat flux corresponding to the onset of flooding; (4) CFR curves are disordered. However, there are rules to follow. That is, the CFR increases with 
increasing the condenser length until the heat flux reaches the value corresponding to half of the onset of flooding. Moreover, CFR has a substantial increase near the flooding limit because of the increase of height of liquid pool.

It is worth noting that increasing the condenser length not only modestly decreases the liquid film thickness but also increases the mass of liquid film within the condenser, which lead to a small upward moving of the filling range map. However, the increase in mass is limited; the changing gradients of CFR and EFR to the condenser length are, therefore, negligible. Additionally, combining (2) and (3), the proportion of the area corresponding to the deprecated region expands with increasing the condenser length.

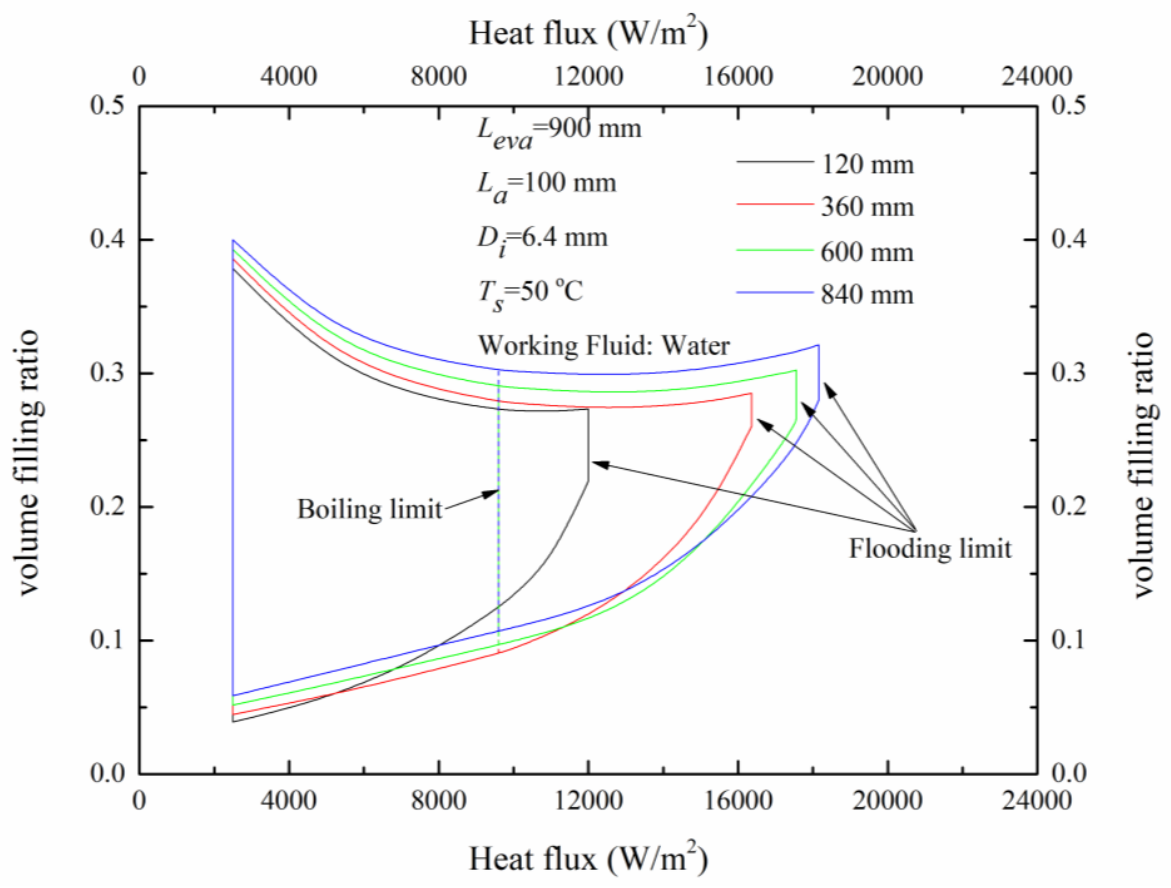

Fig.8 Effect of condenser length on the filling range of TPCT

Fig.9 displays the effects of condenser length on the height of the liquid pool and the thermal resistance of TPCT. It shows clearly that the thermal resistance decreases with increasing the condenser length. It is because the heat fluxes at the condenser decrease with increasing the condenser length, which leads to the decreases of liquid film thickness within the condenser and evaporator and further increases the heat transfer coefficients at these two regions. Besides, under the same heat flux, the height of the liquid pool decreases with increasing the condenser length (see from the inset 
figure on the top right corner), which further decreases the thermal resistance of TPCT. However, the maximum height of liquid pool at CFR seems rule-less with increasing the condenser length.

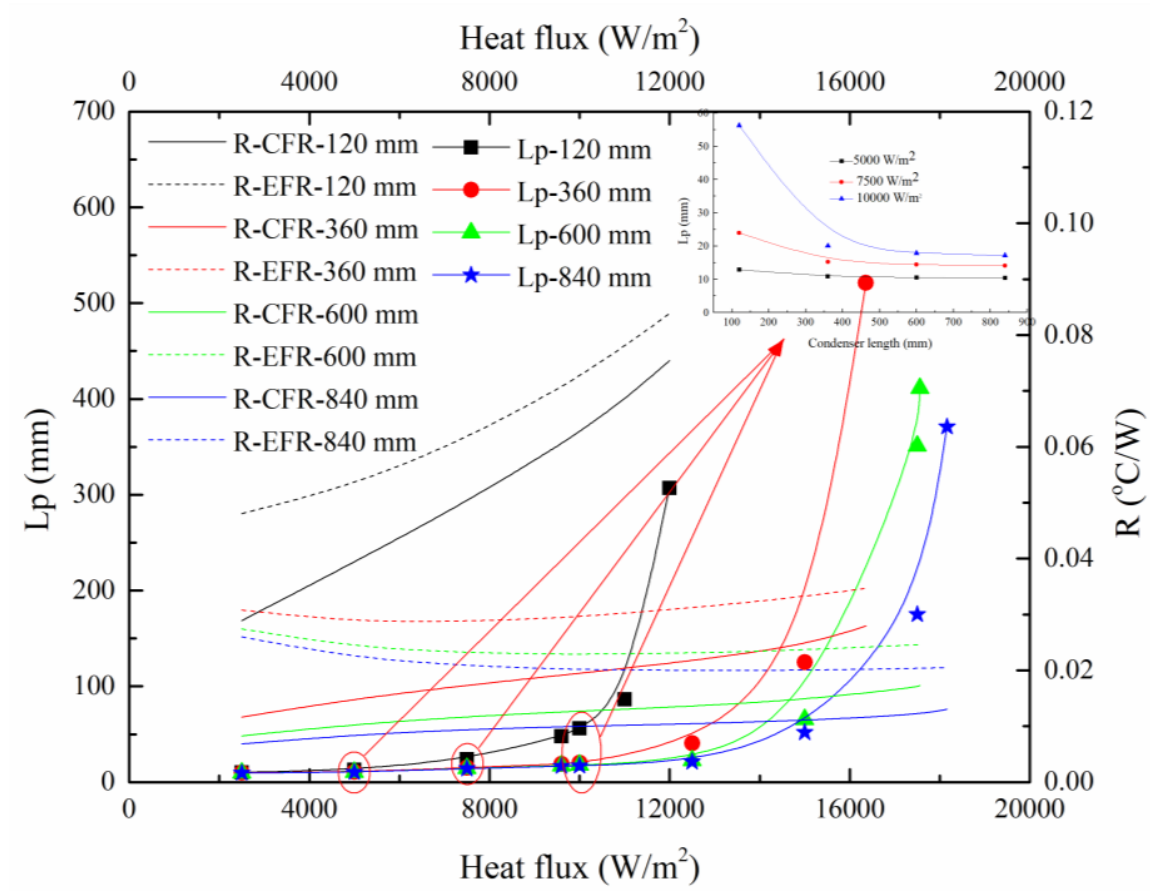

Fig.9 Effect of condenser length on the height of liquid pool and the thermal resistance of TPCT

The effects of condenser length on the TPCT can be summarized as follows: increasing the condenser length, despite has no influence to the boiling limit, increases both the CFR and EFR and modestly increases the heat flux corresponding to the flooding limit.

\subsection{Effect of adiabatic length}

Fig.10 displays the effect of the adiabatic length on the filling range of TPCT, it indicates that increasing the adiabatic length increases both the CFR and EFR but insignificantly changes the operation area. It is because the adiabatic section is assumed as the transition section, in which the parameters unchanged and the thermal resistance is therefore unchanged. The mass of liquid film increases with increasing the adiabatic length and further increases the CFR and EFR. Similar to the effect of condenser length, the filling range map moves upward slightly and the changing gradient of CFR and EFR to the adiabatic length is negligible. 


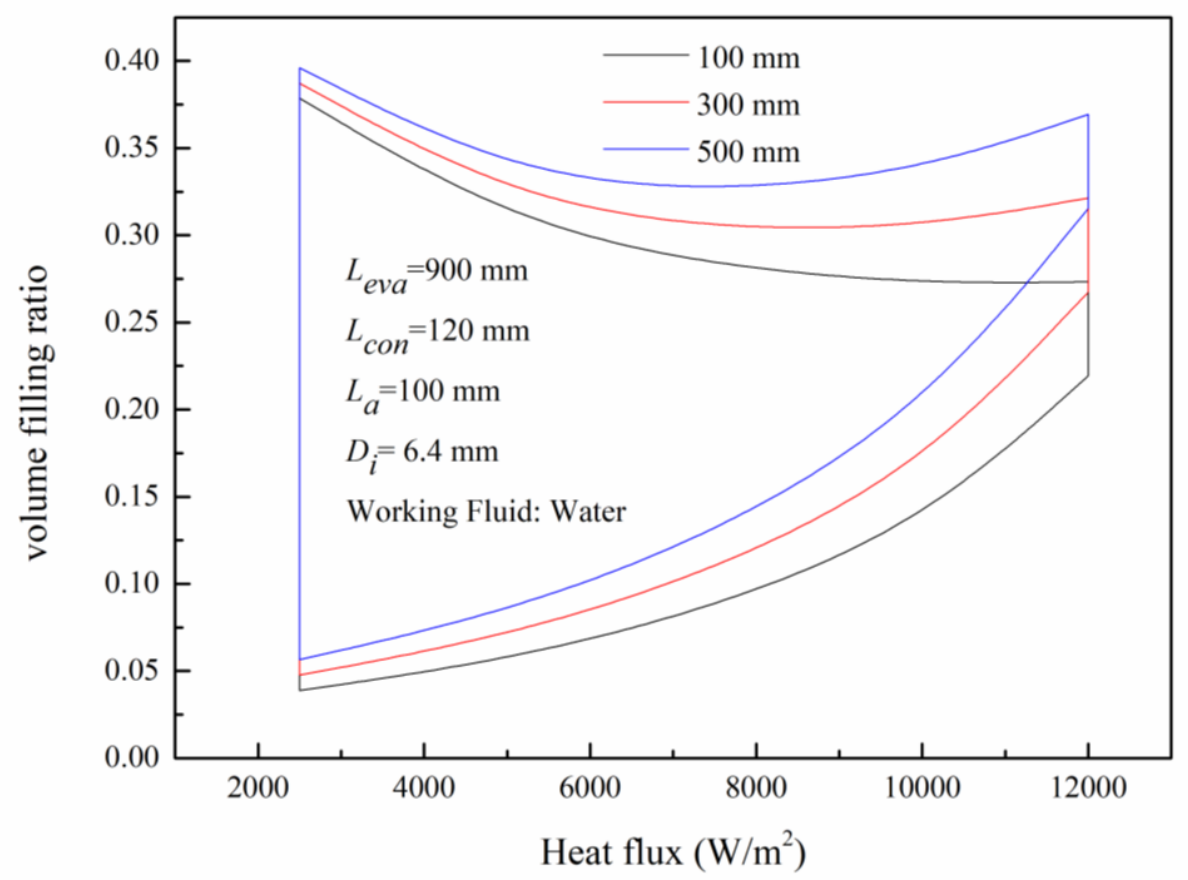

Fig.10 Effect of the adiabatic length on the filling range of TPCT

\subsection{Effect of evaporator length}

Fig.11 presents the effect of evaporator length on the filling range of TPCT, it indicates that decreasing the evaporator length distinctly increases the useful area of the operation envelope and also increases the heat fluxes corresponding to boiling limit and flooding limit. Furthermore, increasing the evaporator length lowers the CFR to a small extent but elevates the EFR to a modest extent. Under the same heat flux, decreasing the evaporator length despite decreases the liquid film thickness; however, the decrease of the void fraction within the liquid pool is more decisive. The EFR is, therefore, modestly enlarged. For the CFR under the same heat flux, decreasing the evaporator length changes the heat transfer regime within the liquid film, for example from the combined convection to the laminar convection or from the nucleate boiling to the combine convection. The transition of heat transfer regime leads to the decrease of attenuation of film thickness, which determines a lower CFR. Additionally, the proportion of the area corresponding to the deprecated region also expands with increasing the evaporator length. 


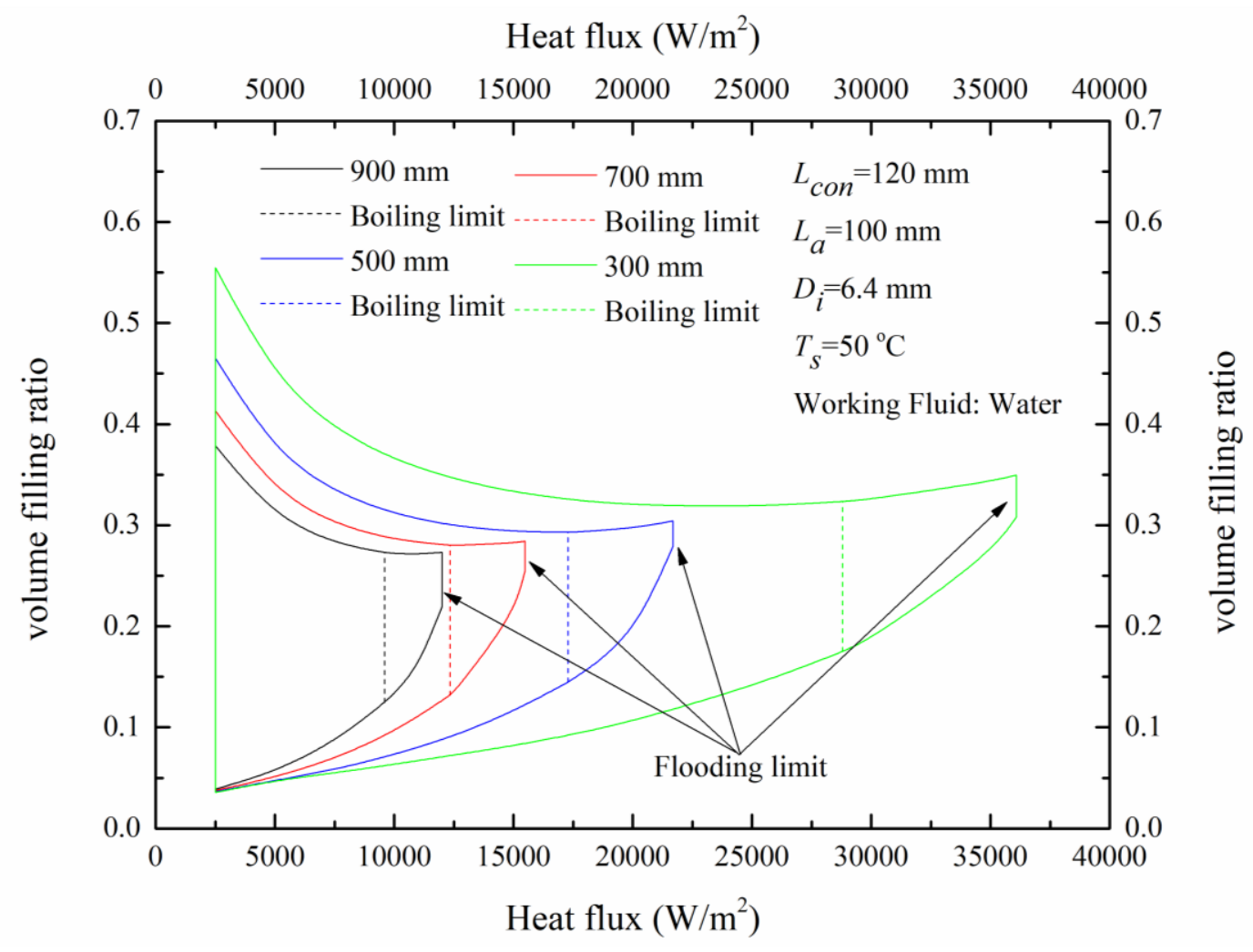

Fig.11 Effect of evaporator length on the filling range of TPCT

The effects of evaporator length on the height of the liquid pool and the thermal resistance are displayed in Fig.12. It reveals that under the same heat flux, decreasing the evaporator length distinctly decreases the thermal resistance at CFR and the height of the liquid pool. It is easy to understand the reason for the latter trend. As for the former, decreasing the evaporator length decreases both the thickness of the liquid film in the condenser and the height of the liquid pool. Both of them contribute to the decrease of thermal resistance. Despite the heat transfer coefficient within evaporator increases with decreasing the evaporator length, which leads to an increase in the thermal resistance, however, the increase is limited.

Fig.12 also shows that the curves of thermal resistance are disordered at EFR. However, similar to the effect of condenser length on the CFR, there are rules to follow. That is, the thermal resistance at EFR increases with decreasing the evaporator length until the heat flux reaches the value corresponding to half of the onset of flooding. Besides, CFR has an evident increase near the heat flux corresponding to flooding limit. 
It is worth mentioning that, firstly, although the maximum heat flux apparently increases with decreasing the evaporator length, the maximum power throughput (W) changes little. The same conclusion can be found in Jiao et al [14]. Secondly, decreasing the evaporator length also decreases the shear stress in the evaporator, which precludes the attenuation of the liquid film. The interactions of above will lead to an impact that the height of the liquid pool equals to zero under low heat fluxes. This phenomenon is unique compared with other parameters.

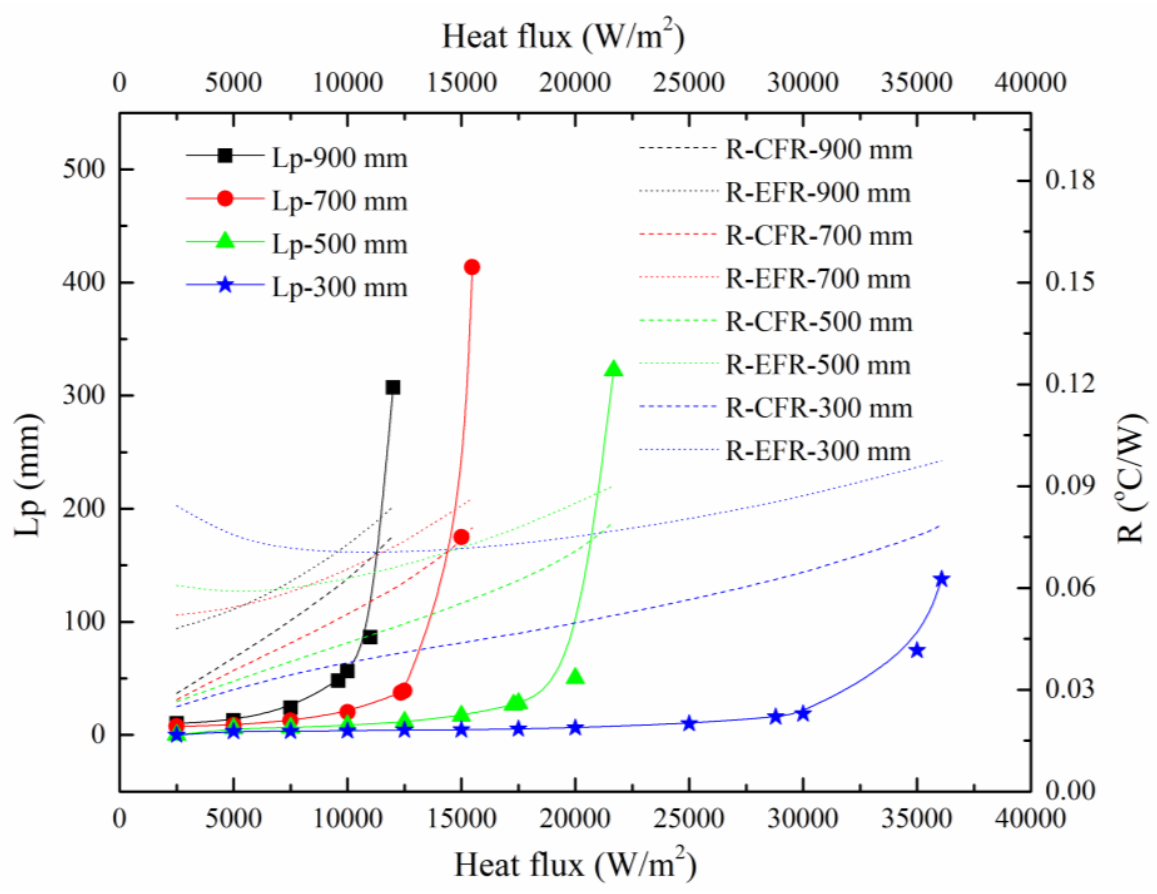

Fig.12 Effect of evaporator length on the height of liquid pool and the thermal resistance of TPCT

\subsection{Effect of the inner diameter of TPCT}

Fig.13 displays the effect of inner diameter on the filling range of TPCT. It elaborates that increasing the inner diameter of TPCT significantly increases the area of operation envelope. That is, increases the heat fluxes corresponding to boiling limit and flooding limit. Such an increase is because increasing the inner diameter of TPCT decreases the internal vapor velocity and further lowers the shear stress at the liquid-vapor interface. Correspondingly, the boiling limit and flooding limit occur at the much higher heat fluxes. Moreover, increasing the inner diameter increases the EFR (most of the time) and decreases the CFR, which increases the filling range at the same time. The decrease of CFR is caused by the decrease of liquid film thickness, 
while the increase of the EFR is caused by the decrease of void fraction in the liquid pool. However, the changing gradient with the inner diameter is different. The changing gradient of CFR is more sensitive, the smaller the inner diameter, the bigger the gradient; while the changing gradient of EFR is more modest. Additionally, the proportion of the area corresponding to the deprecated region shrinks with increasing the inner diameter.

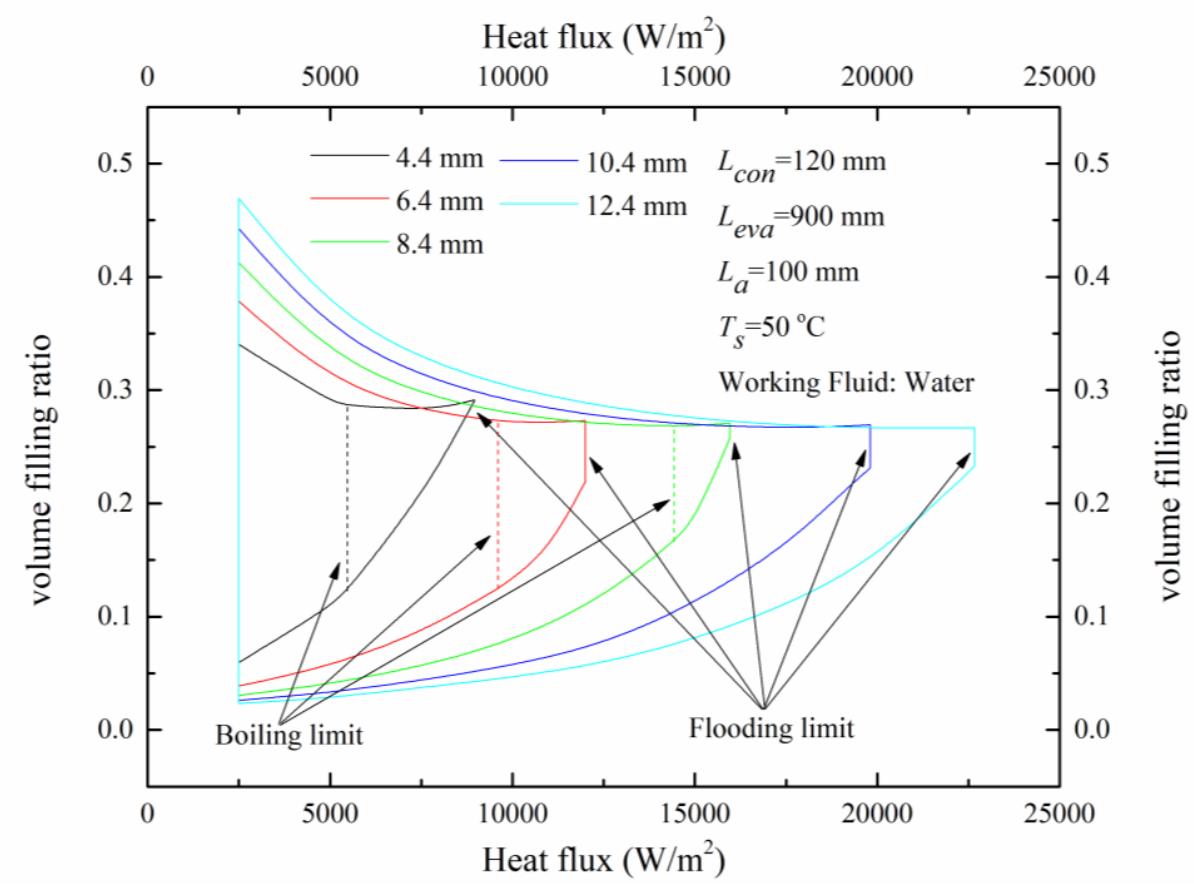

Fig.13 Effect of inner diameter on the filling range of TPCT

There are two additional variations needs to be specially pointed out. Firstly, the EFR is not always decreased with increasing the heat flux; there is an increase near the end. The smaller the inner diameter, the bigger the increase. Actually, a similar trend can also be found in Figs.8,10,11. Such an increase is because increasing the heat flux corresponding to the flooding limit increases the void fraction insignificantly but increases the liquid film thickness significantly, which consequently raises the EFR. Therefore, increasing the condenser length (see Fig.8) and adiabatic length (see Fig.10), and decreasing the evaporator length (see Fig.11) and inner diameter (see Fig.13), can all magnify the fact. Secondly, the boiling limit disappears as the inner diameter bigger than $8.4 \mathrm{~mm}$. It is because the heat fluxes corresponding to the boiling limit are higher than that of the flooding limit under these conditions. It further 
infer that the boiling limit, rather than flooding limit, is more sensitive to the inner diameter.

The effects of inner diameter on the height of the liquid pool and the thermal resistance are presented in Fig.14. It shows clearly that the thermal resistance decreases with increasing the inner diameter. The effect is similar to that of the condenser length. Such a decrease is because increasing the inner diameter decreases the liquid film thicknesses in both the condenser and evaporator, therefore lowers the thermal resistance. Besides, the height of the liquid pool decreases with increasing the inner diameter, which further decreases the thermal resistance at CFR. However, the maximum height of the liquid pool at CFR, corresponding to the flood limit, seems also rule-less with increasing the inner diameter.

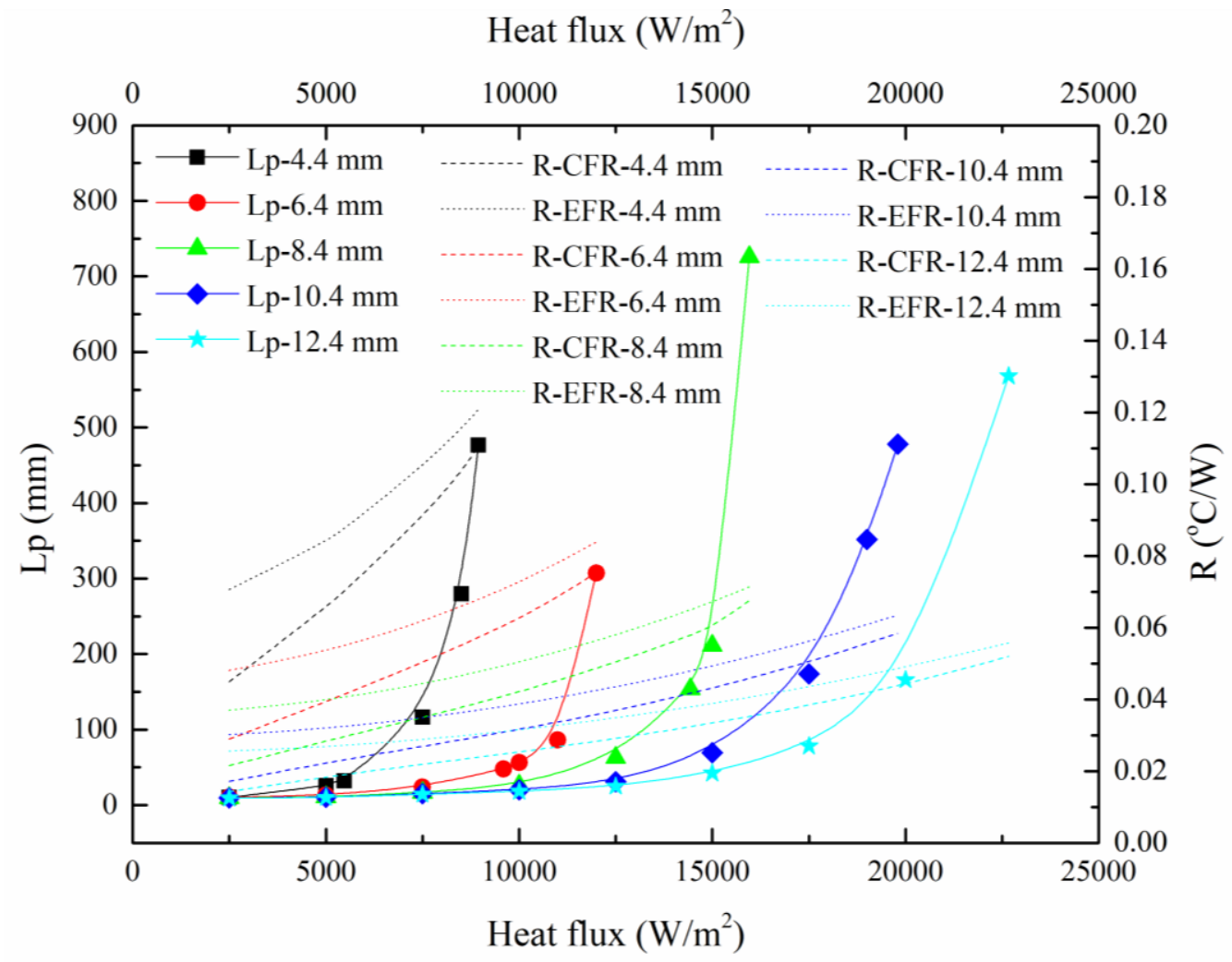

Fig.14 Effect of inner diameter on the height of the liquid pool and the thermal resistance of TPCT 4.5 Effect of vapor temperature

Fig.15 displays the effect of vapor temperature on the filling range of TPCT. It indicates that increasing the vapor temperature also significantly increases the area of the operation envelope. That is, increases the heat fluxes corresponding to the boiling 
limit and flooding limit. It is because increasing the vapor temperature causes a dramatic plunge in shear stress at the liquid-vapor interface, and further obviously increases the heat flux corresponding to flooding limit. Moreover, increasing the vapor temperature increases the EFR and decreases the CFR, and therefore increases the filling range at the same time. The decrease of CFR can also refer to the dramatic plunge in shear stress, because it leads to an evident decrease in liquid film thickness. However, the increase of EFR is determined by the decrease of the mean void fraction in the liquid pool. Besides, as shown in Fig.15, the gradient of increase in EFR is opposite to the gradient of decrease in CFR. That is, when increasing vapor temperature, the curves of EFR are receding while the curves of CFR are approaching. However, the proportion of the area corresponding to the deprecated region is insensitive with increasing the vapor temperature.

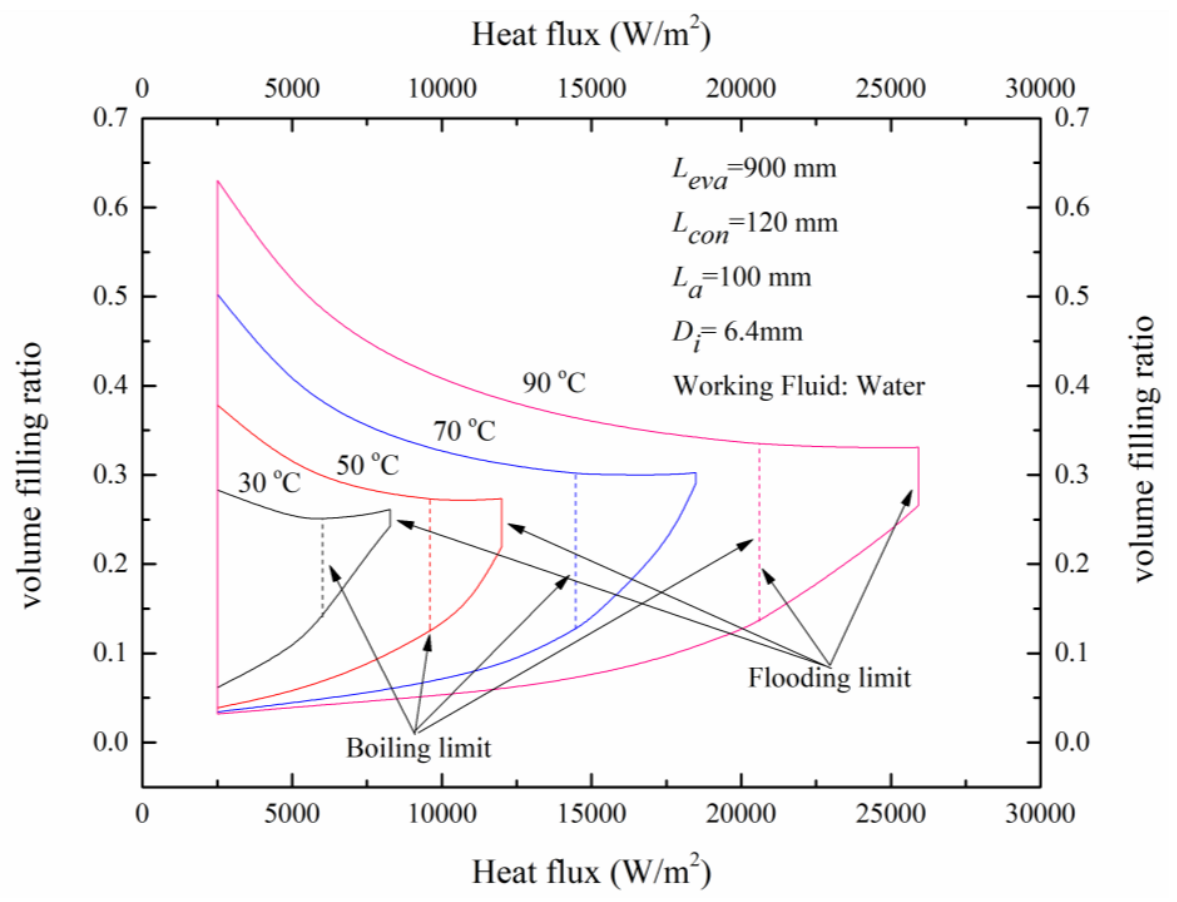

Fig.15 Effect of vapor temperature on the filling range of TPCT

The effects of vapor temperature on the height of the liquid pool and the thermal resistance are presented in Fig.16. It shows clearly that the thermal resistance decreases with increasing the vapor temperature. Such a decrease is because increasing the vapor temperature decreases the liquid film thicknesses in condenser and evaporator, therefore lowers the thermal resistance. Besides, the height of the 
liquid pool also decreases with increasing the vapor temperature, which further decreases the thermal resistance at CFR. However, the maximum height of the liquid pool at CFR, corresponding to the flood limit, seems also rule-less with increasing the vapor temperature.

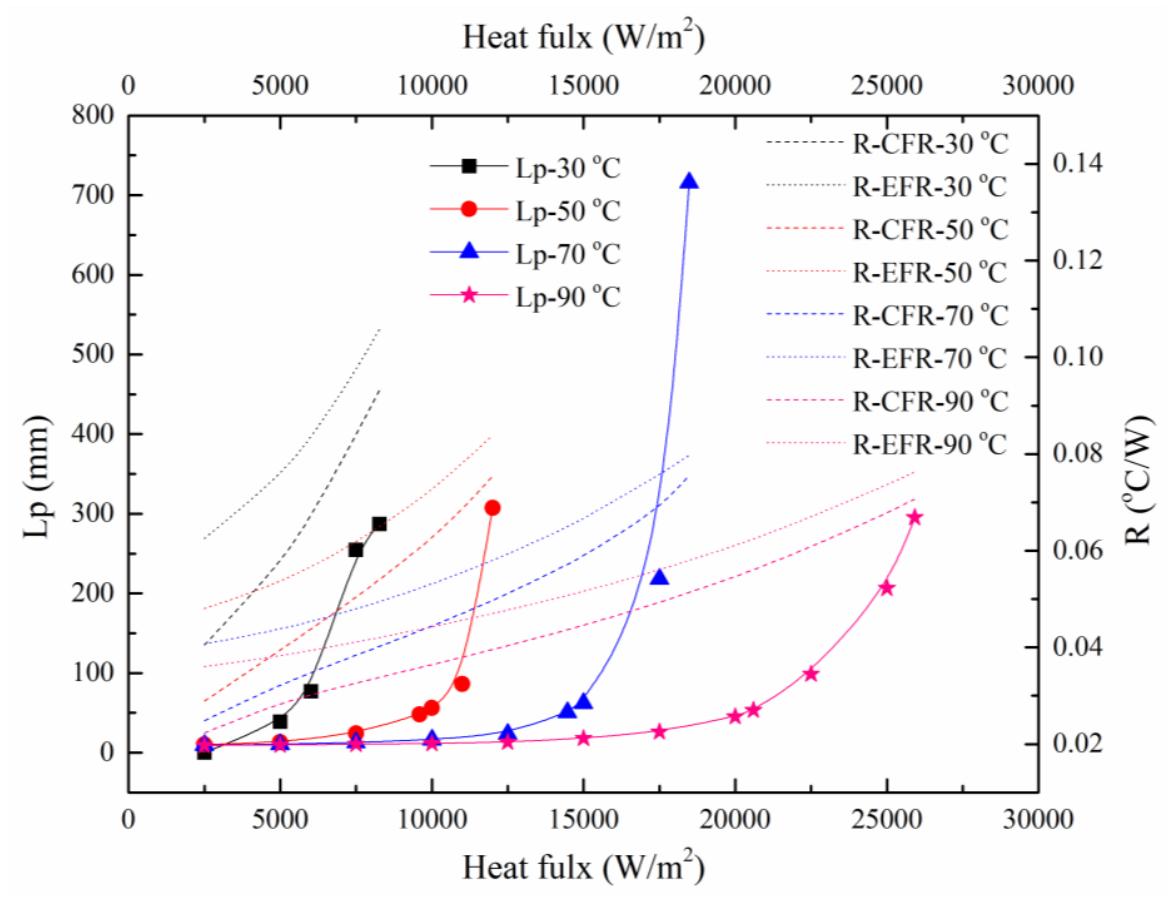

Fig.16 Effect of vapor temperature on the height of liquid pool and the thermal resistance of TPCT

\subsection{Fitting of CFR}

For the applicable CFR, Streltsov [34] developed a simplified correlation, as a function of power throughput, geometries of TPCT and thermophysical properties of the working fluid, to seek its concrete value. Streltsov [34] assumed that the liquid film thickness increased from zero in the condenser, unchanged in adiabatic section, decreased in the evaporator and finally decreased to zero at the end of the evaporator. Moreover, evaporation process within the liquid film was assumed as the inverse process of filmwise condensation. Based on above assumptions, the suggested CFR was expressed as:

$C F R_{0}=\left(\frac{4}{5} L_{c o n}+L_{a}+\frac{4}{5} L_{\text {eva }}\right)\left(\frac{3 \mu_{l} \rho_{l} \pi^{2} D_{i}^{2} \Phi}{h_{f g} g}\right)^{1 / 3}$

Ratios between the simulated results by present study and Streltsov [34] are displayed in Fig.17, in which the effects of heat flux, evaporator length, condenser 
length and inner diameter are illustrated in detail. One important proviso, the latter three are calculated on the basis that the heat flux equals to $5000 \mathrm{~W} / \mathrm{m}^{2}$. The results show that the ratio decreases with increasing the inner diameter and condenser length, but increases with increasing the evaporator length. Meanwhile, the ratio is significantly influenced by heat flux while modestly influenced by the latter three variables. For the former, it is because the height of the liquid pool is significantly determined by the heat flux. However, for the latter three, the interactions of inhibiting effect mentioned above lead to their modest effects on the ratio.

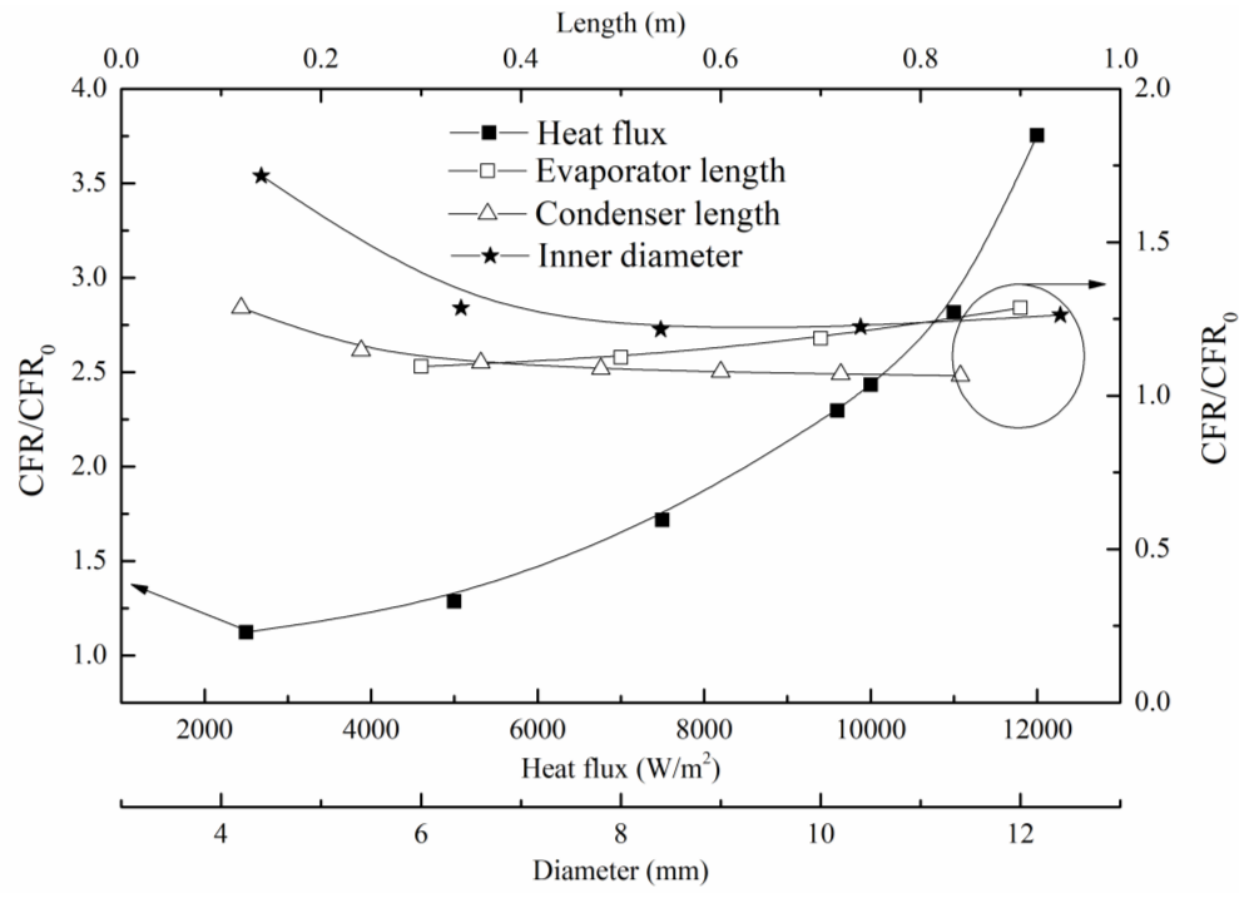

Fig.17 Comparison of CFR between the present study and Streltsov [32]

To sum up, for Eq. (48), ignoring the liquid pool in the evaporator (the decisive factor of CFR most of the time) and ignoring the interfacial shear stresses in both evaporator and condenser limit its applying ranges and make the prediction of CFR much smaller than the real situation. However, as mentioned above, the height of the liquid pool, as a function of geometries, is ruleless. And, also because of that, the authors find it is hard to acquire correlation between the present study and the Eq. (48).

In most cases, the heat fluxes corresponding to the onset of boiling are lower than that of the flooding limit. Heat fluxes below the boiling limit are therefore 
suggested in practical applications. A fitting correlation, based on the simulated results of present model, is developed by the authors:

$$
C F R=\frac{1.2}{1-0.86\left(q^{*}\right)^{-0.30}}\left(L_{e v a}^{*}\right)^{-0.32}\left(1+0.14 L_{a}^{*}\right)\left(D_{i}^{*}\right)^{-0.53}\left(\frac{1+2.67 e^{-7.84 L_{\text {con }}^{*}}}{\left(L_{c o n}^{*}\right)^{-0.4}}\right)
$$

Where $q^{*}=q_{\text {eva }} / q_{\text {bl }}, L_{\text {eva }}^{*}=L_{\text {eva }} / 0.9, L_{a}^{*}=L_{a} / 0.1, L_{c o n}^{*}=L_{c o n} / 0.84, D_{i}^{*}=D_{i} / 0.0124$.

Note that, when applying Eq.(48), the heat flux corresponding to the boiling limit through Eq.(39) should be firstly calculated. However, since the heat fluxes corresponding to the boiling limit are smaller than that of the flooding limit when inner diameter is bigger than $8.4 \mathrm{~mm}$ in the present study. The scope of Eq. (49) is limited as follows:

$0.3 \leq L_{\text {eva }} \leq 0.9,0.12 \leq L_{\text {con }} \leq 0.84,0.0044 \leq D_{i} \leq 0.0084$

Additionally, Eq.(49) is proposed on the premise of that the working fluid is water and the vapor temperature is $50^{\circ} \mathrm{C}$.

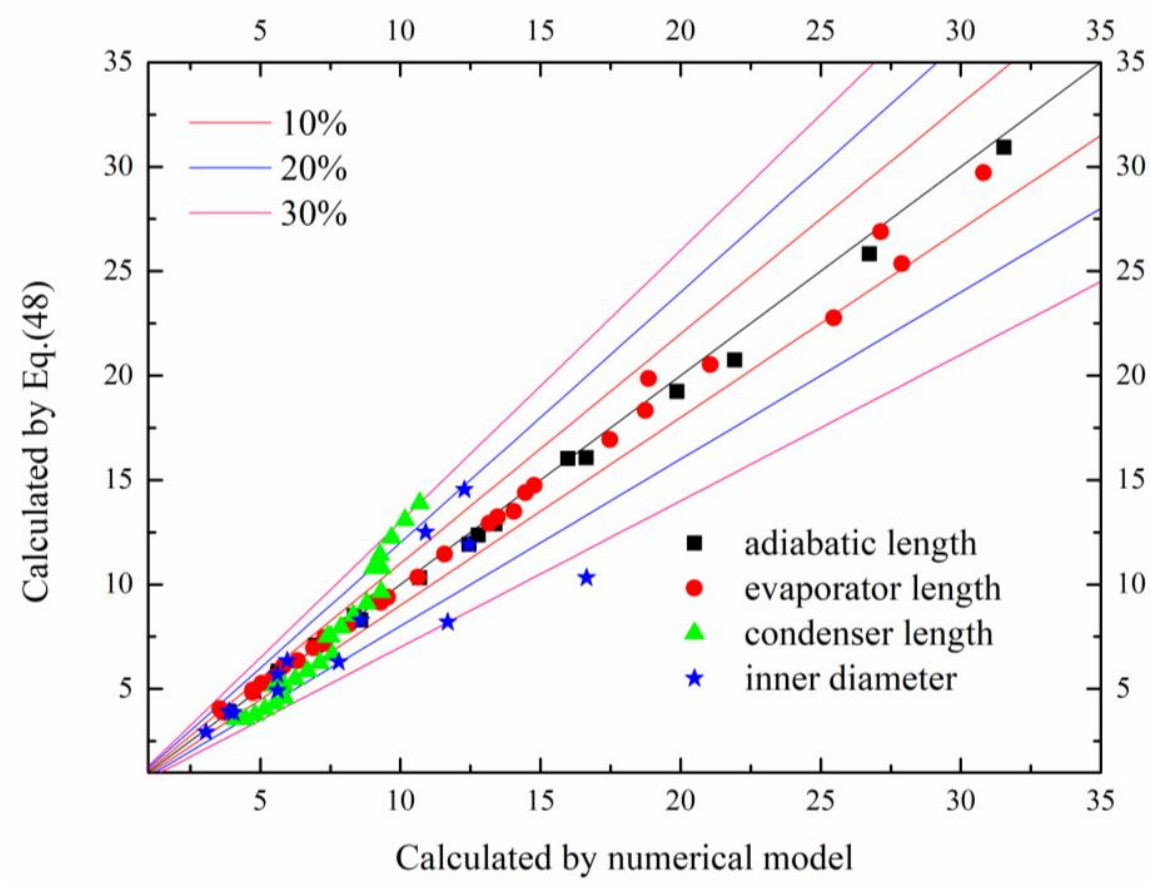

Fig.18 Comparison of CFR between the numerical study and Eq. (49)

The comparisons of CFR, which are respectively calculated by simulation and Eq. (49), are displayed in Fig.18. The results indicate that, for the whole, the agreements are within $30 \%$. However, for the results by varying the adiabatic length 
and evaporator length, the agreements are within $12 \%$. The results vary much when varying the condenser length and inner diameter. It may due to the influence mechanisms of that two parameters are more complicated; it needs, however, a more detailed TPCT model to reveal that.

\section{Conclusions}

There are three heat transfer regimes, in dependence on the heat flux, within the falling liquid film in the evaporator of a TPCT. However, only the laminar convection film evaporation was generally postulated in the previous works. In the present study, the entrainment rate, which is caused by the countercurrent vapor flow during the nucleate boiling within the falling liquid film, is considered and introduced; and a governing equation is developed for the nucleate boiling filmwise evaporation. Based on that, a comprehensive model with considering all the three heat transfer regimes in the evaporator is further established. The suggested CFR and EFR are then determined and updated by utilizing the criterias for local dryout, flooding limit and boiling limit. Effects of geometries and temperature on the filling range are further analyzed in detail; a simplified correlation for CFR is finally proposed based on the numerical data. The following conclusions can be made:

1. The predictions of the distribution of film thickness and the onset of flooding are in good agreement with the published experimental data and numerical simulation results. The droplet entrainment significantly influences the thickness and distribution of the liquid film.

2. A parametric analysis is implemented to investigate the effects of vapor temperature, inner diameter and the lengths of the condenser, adiabatic section and evaporator, on the filling range and thermal performance. The most important influences are those of the vapor temperature, inner diameter and evaporator length. Increasing vapor temperature and inner diameter and decreasing the evaporator length significantly enlarge the filling range (between CFR and EFR), operation envelope (corresponding to boiling limit and flooding limit) and thermal performance of TPCT, despite the changes in gradient vary from each other. Increasing the condenser length increases the filling range and operation envelope 
to a small extent while increasing the adiabatic length slightly upward the filling range.

3. The influence mechanisms of the optimum filling ratio, namely CFR, by the heat flux and geometries are complicated. The height of the liquid pool in the evaporator, which is significantly affected by the heat flux, and the interfacial shear stress, which is affected by the geometries of TPCT, both contribute to that. Within the limited scope, a simplified correlation is proposed by the authors, the agreement of the equation with the simulated results is within $\pm 30 \%$ on the whole.

\section{Acknowledgment}

This work has been sponsored by the Shanghai Sailing Program (18YF1409100), Shanghai Local Capacity Building Program (18020501000), which are gratefully acknowledged by the authors.

\section{References}

[1] Davoud Jafari, Alessandro Franco, Sauro Filippeschi, Paolo Di Marco. Two-phase closed thermosyphons: A review of studies and solar applications, Renewable and Sustainable Energy Reviews, 2016, 53:575-593.

[2] Tao Zhang, Zhiwei Yan, Gang Pei, Qunzhi Zhu, Jie Ji. Experimental optimization on the volume-filling ratio of a loop thermosyphon photovoltaic/thermal system, Renewable Energy, 2019, 143:233-242.

[3] Tao Zhang, Gang Pei, Qunzhi Zhu, Jie Ji. Investigation of the optimum volume-filling ratio of a loop thermosyphon solar water-heating system, Journal of Solar Energy Engineering-T ASME, 2016,138(4): 041006.

[4] Davoud Jafari, Sauro Filippeschi, Alessandro Franco, Paolo Di Marco. Unsteady experimental and numerical analysis of a two-phase closed thermosyphon at different filling ratios, Experimental Thermal and Fluid Science, 2017, 81:164-174.

[5] H. Imura, K.Sasaguchi, H. Kozai, S.Numata. Critical heat flux in a closed two-phase thermosyphon, International Journal of Heat and Mass Transfer, 1983, 26(8): 1181-1188.

[6] K. Harada, S.Inoue, J. Fujita, H. Suematsu, Y. Wakiyama. Heat transfer characteristics of large heat pipes (in Japanese), Hitachi Zosen Giho, 1980, 41:167-174.

[7] Feleman Jr K T, Srinivasan R. Investigation of heat transfer limits in two-phase closed thermosyophon, In: Proceeding of $5^{\text {th }}$ International Heat Pipe Conference, 1984, Tsukuba, Japan, 
192-205.

[8] Negishi K, Sawada T. Heat transfer performance of an ITPCT, International Journal of Heat and Mass Transfer 1983, 26(8): 1207-1213.

[9] S.H.Noie. Heat transfer characteristics of a two-phase closed thermosyphon, Applied Thermal Engineering, 2005, 25(4): 495-506.

[10] Yong JooPark, Hwan Kook Kang, Chul JuKim. Heat transfer characteristics of a two-phase closed thermosyphon to the fill charge ratio, International Journal of Heat and Mass Transfer, 2002, 45(23): 4655-4661.

[11] Zied Lataoui, Abdelmajid Jemni. Experimental investigation of a stainless steel two-phase closed thermosyphon, Applied Thermal Engineering, 2017, 121:721-727.

[12] J.G. Reed and C.L.Tien. Modeling of the two-phase closed thermosyphon, Journal of Heat Transfer, 1987,109(3):722-730.

[13] Z.J.Zuo and F.S. Gunnerson. Numerical modeling of the steady-state two-phase closed thermosyphon, International Journal of Heat and Mass Transfer, 1994, 37(17): 2715-2722.

[14] B. Jiao, L.M. Qiu, X.B. Zhang, Y. Zhang. Investigation on the effect of filling ratio on the steady-state heat transfer performance of a vertical two-phase closed thermosyphon, Applied Thermal Engineering, 2008,28(11-12): 1417-1426.

[15] M.S.El-Genk, H.H.Saber. Heat transfer correlations for liquid film in the evaporator of enclosed, gravity-assisted thermosyphons, Journal of Heat Transfer, 1998,120(2): 477-484.

[16] M.S.El-Genk and H.H Saber. Determination of operation envelopes for closed, two-phase thermosyphon, International Journal of Heat and Mass Transfer, 1999, 42(5): 889-903.

[17] B. Jiao,L. M. Qiu, Z. H. Gan,X. B. Zhang. Determination of operation range of a vertical two-phase closed thermosyphon, Heat and Mass Transfer, 2012, 48(6): 1043-1055.

[18] Hamidreza Shabgard, Bin Xiao, Amir Faghri, Ramesh Gupta, Walter Weissman. Thermal characteristics of a closed thermosyphon under various filling conditions, International Journal of Heat and Mass Transfer, 2014, 70:91-102.

[19] Cerza M and V.Sernas. A bubble growth model for nucleate boiling in thin, falling, superheated, laminar water films, International Journal of Heat and Mass Transfer, 1985, 28(7): 1307-1316.

[20] Cerza M and V.Sernas. Boiling and dryout in falling thin films. In: National Heat Transfer Conference-Heat Transfer Measurements, Analysis, and Flow visualization-ASME,1989, Philadelphia, USA, 112, 107-108.

[21] Yang Pan. Condensation characteristics inside a vertical tube considering the presence of mass transfer, vapor velocity and interfacial shear, International Journal of Heat and Mass Transfer, 2001,44(23):4475-4482. 
[22] M.S.El-Genk, H.H.Saber. Flooding limit in closed, two-phase flow thermosyphons, International Journal of Heat and Mass Transfer, 1997, 40(9): 2147-2164.

[23] R.V.A.Olinmans, B.F.M.Pots, N. Trompe. Modeling of annular dispersed two-phase flow in vertical pipes, International Journal of Multiphase Flow, 1986, 12(5): 711-732.

[24] Kataoka, I., Ishii, M.,. Entrainment and deposition rates of droplets in annular two-phase flow. In: Conference ASME-JSME Thermal Engineering Joint Conference, 1983, Honolulu, HI, USA.

[25] Kataoka, I., Ishii, M., Nakayama, A.,. Entrainment and deposition rates of droplets in annular two-phase flow. International Jounal of Heat and Mass Transfer, 2000, 43, 1573-1589.

[26] M.S. El-Genk, H.H. Saber. Heat transfer correlations for small, uniformly heated liquid pools, International Journal of Heat and Mass Transfer, 1998, 41(2):261-274.

[27] Isao Kataoka, Mamoru Ishii. Drift flux model for large diameter pipe and new correlation for pool void fraction, International Journal of Heat and Mass Transfer, 1987, 30(9): 1927-1939.

[28] Kwang-Won Lee, Se-Jin Baik, Tae-Sun Ro. An utilization of liquid sublayer dryout mechanism in predicting critical heat flux under low pressure and low velocity conditions in round tubes, Nuclear Engineering and Design, 2000,200(1-2): 69-81.

[29] Amir Faghri. Review and Advances in Heat Pipe Science and Technology, Journal of Heat Transfer, 2012, 134(12):123001.

[30] K.W.Mcquillan, P.B.Whalley. Flow patterns in vertical two-phase flow, International Journal of Multiphase Flow, 1985,11(2):161-175.

[31] Shiraishi M, Yoneya M, Yabe A. Visual study of operating limit in the two-phase closed thermosyphon, Proceedings of the $5^{\text {th }}$ International Heat Pipe Conference, 1984, Tsukuba, Japan, $10-17$.

[32] S.J.Chen, J.G. Reed, C.L.Tien. Reflux condensation in a two-phase closed thermosyphon, International Journal of Heat and Mass Transfer, 1984, 27(9): 1587-1594.

[33] Gang Pei, Tao Zhang, Huide Fu, Jie Ji, Yuehong Su. An experimental study on a novel heat-pipe type photovoltaic/thermal system with and without a glass cover, International Journal of Green Energy, 2012, 10(1): 72-89.

[34] A.I.Streltsov. Theoretical and experimental investigation of optimum filling for heat pipes, Heat Transfer-Soviet Research, 1975, 7(1): 23-27. 
Dear Editor and Reviewers,

Thank you for your consideration to our paper entitled "Numerical study of the determination of droplet entrainment within evaporator to the suitable volume-filling ratio of a vertical two-phase closed thermosyphon" (THESCI_2019_1721_R1). We are grateful for the constructive comments and suggestions you have provided.

Yours sincerely,

T. Zhang, Z.W. Yan, L.Y. Wang, W.J. Zheng, Y.H. Su, R.C. Zheng

Comments from editor

We wish to have concise, informative titles. The present title is too long and not very explicit. I wish you could shorten it. If you agree, I would suggest something like : "Droplet entrainment to the suitable volume-filling ratio within the evaporator of a vertical two-phase closed thermosyphon", or something similar.

Response: Thank you for your suggestion, the title has shorten as: Droplet entrainment within the evaporator to the suitable volume-filling ratio of a vertical two-phase closed thermosyphon 


\section{Highlights}

- Entrainment in the evaporator is introduced to improve the existing TPCT model

- Suggested lower and upper limits of VFR are determined by utilizing three criterias

- Parametric analysis on the CFR, EFR and thermal resistance are analyzed in details

- A simplified correlation based on the numerical modeling results is proposed 
Droplet entrainment within the evaporator to the suitable volume-filling ratio of a vertical two-phase closed thermosyphon

\footnotetext{
T. Zhang ${ }^{1,2^{*}}$, Z.W. Yan ${ }^{1}$, L.Y. Wang ${ }^{1}$, W.J. Zheng ${ }^{1}$, Y.H. Su${ }^{2 *}$, R.C. Zheng ${ }^{3}$

${ }^{* 1}$ College of Energy and Mechanical Engineering, Shanghai University of Electric Power, Shanghai 200090, China

${ }^{* 2}$ Department of Architecture and Built Environment, University of Nottingham, Nottingham NG7 2RD, UK

${ }^{3}$ Fujian Provincial Institute of Architectural Design and Research Co.LTD, Fuzhou 350108, China

*Corresponding author, E-mail: taozhang@ shiep.edu.cn; yuehong.su@nottingham.ac.uk
}

Abstract: The present study on vertical two-phase closed thermosyphon (TPCT) is aimed to determine the suitable volume-filling ratio, as a function of geometries, heat flux and vapor temperature, in order to avoid the potential local dryout in the evaporator section and hence to maximize the performance. In the study, the droplet entrainment, which is caused by the internal counter flow during the nucleate boiling within the falling liquid film in the evaporator section, is introduced to improve the existing TPCT model, so a comprehensive model with considering all three heat transfer regimes in the evaporator is further established. The suggested lower and upper limits of volume-filling ratio (CFR and EFR) are then determined by utilizing the criterias for local dryout, flooding limit and boiling limit. Furthermore, the effects of geometries, heat flux and vapor temperature on the range of volume-filling ratio are analyzed in details, a simplified correlation of CFR is then proposed based on the numerical modeling results. Particularly, the predictions of the distribution of falling film thickness and onset of flooding are validated with the published experimental data and other numerical simulation results. It is also found that the droplet entrainment significantly influences the thickness and distribution of the falling film. Increasing vapor temperature and inner diameter and decreasing the evaporator length significantly enlarge the volume-filling ratio range (between CFR and EFR), operation envelope (corresponding to boiling limit and flooding limit) of TPCT. Increasing the condenser length increases the volume-filling ratio range and operation envelope to a small extent. The influence mechanisms of the optimum filling ratio by the heat flux and geometries are complicated; however, a correlation of CFR can be obtained in a good agreement with the numerical modeling results within $\pm 30 \%$ 
deviation for the whole limited scope.

Keywords: two-phase closed thermosyphon; volume-filling ratio; numerical study; heat transfer; nucleate boiling film evaporation.

\begin{tabular}{|c|c|c|c|}
\hline \multicolumn{4}{|l|}{ Nomenclature } \\
\hline$C_{p}$ & Specific heat, $\mathrm{J} /(\mathrm{kg} \cdot \mathrm{K})$ & $b$ & Boiling \\
\hline$D$ & Diameter, $\mathrm{m}$ & $b l$ & Boiling limit \\
\hline$g$ & Acceleration of gravity, $\mathrm{m} / \mathrm{s}^{2}$ & con & Condenser section \\
\hline$h$ & $\begin{array}{l}\text { Convective heat transfer coefficient, } \\
\mathrm{W} /\left(\mathrm{m}^{2} \cdot \mathrm{K}\right)\end{array}$ & $C C-F$ & $\begin{array}{lll}\text { Combined convection film } \\
\text { evaporation }\end{array}$ \\
\hline$h_{f g}$ & Latent heat, $\mathrm{kJ} / \mathrm{kg}$ & eva & Evaporator section \\
\hline$k$ & Heat conductivity coefficient, $\mathrm{W} /(\mathrm{m} \bullet \mathrm{K})$ & ef & Flim of Evaporator \\
\hline$L$ & Length, m & $e p$ & Pool of Evaporator \\
\hline$m$ & Mass,kg & $i$ & Interfacial or inner \\
\hline $\mathrm{Nu}$ & Nusselt number,- & $l$ & Liquid \\
\hline$P$ & Pressure, $\mathrm{Pa}$ & $L C-F$ & $\begin{array}{lll}\text { Laminar } & \text { convection } & \text { film } \\
\text { evaporation } & & \end{array}$ \\
\hline $\operatorname{Pr}$ & Prandtl number, - & $N B-F$ & Nucleate boiling film evaporation \\
\hline$q$ & Heat flux, W/m² & $p$ & Pool \\
\hline$R$ & Heat transfer resistance, ${ }^{\circ} \mathrm{C} / \mathrm{W}$ & $s$ & Saturated vapor \\
\hline$R e$ & Reynolds number, - & $v$ & Vapor \\
\hline$R e_{x}$ & Liquid film local Reynolds number, - & $w$ & Wall \\
\hline$R e_{l}$ & Liquid film Reynolds number, - & $x$ & Local \\
\hline $\operatorname{Ref}_{f}$ & $\begin{array}{l}\text { Liquid film Reynolds number at the onset } \\
\text { of flooding, - }\end{array}$ & & \\
\hline$T$ & Temperature, ${ }^{\circ} \mathrm{C}$ or $\mathrm{K}$ & Greek symbol & \\
\hline$u$ & Velocity of $x$-axis, $\mathrm{m} / \mathrm{s}$ & $\mu$ & Dynamic viscosity, $\mathrm{Pa} \bullet \mathrm{s}$ \\
\hline$v$ & Velocity of $y$-axis, $\mathrm{m} / \mathrm{s}$ & $\rho$ & Density, $\mathrm{kg} / \mathrm{m}^{3}$ \\
\hline V & Volume, $\mathrm{m}^{3}$ & $v$ & kinematic viscosity, $\mathrm{m}^{2} / \mathrm{s}$ \\
\hline$x$ & $x$-axis or distance from zero of $x$-axis & $\tau$ & Shear stress, $N / \mathrm{m}^{2}$ \\
\hline \multirow[t]{2}{*}{$y$} & $y$-axis or distance from zero of $y$-axis & $\delta$ & Thickness, m \\
\hline & & $\Gamma$ & $\begin{array}{l}\text { Mass flow rate per unit perimeter, } \\
\mathrm{kg} /(\mathrm{m} \bullet \mathrm{s})\end{array}$ \\
\hline Abbreviations & & $\alpha$ & Void fraction,- \\
\hline$C F R$ & Critical volume-filling ratio & $\sigma$ & Surface tension, N/m \\
\hline$E F R$ & $\begin{array}{l}\text { Volume-filling ratio when evaporator is } \\
\text { fulfilled replenished }\end{array}$ & $\Phi$ & Power throughput, $\mathrm{W}$ \\
\hline$T P C T$ & Two-phase closed thermosyphon & & \\
\hline \multirow[t]{2}{*}{$V F R$} & Volume-filling ratio & superscript & \\
\hline & & $*$ & Dimensionless \\
\hline Subscripts & & - & Average \\
\hline$a$ & Adiabatic section & & \\
\hline
\end{tabular}




\section{Introduction}

The two-phase closed thermosyphon (TPCT), which is essentially a gravity-assisted wickless heat pipe, has emerged as the most appropriate thermal control solution due to their low cost and excellent heat transfer capabilities [1]. The internal flow of TPCT is normally assumed as an annular, countercurrent and two-phase flow, which consists of many complex physical processes.

Performance of a TPCT is significantly affected by geometries, temperature, volume-filling ratio, inclination angle and working fluid. Among these factors, the volume-filling ratio (VFR) is deemed of great important, because it can directly determine whether the TPCT functioning well [2-4]. An operation and design concern, however, is determining the VFR of the working fluid, as a function of TPCT dimensions, the power or heat flux throughput, type and vapor temperature of the working fluid, to maximize the TPCT performance.

The suggested filling ranges for the TPCT are mostly obtained through experiments. Imura et al [5] suggested that the optimum VFR ranged between 1/5-1/3 of the evaporation volume, while $1 / 5$ should be taken for a tube with a smaller diameter and $1 / 3$ for a larger diameter. The results of Imura et al [5] were similar to that of Harada et al [6], in whose work the optimum VFR between $0.25-0.30$ was suggested. However, the results from Feldman et al [7] suggested that the optimum VFR should be $18 \%-20 \%$ of the whole volume of TPCT. Negishi and Sawada [8] suggested that the optimum VFR ranged between $25 \%-60 \%$ and $40 \%-75 \%$ of the evaporation volume for water and ethanol, respectively. There are also many other experiments involve the influences of VFR to the thermal performances [9-11], however, the results vary from each other.

The numerical models employed to explore the optimum VFR and heat transfer characteristic of TPCT are usually assumed that the heat transfer process within TPCT can be divided into three sub-processes, namely pool boiling, filmwise evaporation and filmwise reflux condensation $[12,13]$. For different heat transfer regimes and VFRs, three flow patterns and two transitions were introduced by Jiao et al [14]. To ensure functional operation, a potential dryout within the falling liquid film, namely 
local dryout, in the evaporator section should be avoided. The local dryout will result in the temperature rising within the evaporator and thereby decreases the thermal performance. On the other hand, a high VFR, although can avoid liquid film dryout in the evaporator, should be also avoided because of two reasons. Firstly, it significantly degrades the TPCT performance, because the heat transfer coefficient of the liquid film is significantly (more than an order of magnitude) higher than that of the pool boiling [15]. Secondly, the two-phase mixture could be extended into the condenser under high VFR, which leads to the heat transfer deterioration within the condenser and the periodic burst boiling within the evaporator.

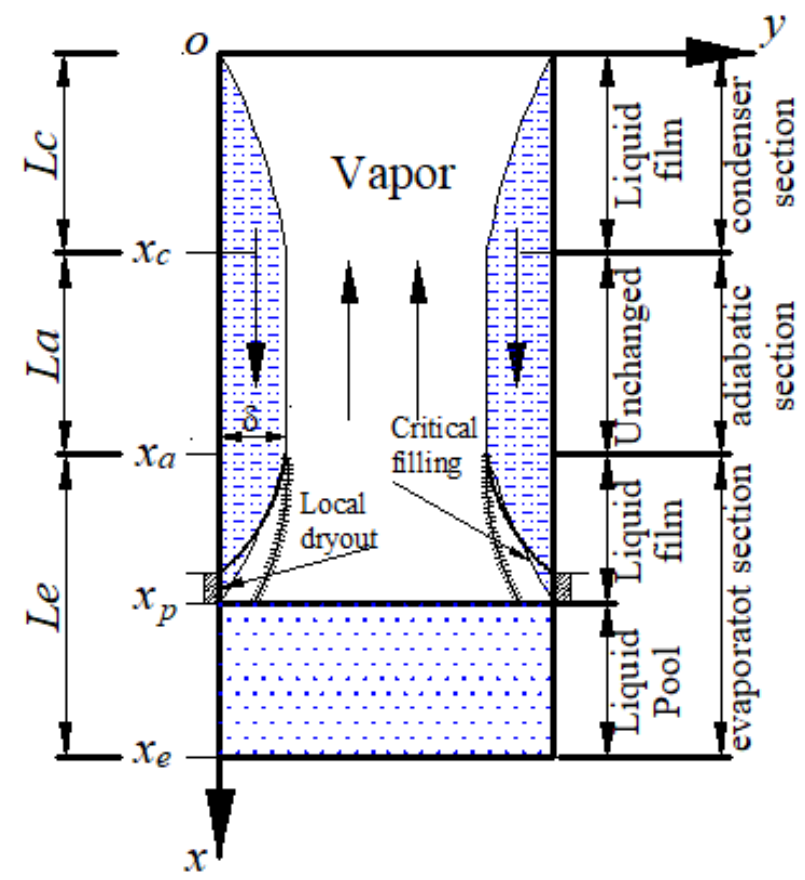

Fig.1 A schematic of TPCT

However, as suggested in [15], one should lengthen the liquid film length to achieve a better heat transfer performance. As shown in Fig.1, the liquid film length takes the highest value when the liquid film thickness in the evaporator taking the minimum value, below which the liquid film will dryout. Correspondingly, the VFR takes the smallest value while the heat transfer coefficient takes the highest value under this condition. VFR under this condition is also defined as the lower boundary of the filling envelope and CFR by El-Genk et al [16] and Jiao et al [14,17], respectively. While the liquid film length takes the smallest value, that is zero, when 
the evaporator is full of working liquid. VFR under this condition is defined as the upper boundary of the operation envelope and EFR, respectively, by above two researchers. It is also identified as the maximum VFR for stable operation. Correspondingly, the heat transfer coefficient takes the smallest value under this condition. In conclusion, a satisfactory state of VFR is situated between CFR and EFR.

Based on the three sub-processes, El-Genk et al [16] and Jiao et al [14,17] numerically studied the filling ranges of TPCTs; while Shabgard et al[18] numerically studied the thermal characteristics of TPCT under different VFRs. According to the results of El-Genk et al [16] and Jiao et al [14,17], CFR and EFR of TPCT are affected simultaneously by geometries of TPCT and vapor temperature. This is also the reason why the experimental results vary from each other.

However, as shown in Fig.2, Cerza et al $[19,20]$ found bubble growing and boiling in the falling liquid films in evaporator, and El-Genk et al [15] then sorted the heat transfer regimes within the falling liquid film into three patterns. In particular, under the high heat flux, the growing vapor bubbles burst at the liquid-vapor interface, dispersing tiny droplets of liquid into the vapor flow. Bubble nucleation at the wall and entrainment of tiny liquid droplets in the vapor flow lead to the enhancement of heat transfer and decrement of film thickness in the evaporator at the same time.
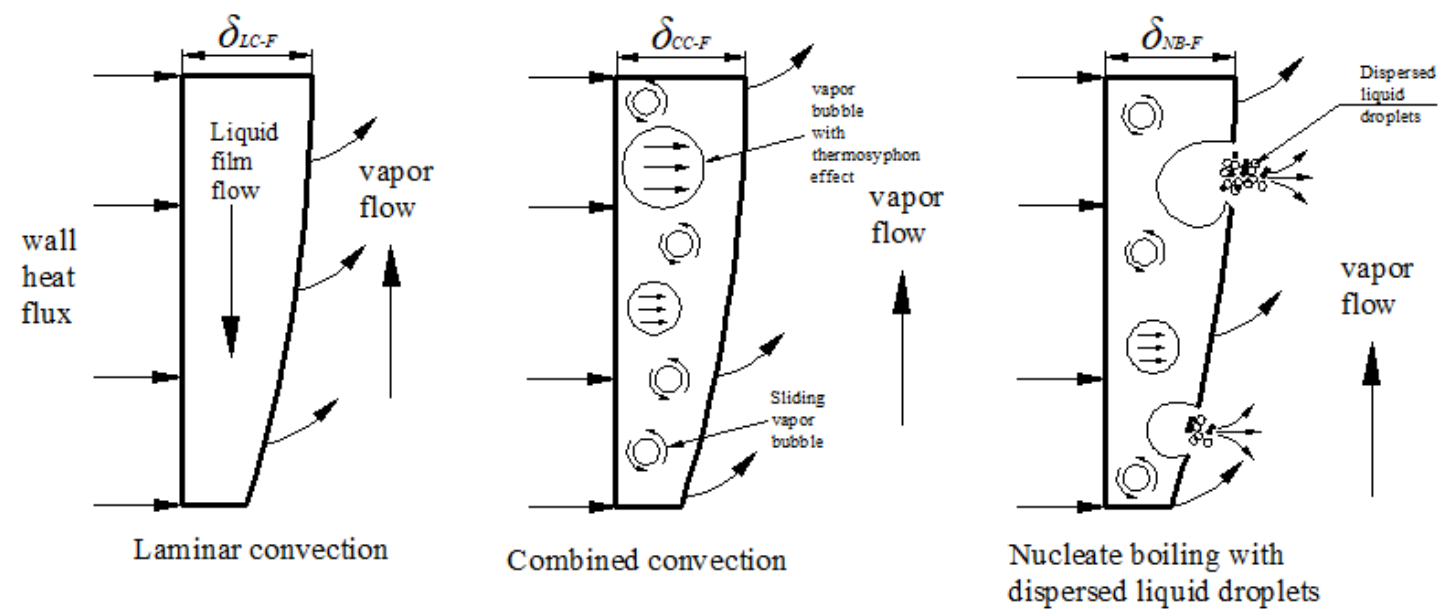

Fig.2 A schematic of the different heat transfer regimes of falling liquid film in a TPCT (reprint from El-Genk et al [15])

To the authors' best knowledge, as illustrated on the left side of Fig.2, most of the 
previous numerical models were established on the basis that the heat transfer regime of the falling liquid film in the evaporator is laminar convection film evaporation. However, the droplet entrainment from the falling liquid film, which is caused by nucleate boiling, will shorten the length of the liquid film under some circumstances and further significantly influences the CFR of TPCT. Further efforts are required to discover the certain impacts. Therefore, in the present study, the entrainment rate, which is caused by the countercurrent vapor flow during the nucleate boiling within the falling liquid film, is introduced to improve the previous TPCT models. A governing equation is developed for the nucleate boiling filmwise evaporation; based on that, a comprehensive model with considering all the three heat transfer regimes in the evaporator is further established. The suggested CFR and EFR are then determined and updated by utilizing the criterias for local dryout, flooding limit and boiling limit; and the effects of geometries and temperature on the filling range are further analyzed in detail. Finally, a simplified correlation for CFR, based on the predicted data from the present model, is proposed.

\section{Mathematical model}

The physical model for the TPCT, as shown in Fig.1, can be divided into three sections: a condenser, an evaporator and an adiabatic section. Normally, changes of mass and momentum are ignored within the adiabatic section. The governing equations, therefore, mainly consist of the liquid film and the liquid pool. Modeling of the TPCT is established on the basis of following assumptions that have been well-accepted: (1) temperature within the liquid film is uniform in the $y$-axis, physical properties are therefore uniform too; (2) Since the film thickness is much less than the tube radius, the curvature effect is negligible and the effects of convective term in momentum and energy equations are negligible; (3) compressibility of the vapor is negligible.

\subsection{Reflux film condensation and laminar convection film evaporation}

Fig. 3 shows the energy balance of a segment of falling film in the condenser. Based on the above assumptions, the governing equations of mass, momentum and energy for a representative elemental volume within the liquid film are (It is noted 
that energy transfer in $y$ direction in the evaporator is opposite to the condenser):

$\frac{\partial u}{\partial x}+\frac{\partial v}{\partial y}=0$

$\mu_{l} \frac{\partial^{2} u}{\partial y^{2}}+\left(\rho_{l}-\rho_{v}\right) g=0$

$$
\frac{\partial^{2} T}{\partial y^{2}}=0
$$

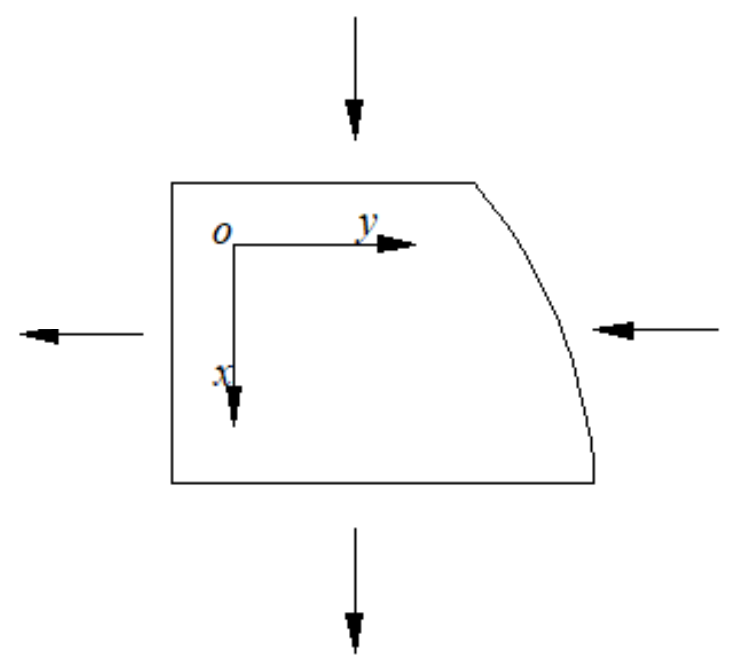

Fig.3 The energy balance of representative elemental volume in the laminar liquid film of the condenser

According to simulation results of Shabgard et al[18], the vapor pressure and the vapor temperature vary little along the falling film, especially under the CFR conditions. Meanwhile, simulation results of different variables were very close when pressure gradient was considered or not. Therefore, the axial pressure gradient is also ignored in the governing equations.

The associated boundary conditions (constant heat flux boundary condition ) are:

$$
\begin{aligned}
& y=0: u=v=0, \mu_{l} \frac{\partial u}{\partial y}=\tau_{w} \\
& y=\delta: \mu_{l} \frac{\partial u}{\partial y}=\tau_{i}, k_{l} \frac{\partial T}{\partial y}=\frac{\partial \Gamma}{\partial x} h_{f g}, T=T_{s} \\
& x=0: u=0, \delta=0, u_{v}=0
\end{aligned}
$$

Integrating the governing equations and boundary conditions yields: 


$$
\begin{aligned}
& u_{l}(y)=\left(\frac{\left(\rho_{l}-\rho_{v}\right) g \delta-\tau_{i}}{\mu_{l}}\right) y-\left(\frac{\left(\rho_{l}-\rho_{v}\right) g}{2 \mu_{l}}\right) y^{2} \\
& \Gamma=\int_{0}^{\delta} \rho_{l} u_{l} d y=\frac{\rho_{l}\left(\rho_{l}-\rho_{v}\right) g}{3 \mu_{l}} \delta^{3}-\frac{\rho_{l} \tau_{i}}{2 \mu_{l}} \delta^{2} \\
& h_{f g} d \Gamma=q d x+d\left[\int_{o}^{\delta} \rho_{l} u_{l} h_{l} d y\right] \\
& \frac{3 C_{2} C_{3}}{32} \delta^{4}+\left(\frac{C_{1} C_{3}}{3}-\frac{C_{2} \tau_{i}}{9}\right) \delta^{3}-\frac{C_{1} \tau_{i}}{2} \delta^{2}=x \\
& \frac{3 C_{2} C_{3}}{32}\left(\delta^{4}-\delta_{a}^{4}\right)+\left(\frac{C_{1} C_{3}}{3}-\frac{C_{2} \tau_{i}}{9}\right)\left(\delta^{3}-\delta_{a}^{3}\right)-\frac{C_{1} \tau_{i}}{2}\left(\delta^{2}-\delta_{a}^{2}\right)=x-x_{a}
\end{aligned}
$$

Where $C_{1}=\frac{h_{f g} \rho_{l}}{q \mu_{l}}, C_{2}=\frac{\rho_{l} C_{p}}{\mu_{l} k_{l}}, C_{3}=\left(\rho_{l}-\rho_{v}\right) g$.

The shear stress at the liquid-vapor interface, $\tau_{i}$, which consists of viscous shear stress, $\tau_{f}$, and dynamic shear stress, $\tau_{m}$, can generally be calculated as:

$$
\begin{aligned}
& \tau_{i}=\tau_{f} \pm \tau_{m}=0.5 C_{f i} \rho_{v}\left(u_{l(\delta)}+u_{v}\right)^{2} \pm \frac{q_{e v a}\left(u_{l(\delta)}+u_{v}\right)}{h_{f g}} \\
& u_{v}=4 \Gamma /\left(\rho_{l} D_{i}\right)
\end{aligned}
$$

where $C_{f i}$ is the friction coefficient and its value can be referenced to Yang [21]. The plus and minus signs on the right-hand-side of Eq.(9) account for the effect of condenser and evaporator at the liquid-vapor interface, respectively [22].

The heat transfer coefficients of the film condensation and laminar convection film evaporation are defined as [12, 13]:

$$
\begin{array}{ll}
h=\frac{k_{l}}{\delta} & \left(\text { Laminar liquid film, } \operatorname{Re}_{l} \leq 2040 ;\right) \\
h=\frac{0.056 \operatorname{Re}_{l}^{-0.2} \operatorname{Pr}^{1 / 3} k_{l}}{\left(v_{l}^{2} / g\right)^{1 / 3}} \quad\left(\text { Turbulent liquid film, } \operatorname{Re}_{l} \geq 2040\right) \\
\operatorname{Re}_{l}=\frac{u_{l} \delta}{v_{l}}=\frac{4 \Gamma_{x}}{\mu_{l}}
\end{array}
$$

2.2 Nucleate boiling film evaporation and combined convection film evaporation 
As shown in Fig. 2, laminar convection film evaporation occurs under the low heat fluxes. In this regime, the liquid film has a progressively decreasing thickness along the evaporator under the interaction of vaporization and interfacial shear stress. However, under the high heat fluxes, nucleate boiling occurs within the falling liquid film. Bubbles grow in the falling liquid film and continue to grow as they are swept from their nucleation sites until they burst at the liquid-vapor interface and disperse tiny droplets into the vapor flow. The bubbles are continuously growing, sliding and dispersing during the nucleate boiling film evaporation. Heat transfer regime situated between laminar convection and nucleate boiling is named combined convection, in which bubbles are growing and sliding but not splashing.

The vapor bubbles bursting at the liquid-vapor interface disturbs the shear stress at the liquid-vapor interface and further weaken the decisive effect of shear stress on the thickness of the liquid film. The authors assume that the decisive effect is replaced by the droplet entrainment under this condition. Besides, bubbles growing and sliding within the liquid film must also muss up the falling flow pattern of the liquid film; thus, additional with the last assumption, the change of the flow velocity of the liquid film, along the evaporator, is further neglected in the present study; furthermore, since the liquid film thickness is much less than tube inner diameter, influences of bubbles to the mass and thickness of the liquid film are negligible. For the nucleate boiling film evaporation, the equations can be expressed as:

$$
\begin{aligned}
& \frac{d \Gamma}{d x}+\frac{q_{e v a}}{h_{f g}}\left(1+e_{b}\right)=0 \\
& \frac{d \delta}{d x}=\frac{1}{\rho_{l} \overline{u_{l(\delta)}}} \frac{d \Gamma}{d x}
\end{aligned}
$$

where $e_{b}$ is the entrainment rate caused by the internal countercurrent flow, it can be calculated as [23]:

$$
\frac{e_{b}}{1-e_{b}}=10^{-2.52} \rho_{l}^{1.08} \rho_{v}^{0.18} \mu_{l}^{0.27} \mu_{v}^{0.28} \sigma^{-1.8} D_{i}^{1.72} u_{l(\delta)}^{0.70} u_{v}^{1.44} g^{0.46}
$$

The thickness of liquid film under the combined convection film evaporation is assumed as the average value of laminar convection film evaporation and nucleate 
boiling film evaporation, that is:

$$
\delta_{C C-F}=\frac{\delta_{L C-F}+\delta_{N B-F}}{2}
$$

The heat transfer regimes and heat transfer coefficients within the liquid film are respectively classified and calculated by El-Genk et al [15]:

$$
\begin{aligned}
& N u_{L C-F}=(4 / 3)^{1 / 3}\left(\operatorname{Re}_{x}\right) \quad\left(X_{F} \leq 10^{9}\right) \\
& N u_{N B-F}=1.155 \times 10^{-3} N_{u f}^{0.33} \operatorname{Pr}_{l}^{0.35}\left(\frac{p I_{m}}{\sigma}\right)^{0.7}\left(\frac{q_{\text {eva }} I_{m}}{\rho_{v} h_{f g} v_{l}}\right)^{0.7} \quad\left(X_{F} \geq 2.7 \times 10^{10}\right) \\
& N u_{C C-F}=\left(N u_{L C-F}^{3}+N u_{N B-F}^{3}\right)^{1 / 3} \quad\left(10^{9}<X_{F}<2.7 \times 10^{10}\right)
\end{aligned}
$$

where $I_{m}$ is the bubble length scale, $\mathrm{m} ; N_{\mu f}$ is the viscosity number. The film Nusselt number is based on the film thickness scale $l_{l}$, and $X_{F}$ is the discriminant parameter.

$$
\begin{aligned}
& I_{m}=\sqrt{\frac{\sigma}{g\left(\rho_{l}-\rho_{v}\right)}} \\
& N_{u f}=\mu_{l} / \sqrt{I_{m} \sigma \rho_{l}} \\
& l_{l}=\left(\frac{\mu_{l}^{2}}{g \rho_{l}\left(\rho_{l}-\rho_{v}\right)}\right)^{1 / 3} \\
& X_{F}=\left(\frac{q_{e v a} I_{m}}{\rho_{v} h_{f g} \nu_{l}}\right)^{2}\left(\frac{p I_{m}}{\sigma}\right)^{2} \frac{\operatorname{Re}_{x}}{\operatorname{Pr}_{l}} \\
& \operatorname{Re}_{x}=\frac{4 \Gamma_{x}}{\mu_{l}}=\frac{4 q_{e v a}\left(x_{e}-x\right)}{\mu_{l} h_{f g}}
\end{aligned}
$$

Introducing the droplet entrainment to improve the existing TPCT model and further to modify the existing CFR and the thermal resistance of TPCT are firstly attempted by the present study. Therefore, simplifications and assumptions are set to enable the implementation of the present model. The limitation and rationality are suggested as following:

Firstly, one can make certain the heat transfer regime within the falling film according to Eqs.(21-23). Under the fully developed entrainment region, that is under 
the relatively high heat flux, the bubbles growing in the falling liquid film influence the mass of the liquid film like that in the pool boiling and influence the thickness of liquid film at the same time. However, the bubbles burst at the liquid-vapor interface and disperse tiny droplets into the vapor flow. Meanwhile, considering that the liquid film thickness is much less than the tube inner diameter and the bubbles burst rapidly. The influences have been diminished when the entrainment rate is included in the governing equations (see Eqs.(17-18)). Therefore, under the fully developed entrainment region, the assumptions are relatively reasonable.

However, the present model has limitations under the low heat flux conditions, especially under the combined convection film evaporation. For conditions with very small entrainment rate or the developing entrainment regions (transition regime), Ishii and Kataoka [24] and Kataoka et al [25] proposed the correction factors which were smaller than 1 to amend the influence. But the correction factor is ignored in the present study on the premise that firstly, the entrainment rates are already small in these cases. Furthermore, droplet entrainment captured by equation (19) has a relatively large uncertainty under low heat fluxes. For the combined convection film evaporation, the bubbles are growing and sliding but not splashing. Like that in pool boiling, their influences to the mass and thickness of liquid film can not be ignored. However, to the authors' best knowledge, theoretical models or semi-empirical correlations to estimate the geometries and amount of the bubbles are rare. Therefore, thickness of liquid film under the combined convection film evaporation is assumed as the average value of that under the laminar convection film evaporation and nucleate boiling film evaporation (see Eq.(20)). The latter is employed to reflect the mass reduction caused by bubbles. In a word, as validated by the simulation results, results under the developing entrainment regions and the combined convection film evaporation are close to the laminar convection film evaporation and the previous studies.

\subsection{Liquid pool}

The heat transfer regime within the liquid pool is usually perceived as nucleate boiling. However, based on the variation of wall heat flux, there are also three heat 
transfer regimes in liquid pool, namely natural convection, combined convection and nucleate boiling. Owing to the complexity of heat transfer in the liquid pool, well-accepted empirical correlations for the heat transfer coefficients, which were also proposed by El-Genk et al [26], are employed in the present study. However, the equations are not listed in this paper.

Plenty of bubbles generate in the liquid pool during the pool boiling, their influences on calculating the liquid mass within the elemental volume, as well as on calculating the height of liquid pool, cannot be ignored. Void fraction is introduced to take this effect into account. The local void fraction, given by the drift flux model [27], can be expressed as:

$$
\alpha_{b}(x)=\frac{j_{v}(x)}{C_{0} j_{v}(x)+\overline{V_{v j}}}
$$

where $C_{0}$ is the distribution coefficient; $j_{v}(x)$ is the local superficial velocity of vapor, $\mathrm{m} / \mathrm{s} ; \overline{V_{v j}}$ is the area average local drift velocity, $\mathrm{m} / \mathrm{s}$. These three variables can be expressed as:

$$
\begin{aligned}
& C_{0}=1.2-0.2 \sqrt{\rho_{v} / \rho_{l}} \\
& j_{v}(x)=\frac{4 q_{\text {eva }} L_{p}}{\rho_{v} D_{i} h_{f g}}\left(1-\frac{x-x_{a}}{L_{p}}\right) \\
& \overline{V_{v j}}=V_{v j}^{+}\left(\frac{\sigma g\left(\rho_{l}-\rho_{v}\right)}{\rho_{l}^{2}}\right)^{0.25}
\end{aligned}
$$

The dimensionless vapor drift velocity in Eq.(32), $V_{v j}^{+}$, is in terms of the liquid viscosity number, $N_{u f}$, and the hydraulic diameter of the pool, $D_{i}^{+}$:

$$
\begin{aligned}
& V_{v j}^{+}=0.03\left(\frac{\rho_{l}}{\rho_{v}}\right)^{0.157} N_{u f}^{-0.562} \quad\left(D_{i}^{+} \leq 30, N_{u f}<2.25 \times 10^{-3}\right) \\
& V_{v j}^{+}=0.0019\left(D_{i}^{+}\right)^{0.809}\left(\frac{\rho_{l}}{\rho_{v}}\right)^{0.157} N_{u f}^{-0.562} \quad\left(D_{i}^{+}>30, N_{u f}<2.25 \times 10^{-3}\right)
\end{aligned}
$$




$$
\begin{aligned}
& V_{v j}^{+}=0.92\left(\frac{\rho_{l}}{\rho_{v}}\right)^{0.157} \quad\left(N_{u f} \geq 2.25 \times 10^{-3}\right) \\
& D_{i}^{+}=D_{i} \sqrt{\frac{g\left(\rho_{l}-\rho_{v}\right)}{\sigma}}
\end{aligned}
$$

The mean void fraction of the liquid pool is expressed as follow:

$$
\alpha_{b}=\frac{1}{L_{p}} \int_{x_{p}}^{x_{\text {eva }}} \alpha_{b}(x) d x
$$

\subsection{Criterias}

In the numerical models of El-Genk et al [16] and Jiao et al [17], the critical film thickness was introduced, beyond which a film dryout could occur. The length of the liquid film in the evaporator is thus determined on the basis of that. However, in the present study, since the liquid film has a probability to burst during the nucleate boiling film evaporation. Therefore, the critical mass flow rate is used instead. It is hypothesized that if the mass flow rate decreases to $1 \%$ of its initial value (exit of condenser), the bubbles are certain to burst [28]:

$$
\Gamma_{x, \text { eva }}=0.01 \Gamma_{x_{\text {con }}} \text { or } \sum_{j=1}^{M} \frac{d \Gamma_{x}}{d x}=0.99 \Gamma_{x_{c o n}}
$$

The flooding limit and boiling limit also preclude a TPCT from operating well. The boiling limit in thermosyphon is due to the film boiling, which occurs when a vapor film forming between the pipe wall and the liquid in the evaporator [29]. Correspondingly, the onset of boiling is assumed as the flow regime turns from churn flow to annular within the pool. Therefore, the criterion of flow pattern rather than the empirical equations is employed to predicate the onset of boiling, which can be expressed as [30]:

$$
V_{v j}^{*}=J_{v}(x) \sqrt{\frac{\rho_{v}}{g D_{i}\left(\rho_{l}-\rho_{v}\right)}} \geq 1
$$

where $V_{v j}^{*}$ is the modified Froude number.

Flooding occurs when the upward velocity of the vapor is high enough to prevent the liquid film from flowing back to the evaporator due to the shear stress at the 
interface of the countercurrent liquid-vapor flow. It has been confirmed by visualization experiments [31] and numerical studies [22] that the onset of flooding occurs first at the exit of the condenser. Therefore, the onset of flooding, based on the numerical model, can be expressed as:

$$
\Gamma_{x_{c o n}}=0
$$

Based on the governing equations and criterias, the distribution of the thickness of the liquid film, as well as the void fraction and the height of the liquid pool, can be finally determined. The CFR, EFR and thermal resistance can also be further determined. The total mass of working fluid, which consists of the liquid films in the condenser and evaporator, the liquid pool in the evaporator and the vapor in the whole TPCT, can be expressed as:

$$
\begin{aligned}
& m_{c o n}=\pi \int_{0}^{x_{c o n}}\left\{\left[\left(\frac{D_{i}}{2}\right)^{2}-\left(\frac{D_{i}}{2}-\delta\right)^{2}\right] \rho_{l}+\left(\frac{D_{i}}{2}-\delta\right)^{2} \rho_{v}\right\} d x \\
& m_{e f}=\pi \int_{x_{a}}^{x_{e f}}\left\{\left[\left(\frac{D_{i}}{2}\right)^{2}-\left(\frac{D_{i}}{2}-\delta\right)^{2}\right] \rho_{l}+\left(\frac{D_{i}}{2}-\delta\right)^{2} \rho_{v}\right\} d x \\
& m_{e p}=\frac{\pi D_{i}^{2}}{4} L_{p}\left[\alpha_{b} \rho_{v}+\left(1-\alpha_{b}\right) \rho_{l}\right] \\
& m_{a}=\pi \int_{x_{c o n}}^{x_{a}}\left\{\left[\left(\frac{D_{i}}{2}\right)^{2}-\left(\frac{D_{i}}{2}-\delta_{a}\right)^{2}\right] \rho_{l}+\left(\frac{D_{i}}{2}-\delta_{a}\right)^{2} \rho_{v}\right\} d x
\end{aligned}
$$

The VFR of TPCT is expressed as:

$$
V F R=\left(m_{c}+m_{e f}+m_{e p}+m_{a}\right) / \rho_{v} V_{e v a}
$$

The effective heat transfer coefficient of the evaporator is expressed as El-Genk et al [16] and Jiao et al [17]:

$$
h_{\text {eva }}=h_{e f} \frac{L_{e f}}{L_{\text {eva }}}+h_{e p} \frac{L_{p}}{L_{e v a}}
$$

The overall thermal resistance of the TPCT is expressed as:

$$
R=\frac{1}{h_{\text {eva }} \pi D_{i} L_{\text {eva }}}+\frac{1}{h_{c o n} \pi D_{i} L_{c o n}}
$$


TPCT operates unstably when boiling limit and flooding limit occurs. According to Jiao et al [17], heat flux corresponding to the onset of boiling is smaller than that of the flooding limit. The VFR and the operation envelope between that interval, therefore, is not recommended, correspondingly.

\section{Model validation}

Based on the numerical model of TPCT, one can conclude that the VFR and the thermal resistance are mainly determined by liquid film thickness, liquid film length, height of liquid pool, heat flux throughput, void fraction of liquid pool and the heat transfer coefficients of liquid film and liquid pool. The latter three are calculated through empirical correlations in the present study, while the height of the liquid pool can be easily obtained based on the length of the liquid film. Therefore, the liquid film thickness along the TPCT and the heat flux play the most important roles. In the following, the liquid film thickness along the TPCT and the onset of flooding are compared and validated with the published literatures, respectively.

Fig.4 shows the comparisons of the distributions of liquid film thickness along the TPCT with the same thermal boundary conditions. In the present study, two simulated results are compared with Shabgard et al [18]. The first one is based on the normal processing mode. That is, assuming that the heat transfer pattern within the falling liquid film in the evaporator is laminar convection film evaporation, and film thickness is mainly determined by interfacial shear stress. The other one is based on developed model on section 2.1 and 2.2, droplet entrainment is additionally considered in nucleate boiling film evaporation. 


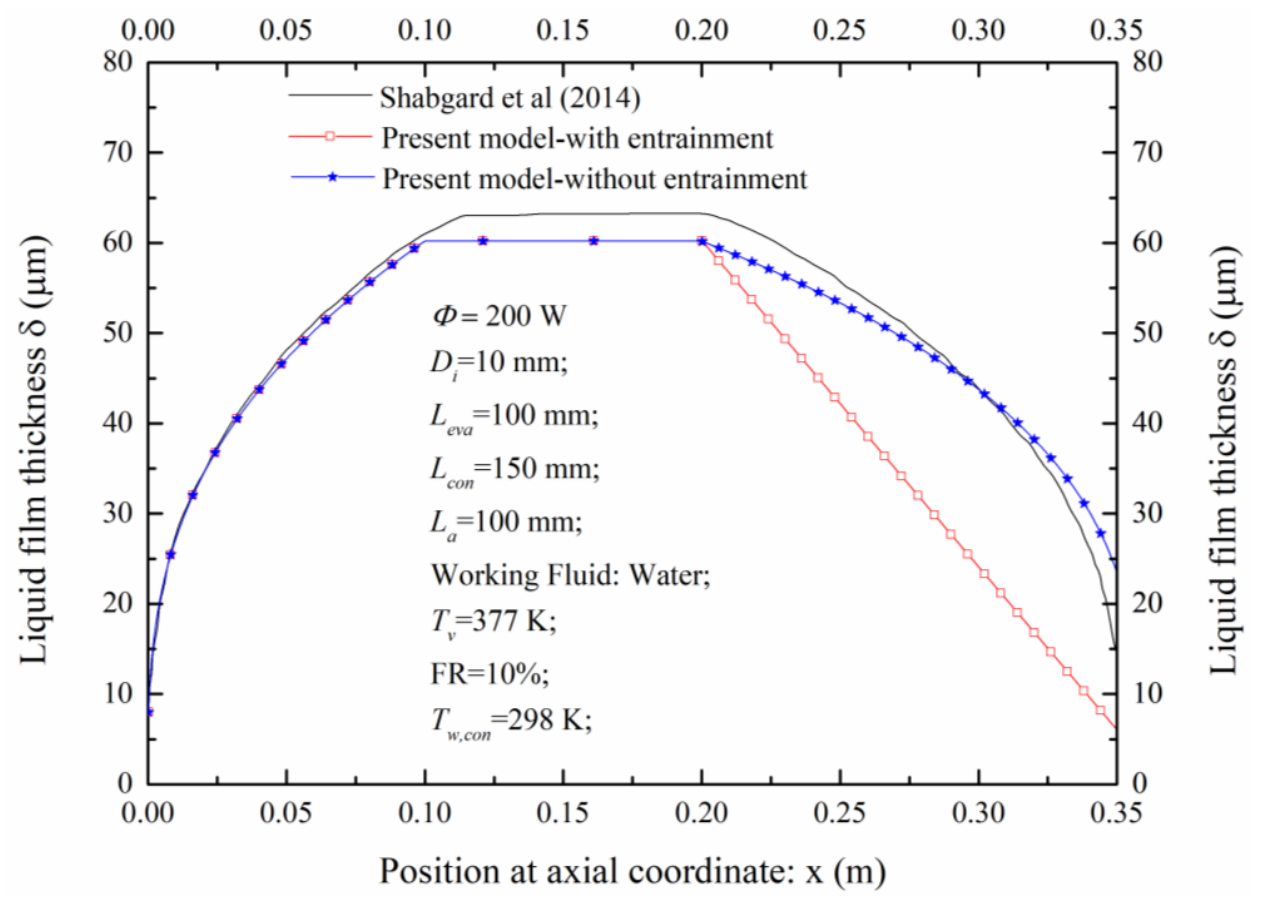

Fig.4 Comparisons of liquid film thickness with Shabgard et al [18]

According to Eqs. (21-28), the heat transfer regime of the falling liquid film within the evaporator in Shabgard et al [18] is nucleate boiling film evaporation. Fig.4 shows that the curve without considering the droplet entrainment agrees well with that of Shabgard et al [18], except the points at the very end of evaporator. The film thickness increases and decreases like a parabola along both the condenser and evaporator. However, when considering the droplet entrainment, the film thickness linearly decreases in the evaporator.

Fig.5 compares the numerical calculated dimensionless liquid film thickness $\left(2 \delta / D_{i}\right)$, as a function of the Reynolds number, with the experimental data. The maximum film Reynolds number indicates the onset of flooding. The results show that the predictions of the present model are in excellent agreement with the experimental data of Reed et al [32]. At the same time, the maximum value of the Reynolds number, which is 129.9 predicted by the present model, agrees well with the values predicted by the models of El-Genk et al [22] and Reed et al [12] ( 125 and $\sim 145$, respectively). According to the analysis of El-Genk et al [22], the higher value from Reed et al [12] is due to the neglecting contribution of the dynamic shear stress. 


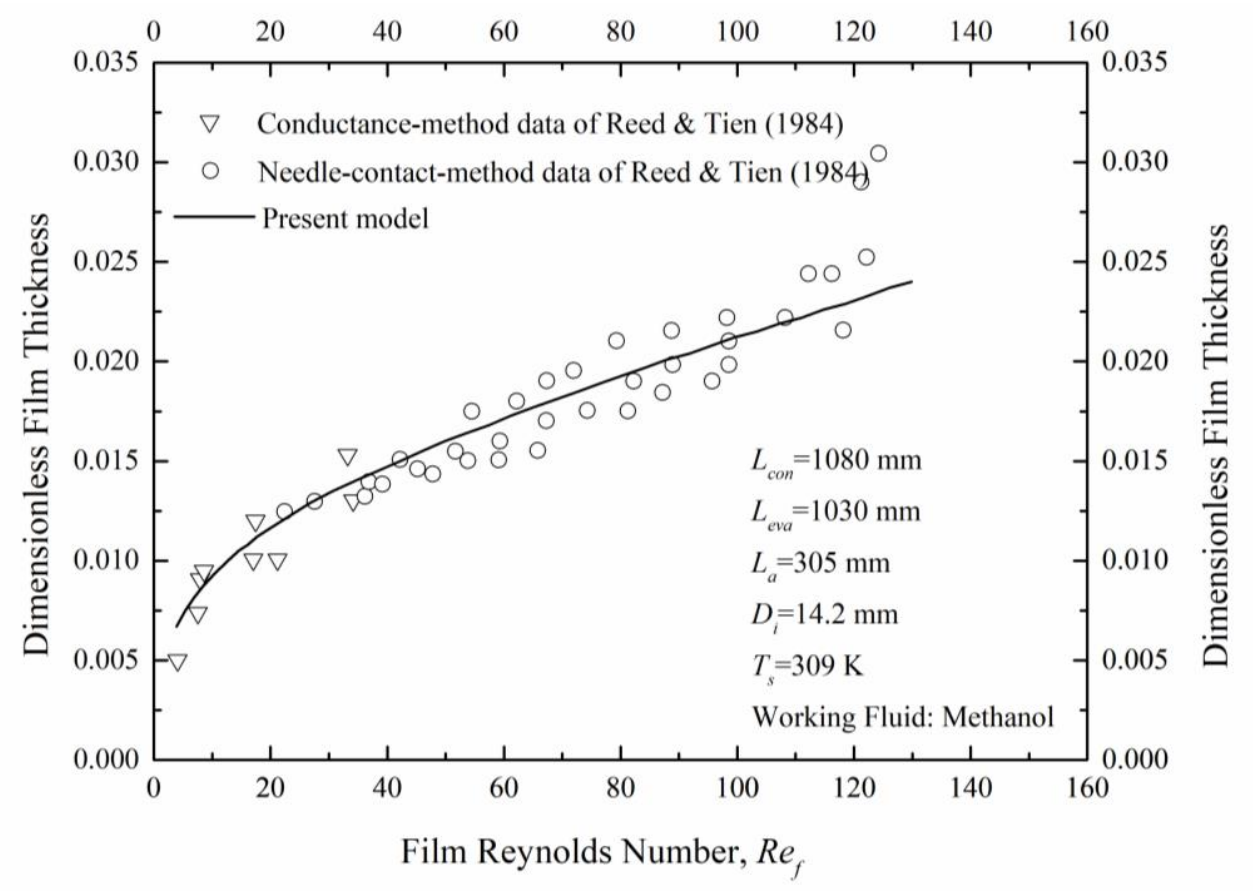

Fig.5 Comparison of present and Reed et al's experimental data [30] for the CCFL at the exit of the condenser

In Fig.5, the mean error of the film thickness between the present model and the Shabgard et al's model [18] is 4.58\%. From Fig.5, the error of the Reynolds number at the onset of flooding between the present model and the El-Genk et al's model [22] is $3.92 \%$. Hence, the predictions of the two most important variables in determining the VFR and thermal resistance, which are heat flux at the onset of flooding and thickness distribution of the liquid film, are reasonable; the deprecated region, which is the heat flux interval between onset of boiling and the onset of flooding, is also reliable.

\section{Results and Discussion}

For the numerical simulation of the CFR, EFR and thermal resistance of TPCT under various heat fluxes, a copper-water TPCT with the dimensions similar to authors' previous work [33] is selected. The sealed filling range of a vertical TPCT under various heat fluxes is shown in Fig.6. As labeled in Fig.6, CFR and EFR are the lower and upper boundaries of the envelope, respectively. Since the relative position of CFR and EFR is stable, the labels are omitted in the subsequent paragraphs. The curves of CFR and EFR are confined by the minimum and the maximum heat fluxes. The maximum heat flux corresponds to the onset of the flooding. The minimum heat 
flux is set as $2500 \mathrm{~W} / \mathrm{m}^{2}$ in the present study. And then the envelope is diced by the boiling limit. The semi-trapezoid region between the boiling limit and the flooding limit is the deprecated region for practical operation.

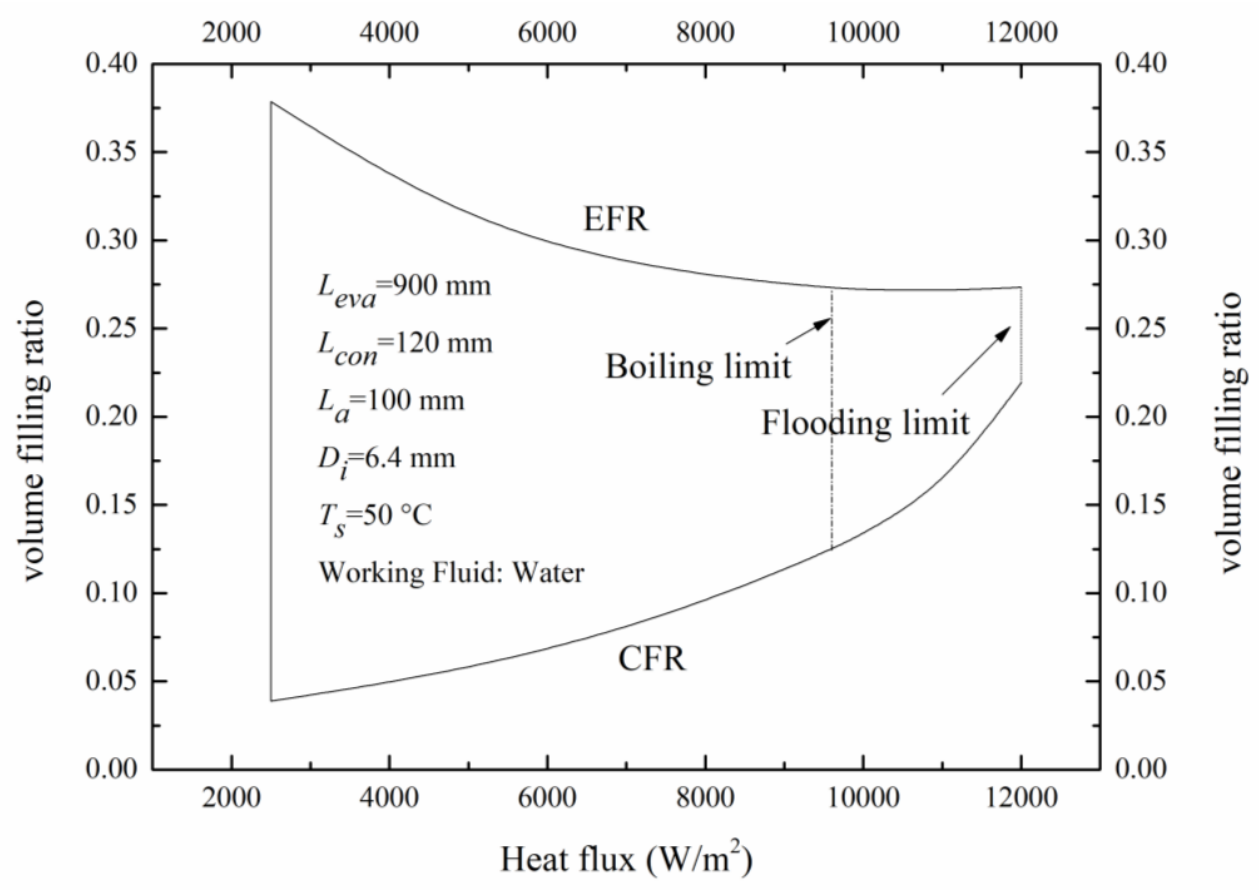

Fig.6 The sealed filling range of a vertical TPCT

As shown in Fig.6, firstly, the EFR decreases while the CFR increases, with increasing the heat flux; secondly, the difference between EFR and CFR decreases with increasing the heat flux; the trends agree well with Jiao et al [14]. The decrease of EFR is resulting from the increase of void fraction in the liquid pool. However, the determining of CFR is relatively complex, which have to be expected with additional evidences, see Fig.7.

Under the conditions of CFR and EFR, variations of the liquid film thickness at the exit of the condenser, the height of the liquid pool and the thermal resistance are presented in detail in Fig.7. It illustrates that the liquid film thickness and the thermal resistance gradually increase with increasing the heat flux; while the height of the liquid pool slightly increases as heat fluxes below $7500 \mathrm{~W} / \mathrm{m}^{2}$ and sharply increases after that. 


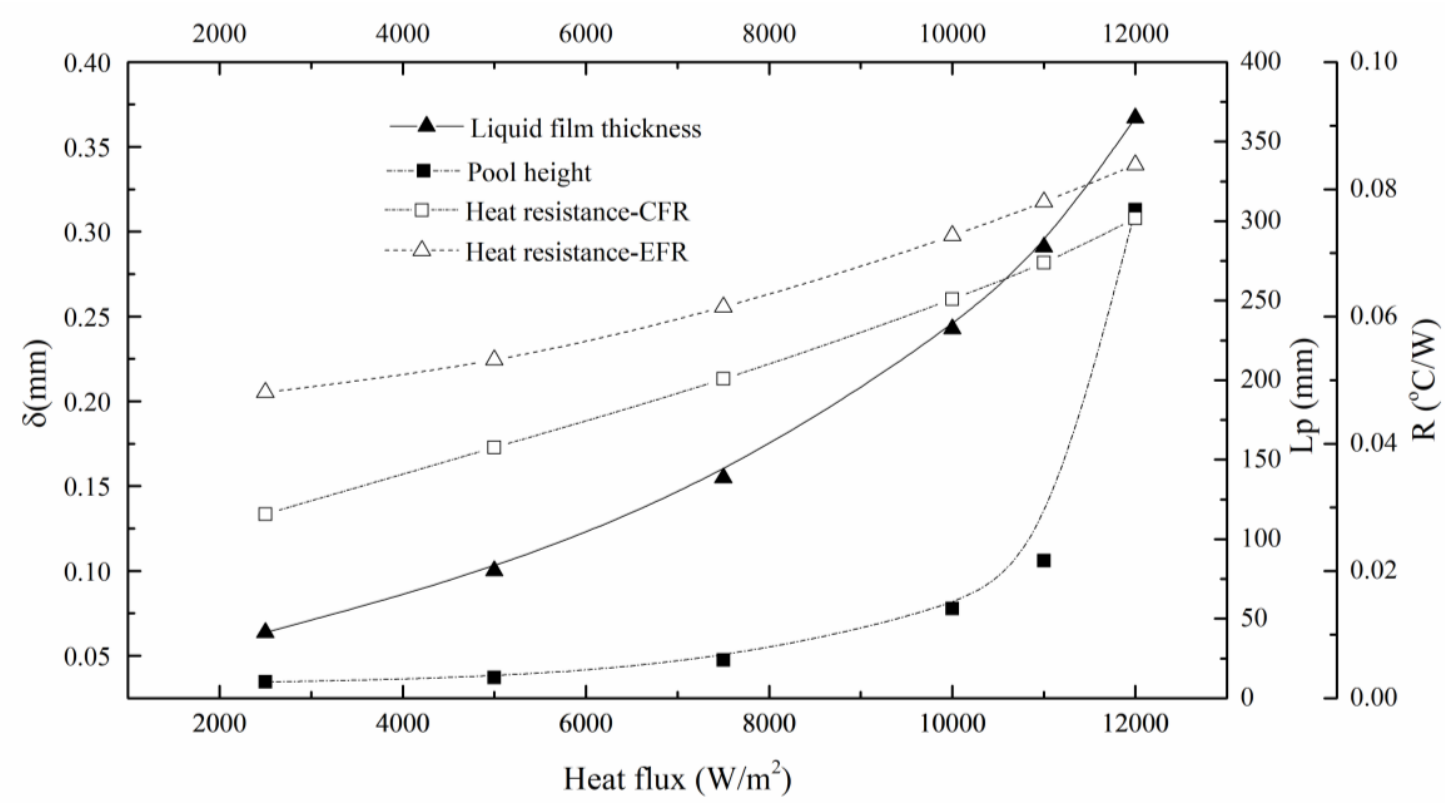

Fig.7 Variations of liquid film thickness, the height of liquid pool and the thermal resistance of

TPCT with increasing the heat flux

The increase of liquid film thickness is dominantly responsible for the increase of thermal resistance. Increasing the heat flux increases the liquid film thickness in the condenser but also increases the attenuation of liquid film thickness in the evaporator. The interaction of above inhibiting effect is responsible for the slight increase in the height of the liquid pool when heat flux below $7500 \mathrm{~W} / \mathrm{m}^{2}$. When under the high heat flux, the heat transfer regime within the falling liquid film in evaporator turns from the combined convection to the nucleate boiling. The droplet entrainment participates the decrease of film thickness. Meanwhile, the entrainment rate increases with increasing the heat flux, which drastically decreases the film thickness and thereby sharply increases the height of the liquid pool. The latter is responsible for the increase of CFR in Fig.6 and also responsible for the decrease of thermal resistance difference between CFR and EFR.

\subsection{Effect of condenser length}

Fig.8 shows the effect of condenser length on the filling range of TPCT, it indicates that increasing the condenser length: (1) increases EFR; (2) the value of heat flux corresponding to the onset of boiling, however, is constant; (3) increases the value of heat flux corresponding to the onset of flooding; (4) CFR curves are disordered. However, there are rules to follow. That is, the CFR increases with 
increasing the condenser length until the heat flux reaches the value corresponding to half of the onset of flooding. Moreover, CFR has a substantial increase near the flooding limit because of the increase of height of liquid pool.

It is worth noting that increasing the condenser length not only modestly decreases the liquid film thickness but also increases the mass of liquid film within the condenser, which lead to a small upward moving of the filling range map. However, the increase in mass is limited; the changing gradients of CFR and EFR to the condenser length are, therefore, negligible. Additionally, combining (2) and (3), the proportion of the area corresponding to the deprecated region expands with increasing the condenser length.

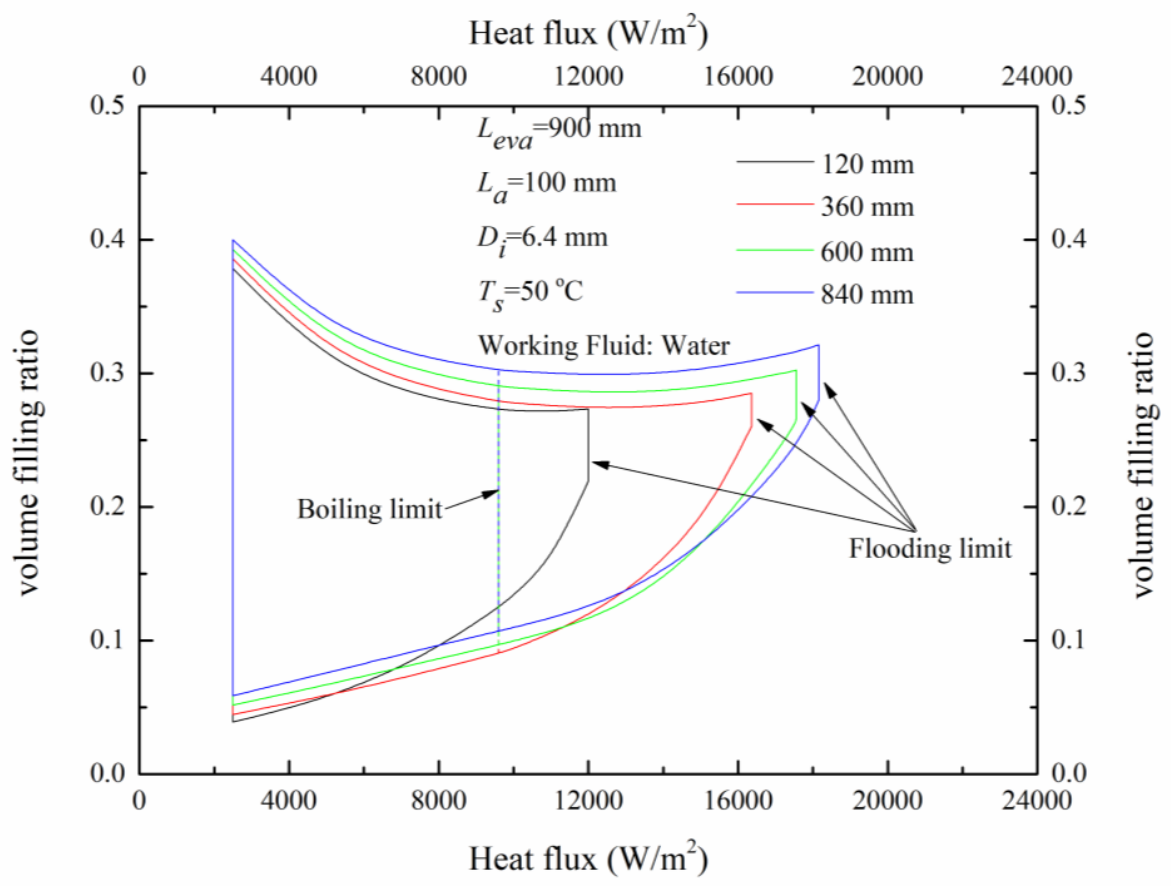

Fig.8 Effect of condenser length on the filling range of TPCT

Fig.9 displays the effects of condenser length on the height of the liquid pool and the thermal resistance of TPCT. It shows clearly that the thermal resistance decreases with increasing the condenser length. It is because the heat fluxes at the condenser decrease with increasing the condenser length, which leads to the decreases of liquid film thickness within the condenser and evaporator and further increases the heat transfer coefficients at these two regions. Besides, under the same heat flux, the height of the liquid pool decreases with increasing the condenser length (see from the inset 
figure on the top right corner), which further decreases the thermal resistance of TPCT. However, the maximum height of liquid pool at CFR seems rule-less with increasing the condenser length.

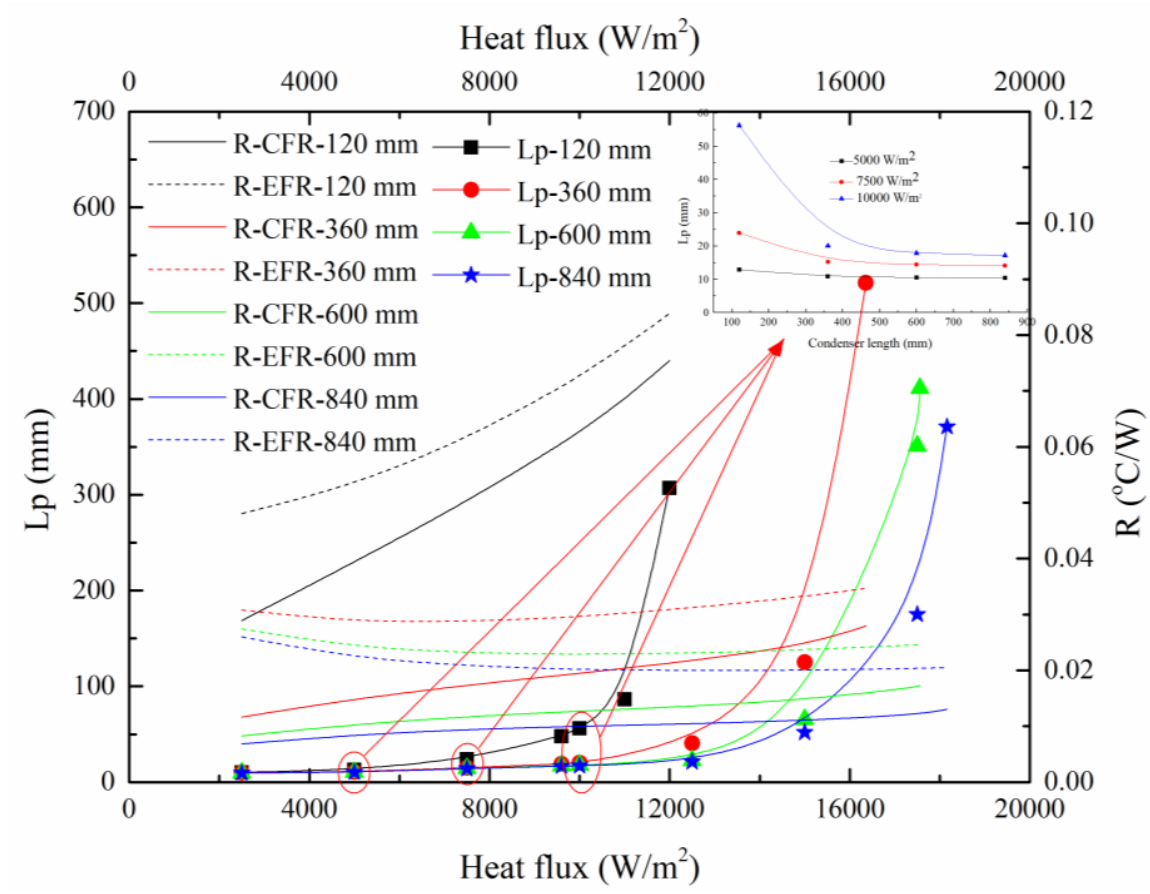

Fig.9 Effect of condenser length on the height of liquid pool and the thermal resistance of TPCT

The effects of condenser length on the TPCT can be summarized as follows: increasing the condenser length, despite has no influence to the boiling limit, increases both the CFR and EFR and modestly increases the heat flux corresponding to the flooding limit.

\subsection{Effect of adiabatic length}

Fig.10 displays the effect of the adiabatic length on the filling range of TPCT, it indicates that increasing the adiabatic length increases both the CFR and EFR but insignificantly changes the operation area. It is because the adiabatic section is assumed as the transition section, in which the parameters unchanged and the thermal resistance is therefore unchanged. The mass of liquid film increases with increasing the adiabatic length and further increases the CFR and EFR. Similar to the effect of condenser length, the filling range map moves upward slightly and the changing gradient of CFR and EFR to the adiabatic length is negligible. 


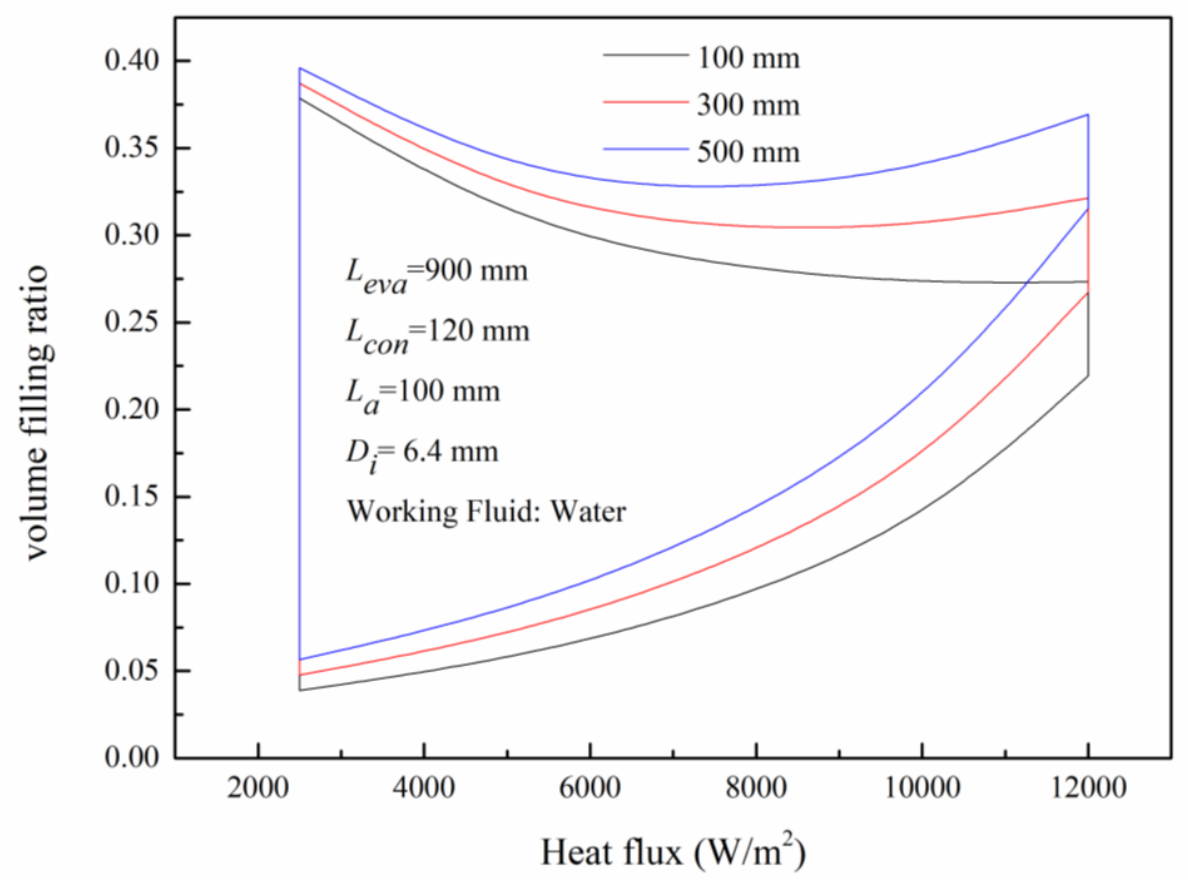

Fig.10 Effect of the adiabatic length on the filling range of TPCT

\subsection{Effect of evaporator length}

Fig.11 presents the effect of evaporator length on the filling range of TPCT, it indicates that decreasing the evaporator length distinctly increases the useful area of the operation envelope and also increases the heat fluxes corresponding to boiling limit and flooding limit. Furthermore, increasing the evaporator length lowers the CFR to a small extent but elevates the EFR to a modest extent. Under the same heat flux, decreasing the evaporator length despite decreases the liquid film thickness; however, the decrease of the void fraction within the liquid pool is more decisive. The EFR is, therefore, modestly enlarged. For the CFR under the same heat flux, decreasing the evaporator length changes the heat transfer regime within the liquid film, for example from the combined convection to the laminar convection or from the nucleate boiling to the combine convection. The transition of heat transfer regime leads to the decrease of attenuation of film thickness, which determines a lower CFR. Additionally, the proportion of the area corresponding to the deprecated region also expands with increasing the evaporator length. 


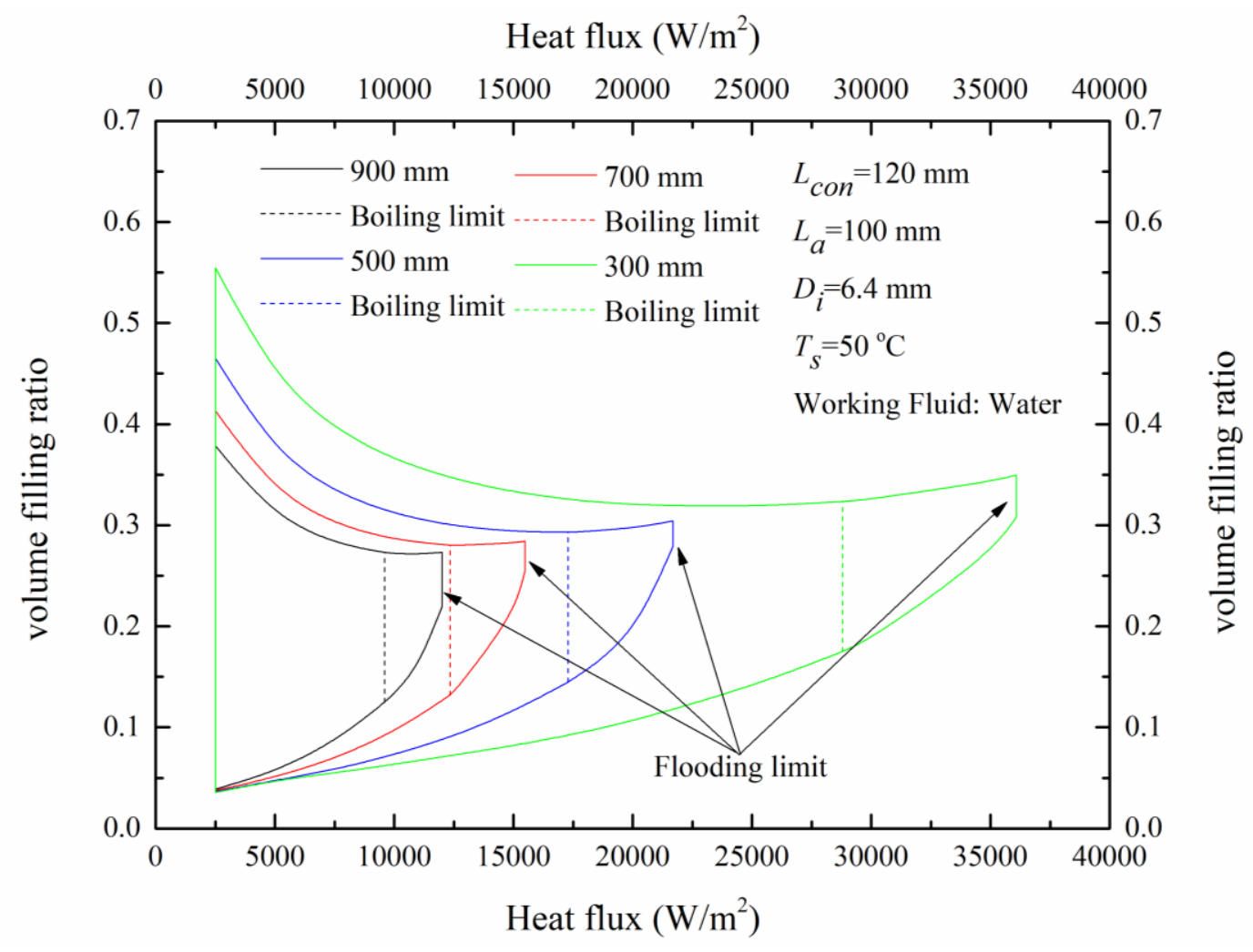

Fig.11 Effect of evaporator length on the filling range of TPCT

The effects of evaporator length on the height of the liquid pool and the thermal resistance are displayed in Fig.12. It reveals that under the same heat flux, decreasing the evaporator length distinctly decreases the thermal resistance at CFR and the height of the liquid pool. It is easy to understand the reason for the latter trend. As for the former, decreasing the evaporator length decreases both the thickness of the liquid film in the condenser and the height of the liquid pool. Both of them contribute to the decrease of thermal resistance. Despite the heat transfer coefficient within evaporator increases with decreasing the evaporator length, which leads to an increase in the thermal resistance, however, the increase is limited.

Fig.12 also shows that the curves of thermal resistance are disordered at EFR. However, similar to the effect of condenser length on the CFR, there are rules to follow. That is, the thermal resistance at EFR increases with decreasing the evaporator length until the heat flux reaches the value corresponding to half of the onset of flooding. Besides, CFR has an evident increase near the heat flux corresponding to flooding limit. 
It is worth mentioning that, firstly, although the maximum heat flux apparently increases with decreasing the evaporator length, the maximum power throughput (W) changes little. The same conclusion can be found in Jiao et al [14]. Secondly, decreasing the evaporator length also decreases the shear stress in the evaporator, which precludes the attenuation of the liquid film. The interactions of above will lead to an impact that the height of the liquid pool equals to zero under low heat fluxes. This phenomenon is unique compared with other parameters.

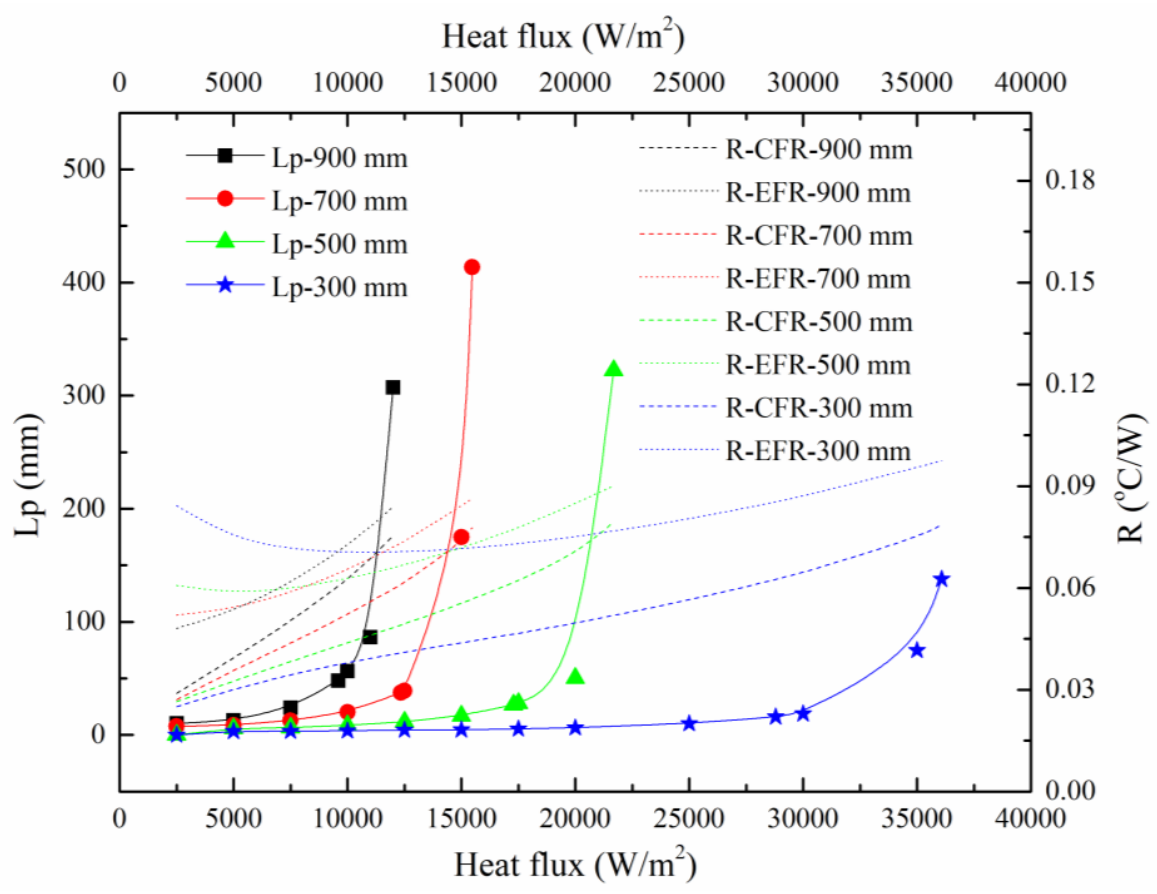

Fig.12 Effect of evaporator length on the height of liquid pool and the thermal resistance of TPCT

\subsection{Effect of the inner diameter of TPCT}

Fig.13 displays the effect of inner diameter on the filling range of TPCT. It elaborates that increasing the inner diameter of TPCT significantly increases the area of operation envelope. That is, increases the heat fluxes corresponding to boiling limit and flooding limit. Such an increase is because increasing the inner diameter of TPCT decreases the internal vapor velocity and further lowers the shear stress at the liquid-vapor interface. Correspondingly, the boiling limit and flooding limit occur at the much higher heat fluxes. Moreover, increasing the inner diameter increases the EFR (most of the time) and decreases the CFR, which increases the filling range at the same time. The decrease of CFR is caused by the decrease of liquid film thickness, 
while the increase of the EFR is caused by the decrease of void fraction in the liquid pool. However, the changing gradient with the inner diameter is different. The changing gradient of CFR is more sensitive, the smaller the inner diameter, the bigger the gradient; while the changing gradient of EFR is more modest. Additionally, the proportion of the area corresponding to the deprecated region shrinks with increasing the inner diameter.

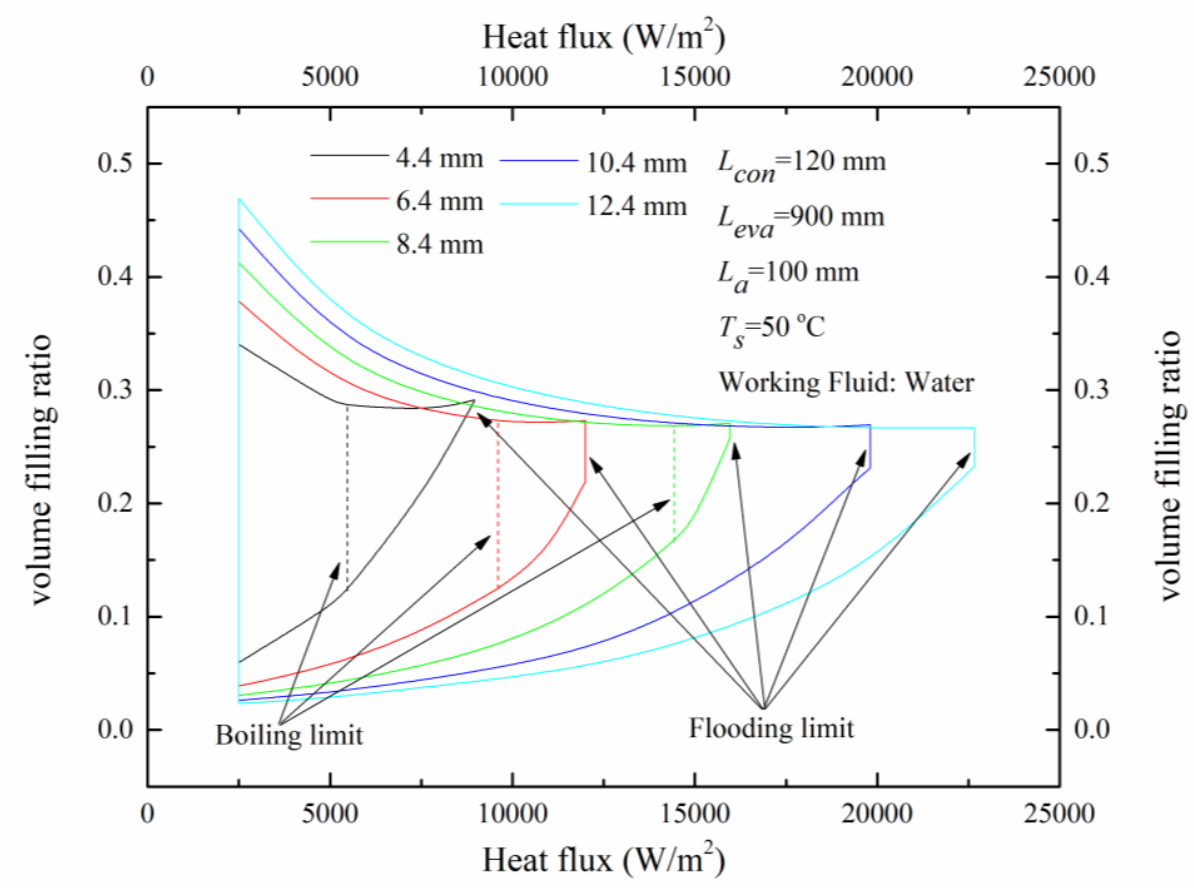

Fig.13 Effect of inner diameter on the filling range of TPCT

There are two additional variations needs to be specially pointed out. Firstly, the EFR is not always decreased with increasing the heat flux; there is an increase near the end. The smaller the inner diameter, the bigger the increase. Actually, a similar trend can also be found in Figs.8,10,11. Such an increase is because increasing the heat flux corresponding to the flooding limit increases the void fraction insignificantly but increases the liquid film thickness significantly, which consequently raises the EFR. Therefore, increasing the condenser length (see Fig.8) and adiabatic length (see Fig.10), and decreasing the evaporator length (see Fig.11) and inner diameter (see Fig.13), can all magnify the fact. Secondly, the boiling limit disappears as the inner diameter bigger than $8.4 \mathrm{~mm}$. It is because the heat fluxes corresponding to the boiling limit are higher than that of the flooding limit under these conditions. It further 
infer that the boiling limit, rather than flooding limit, is more sensitive to the inner diameter.

The effects of inner diameter on the height of the liquid pool and the thermal resistance are presented in Fig.14. It shows clearly that the thermal resistance decreases with increasing the inner diameter. The effect is similar to that of the condenser length. Such a decrease is because increasing the inner diameter decreases the liquid film thicknesses in both the condenser and evaporator, therefore lowers the thermal resistance. Besides, the height of the liquid pool decreases with increasing the inner diameter, which further decreases the thermal resistance at CFR. However, the maximum height of the liquid pool at CFR, corresponding to the flood limit, seems also rule-less with increasing the inner diameter.

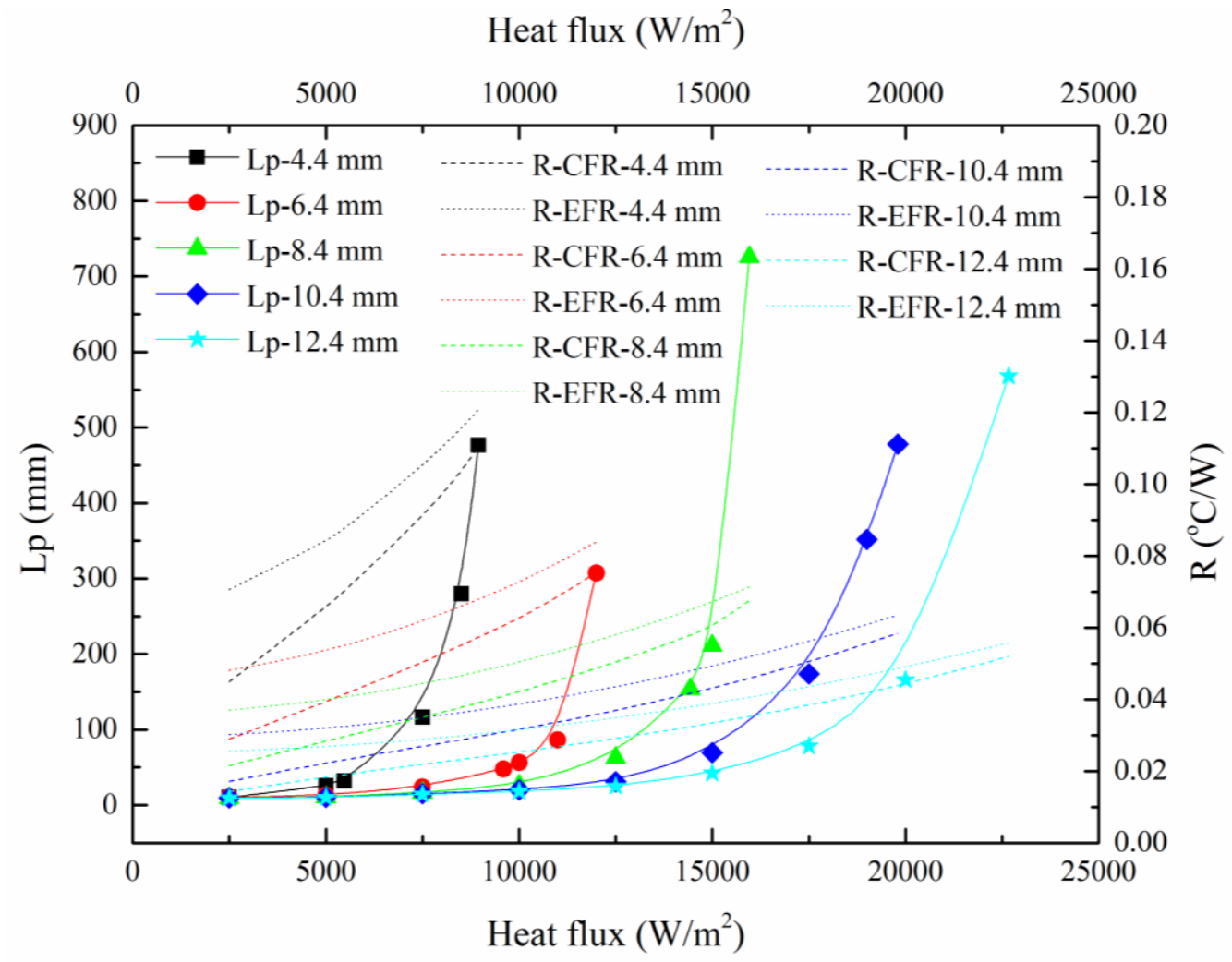

Fig.14 Effect of inner diameter on the height of the liquid pool and the thermal resistance of TPCT 4.5 Effect of vapor temperature

Fig.15 displays the effect of vapor temperature on the filling range of TPCT. It indicates that increasing the vapor temperature also significantly increases the area of the operation envelope. That is, increases the heat fluxes corresponding to the boiling 
limit and flooding limit. It is because increasing the vapor temperature causes a dramatic plunge in shear stress at the liquid-vapor interface, and further obviously increases the heat flux corresponding to flooding limit. Moreover, increasing the vapor temperature increases the EFR and decreases the CFR, and therefore increases the filling range at the same time. The decrease of CFR can also refer to the dramatic plunge in shear stress, because it leads to an evident decrease in liquid film thickness. However, the increase of EFR is determined by the decrease of the mean void fraction in the liquid pool. Besides, as shown in Fig.15, the gradient of increase in EFR is opposite to the gradient of decrease in CFR. That is, when increasing vapor temperature, the curves of EFR are receding while the curves of CFR are approaching. However, the proportion of the area corresponding to the deprecated region is insensitive with increasing the vapor temperature.

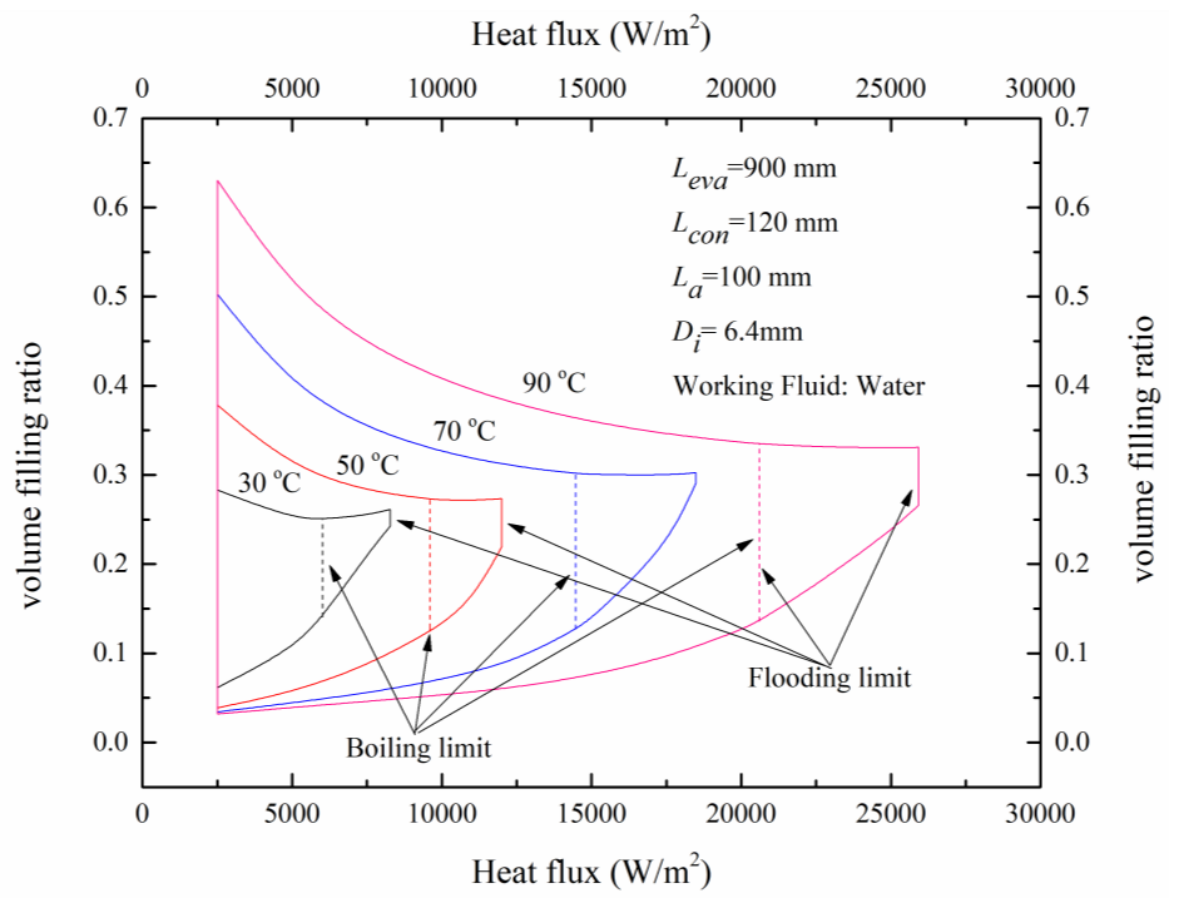

Fig.15 Effect of vapor temperature on the filling range of TPCT

The effects of vapor temperature on the height of the liquid pool and the thermal resistance are presented in Fig.16. It shows clearly that the thermal resistance decreases with increasing the vapor temperature. Such a decrease is because increasing the vapor temperature decreases the liquid film thicknesses in condenser and evaporator, therefore lowers the thermal resistance. Besides, the height of the 
liquid pool also decreases with increasing the vapor temperature, which further decreases the thermal resistance at CFR. However, the maximum height of the liquid pool at CFR, corresponding to the flood limit, seems also rule-less with increasing the vapor temperature.

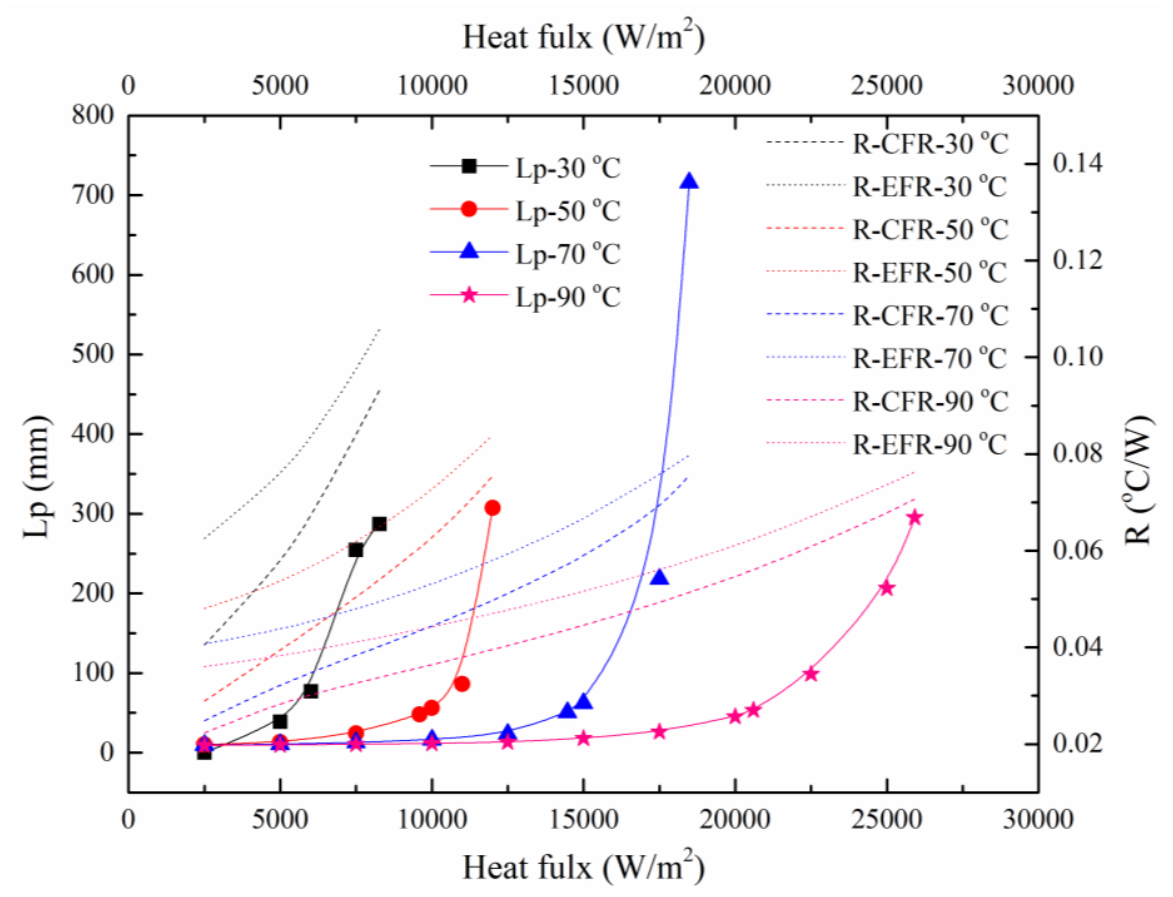

Fig.16 Effect of vapor temperature on the height of liquid pool and the thermal resistance of TPCT

\subsection{Fitting of CFR}

For the applicable CFR, Streltsov [34] developed a simplified correlation, as a function of power throughput, geometries of TPCT and thermophysical properties of the working fluid, to seek its concrete value. Streltsov [34] assumed that the liquid film thickness increased from zero in the condenser, unchanged in adiabatic section, decreased in the evaporator and finally decreased to zero at the end of the evaporator. Moreover, evaporation process within the liquid film was assumed as the inverse process of filmwise condensation. Based on above assumptions, the suggested CFR was expressed as:

$C F R_{0}=\left(\frac{4}{5} L_{c o n}+L_{a}+\frac{4}{5} L_{\text {eva }}\right)\left(\frac{3 \mu_{l} \rho_{l} \pi^{2} D_{i}^{2} \Phi}{h_{f g} g}\right)^{1 / 3}$

Ratios between the simulated results by present study and Streltsov [34] are displayed in Fig.17, in which the effects of heat flux, evaporator length, condenser 
length and inner diameter are illustrated in detail. One important proviso, the latter three are calculated on the basis that the heat flux equals to $5000 \mathrm{~W} / \mathrm{m}^{2}$. The results show that the ratio decreases with increasing the inner diameter and condenser length, but increases with increasing the evaporator length. Meanwhile, the ratio is significantly influenced by heat flux while modestly influenced by the latter three variables. For the former, it is because the height of the liquid pool is significantly determined by the heat flux. However, for the latter three, the interactions of inhibiting effect mentioned above lead to their modest effects on the ratio.

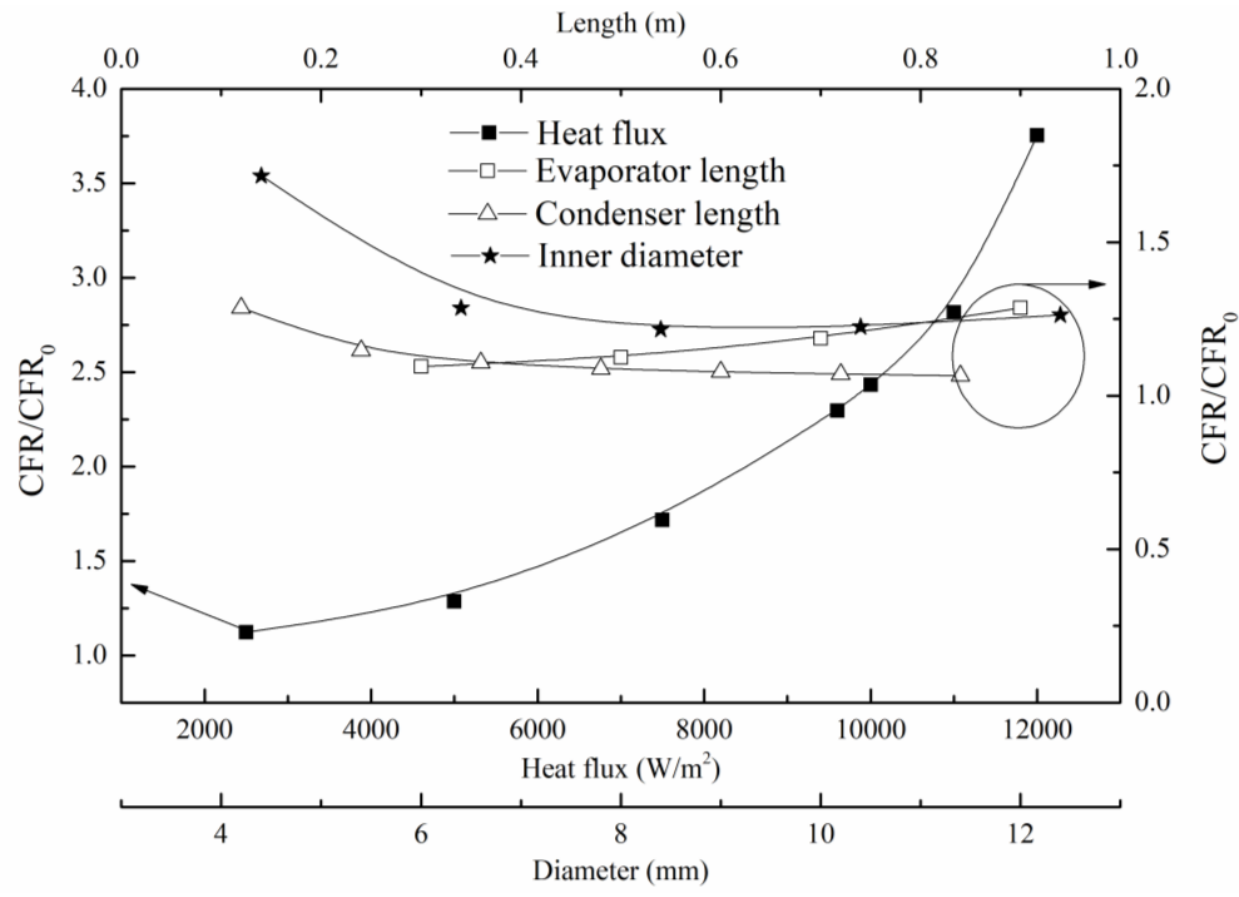

Fig.17 Comparison of CFR between the present study and Streltsov [32]

To sum up, for Eq. (48), ignoring the liquid pool in the evaporator (the decisive factor of CFR most of the time) and ignoring the interfacial shear stresses in both evaporator and condenser limit its applying ranges and make the prediction of CFR much smaller than the real situation. However, as mentioned above, the height of the liquid pool, as a function of geometries, is ruleless. And, also because of that, the authors find it is hard to acquire correlation between the present study and the Eq. (48).

In most cases, the heat fluxes corresponding to the onset of boiling are lower than that of the flooding limit. Heat fluxes below the boiling limit are therefore 
suggested in practical applications. A fitting correlation, based on the simulated results of present model, is developed by the authors:

$$
C F R=\frac{1.2}{1-0.86\left(q^{*}\right)^{-0.30}}\left(L_{e v a}^{*}\right)^{-0.32}\left(1+0.14 L_{a}^{*}\right)\left(D_{i}^{*}\right)^{-0.53}\left(\frac{1+2.67 e^{-7.84 L_{\text {con }}^{*}}}{\left(L_{c o n}^{*}\right)^{-0.4}}\right)
$$

Where $q^{*}=q_{\text {eva }} / q_{\text {bl }}, L_{\text {eva }}^{*}=L_{\text {eva }} / 0.9, L_{a}^{*}=L_{a} / 0.1, L_{c o n}^{*}=L_{c o n} / 0.84, D_{i}^{*}=D_{i} / 0.0124$.

Note that, when applying Eq.(48), the heat flux corresponding to the boiling limit through Eq.(39) should be firstly calculated. However, since the heat fluxes corresponding to the boiling limit are smaller than that of the flooding limit when inner diameter is bigger than $8.4 \mathrm{~mm}$ in the present study. The scope of Eq. (49) is limited as follows:

$0.3 \leq L_{\text {eva }} \leq 0.9,0.12 \leq L_{\text {con }} \leq 0.84,0.0044 \leq D_{i} \leq 0.0084$

Additionally, Eq.(49) is proposed on the premise of that the working fluid is water and the vapor temperature is $50^{\circ} \mathrm{C}$.

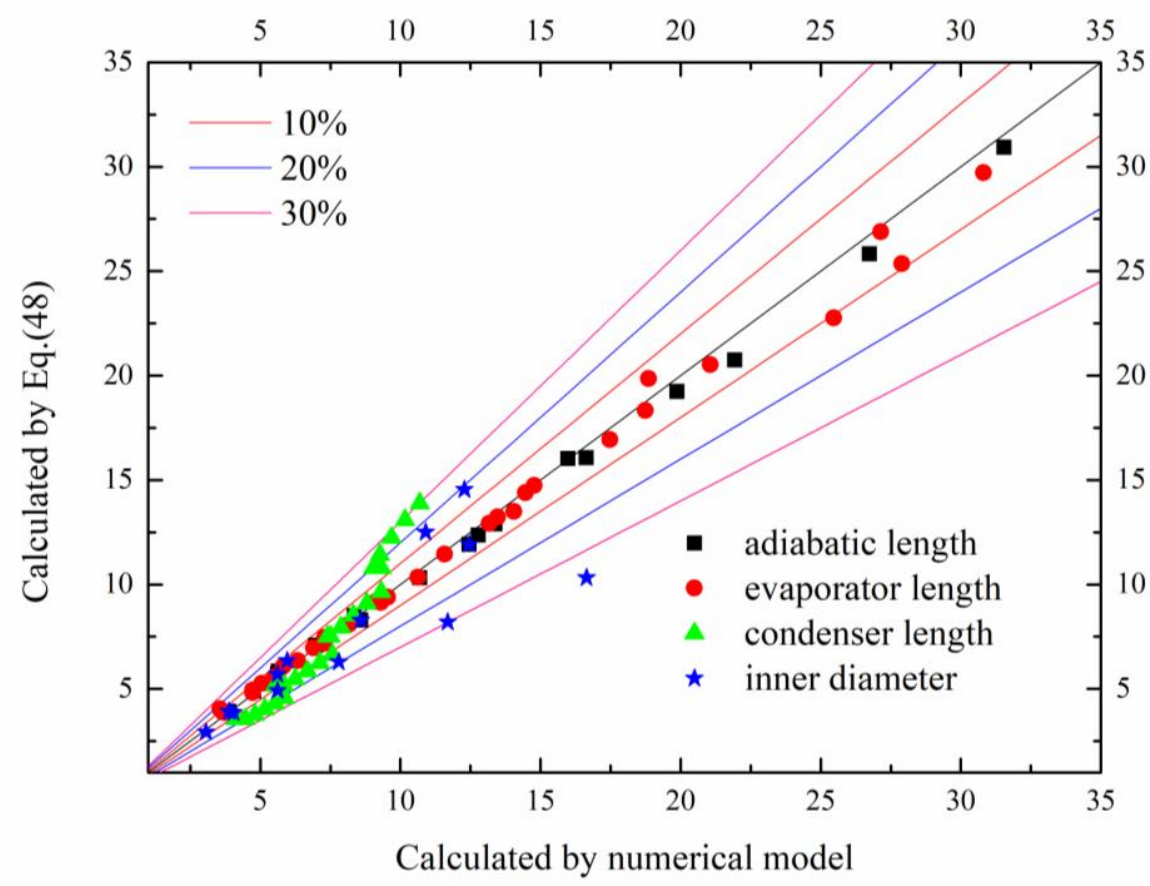

Fig.18 Comparison of CFR between the numerical study and Eq. (49)

The comparisons of CFR, which are respectively calculated by simulation and Eq. (49), are displayed in Fig.18. The results indicate that, for the whole, the agreements are within $30 \%$. However, for the results by varying the adiabatic length 
and evaporator length, the agreements are within $12 \%$. The results vary much when varying the condenser length and inner diameter. It may due to the influence mechanisms of that two parameters are more complicated; it needs, however, a more detailed TPCT model to reveal that.

\section{Conclusions}

There are three heat transfer regimes, in dependence on the heat flux, within the falling liquid film in the evaporator of a TPCT. However, only the laminar convection film evaporation was generally postulated in the previous works. In the present study, the entrainment rate, which is caused by the countercurrent vapor flow during the nucleate boiling within the falling liquid film, is considered and introduced; and a governing equation is developed for the nucleate boiling filmwise evaporation. Based on that, a comprehensive model with considering all the three heat transfer regimes in the evaporator is further established. The suggested CFR and EFR are then determined and updated by utilizing the criterias for local dryout, flooding limit and boiling limit. Effects of geometries and temperature on the filling range are further analyzed in detail; a simplified correlation for CFR is finally proposed based on the numerical data. The following conclusions can be made:

1. The predictions of the distribution of film thickness and the onset of flooding are in good agreement with the published experimental data and numerical simulation results. The droplet entrainment significantly influences the thickness and distribution of the liquid film.

2. A parametric analysis is implemented to investigate the effects of vapor temperature, inner diameter and the lengths of the condenser, adiabatic section and evaporator, on the filling range and thermal performance. The most important influences are those of the vapor temperature, inner diameter and evaporator length. Increasing vapor temperature and inner diameter and decreasing the evaporator length significantly enlarge the filling range (between CFR and EFR), operation envelope (corresponding to boiling limit and flooding limit) and thermal performance of TPCT, despite the changes in gradient vary from each other. Increasing the condenser length increases the filling range and operation envelope 
to a small extent while increasing the adiabatic length slightly upward the filling range.

3. The influence mechanisms of the optimum filling ratio, namely CFR, by the heat flux and geometries are complicated. The height of the liquid pool in the evaporator, which is significantly affected by the heat flux, and the interfacial shear stress, which is affected by the geometries of TPCT, both contribute to that. Within the limited scope, a simplified correlation is proposed by the authors, the agreement of the equation with the simulated results is within $\pm 30 \%$ on the whole.

\section{Acknowledgment}

This work has been sponsored by the Shanghai Sailing Program (18YF1409100), Shanghai Local Capacity Building Program (18020501000), which are gratefully acknowledged by the authors.

\section{References}

[1] Davoud Jafari, Alessandro Franco, Sauro Filippeschi, Paolo Di Marco. Two-phase closed thermosyphons: A review of studies and solar applications, Renewable and Sustainable Energy Reviews, 2016, 53:575-593.

[2] Tao Zhang, Zhiwei Yan, Gang Pei, Qunzhi Zhu, Jie Ji. Experimental optimization on the volume-filling ratio of a loop thermosyphon photovoltaic/thermal system, Renewable Energy, 2019, 143:233-242.

[3] Tao Zhang, Gang Pei, Qunzhi Zhu, Jie Ji. Investigation of the optimum volume-filling ratio of a loop thermosyphon solar water-heating system, Journal of Solar Energy Engineering-T ASME, 2016,138(4): 041006.

[4] Davoud Jafari, Sauro Filippeschi, Alessandro Franco, Paolo Di Marco. Unsteady experimental and numerical analysis of a two-phase closed thermosyphon at different filling ratios, Experimental Thermal and Fluid Science, 2017, 81:164-174.

[5] H. Imura, K.Sasaguchi, H. Kozai, S.Numata. Critical heat flux in a closed two-phase thermosyphon, International Journal of Heat and Mass Transfer, 1983, 26(8): 1181-1188.

[6] K. Harada, S.Inoue, J. Fujita, H. Suematsu, Y. Wakiyama. Heat transfer characteristics of large heat pipes (in Japanese), Hitachi Zosen Giho, 1980, 41:167-174.

[7] Feleman Jr K T, Srinivasan R. Investigation of heat transfer limits in two-phase closed thermosyophon, In: Proceeding of $5^{\text {th }}$ International Heat Pipe Conference, 1984, Tsukuba, Japan, 
192-205.

[8] Negishi K, Sawada T. Heat transfer performance of an ITPCT, International Journal of Heat and Mass Transfer 1983, 26(8): 1207-1213.

[9] S.H.Noie. Heat transfer characteristics of a two-phase closed thermosyphon, Applied Thermal Engineering, 2005, 25(4): 495-506.

[10] Yong JooPark, Hwan Kook Kang, Chul JuKim. Heat transfer characteristics of a two-phase closed thermosyphon to the fill charge ratio, International Journal of Heat and Mass Transfer, 2002, 45(23): 4655-4661.

[11] Zied Lataoui, Abdelmajid Jemni. Experimental investigation of a stainless steel two-phase closed thermosyphon, Applied Thermal Engineering, 2017, 121:721-727.

[12] J.G. Reed and C.L.Tien. Modeling of the two-phase closed thermosyphon, Journal of Heat Transfer, 1987,109(3):722-730.

[13] Z.J.Zuo and F.S. Gunnerson. Numerical modeling of the steady-state two-phase closed thermosyphon, International Journal of Heat and Mass Transfer, 1994, 37(17): 2715-2722.

[14] B. Jiao, L.M. Qiu, X.B. Zhang, Y. Zhang. Investigation on the effect of filling ratio on the steady-state heat transfer performance of a vertical two-phase closed thermosyphon, Applied Thermal Engineering, 2008,28(11-12): 1417-1426.

[15] M.S.El-Genk, H.H.Saber. Heat transfer correlations for liquid film in the evaporator of enclosed, gravity-assisted thermosyphons, Journal of Heat Transfer, 1998,120(2): 477-484.

[16] M.S.El-Genk and H.H Saber. Determination of operation envelopes for closed, two-phase thermosyphon, International Journal of Heat and Mass Transfer, 1999, 42(5): 889-903.

[17] B. Jiao,L. M. Qiu, Z. H. Gan,X. B. Zhang. Determination of operation range of a vertical two-phase closed thermosyphon, Heat and Mass Transfer, 2012, 48(6): 1043-1055.

[18] Hamidreza Shabgard, Bin Xiao, Amir Faghri, Ramesh Gupta, Walter Weissman. Thermal characteristics of a closed thermosyphon under various filling conditions, International Journal of Heat and Mass Transfer, 2014, 70:91-102.

[19] Cerza M and V.Sernas. A bubble growth model for nucleate boiling in thin, falling, superheated, laminar water films, International Journal of Heat and Mass Transfer, 1985, 28(7): 1307-1316.

[20] Cerza M and V.Sernas. Boiling and dryout in falling thin films. In: National Heat Transfer Conference-Heat Transfer Measurements, Analysis, and Flow visualization-ASME,1989, Philadelphia, USA, 112, 107-108.

[21] Yang Pan. Condensation characteristics inside a vertical tube considering the presence of mass transfer, vapor velocity and interfacial shear, International Journal of Heat and Mass Transfer, 2001,44(23):4475-4482. 
[22] M.S.El-Genk, H.H.Saber. Flooding limit in closed, two-phase flow thermosyphons, International Journal of Heat and Mass Transfer, 1997, 40(9): 2147-2164.

[23] R.V.A.Olinmans, B.F.M.Pots, N. Trompe. Modeling of annular dispersed two-phase flow in vertical pipes, International Journal of Multiphase Flow, 1986, 12(5): 711-732.

[24] Kataoka, I., Ishii, M.,. Entrainment and deposition rates of droplets in annular two-phase flow. In: Conference ASME-JSME Thermal Engineering Joint Conference, 1983, Honolulu, HI, USA.

[25] Kataoka, I., Ishii, M., Nakayama, A.,. Entrainment and deposition rates of droplets in annular two-phase flow. International Jounal of Heat and Mass Transfer, 2000, 43, 1573-1589.

[26] M.S. El-Genk, H.H. Saber. Heat transfer correlations for small, uniformly heated liquid pools, International Journal of Heat and Mass Transfer, 1998, 41(2):261-274.

[27] Isao Kataoka, Mamoru Ishii. Drift flux model for large diameter pipe and new correlation for pool void fraction, International Journal of Heat and Mass Transfer, 1987, 30(9): 1927-1939.

[28] Kwang-Won Lee, Se-Jin Baik, Tae-Sun Ro. An utilization of liquid sublayer dryout mechanism in predicting critical heat flux under low pressure and low velocity conditions in round tubes, Nuclear Engineering and Design, 2000,200(1-2): 69-81.

[29] Amir Faghri. Review and Advances in Heat Pipe Science and Technology, Journal of Heat Transfer, 2012, 134(12):123001.

[30] K.W.Mcquillan, P.B.Whalley. Flow patterns in vertical two-phase flow, International Journal of Multiphase Flow, 1985,11(2):161-175.

[31] Shiraishi M, Yoneya M, Yabe A. Visual study of operating limit in the two-phase closed thermosyphon, Proceedings of the $5^{\text {th }}$ International Heat Pipe Conference, 1984, Tsukuba, Japan, $10-17$.

[32] S.J.Chen, J.G. Reed, C.L.Tien. Reflux condensation in a two-phase closed thermosyphon, International Journal of Heat and Mass Transfer, 1984, 27(9): 1587-1594.

[33] Gang Pei, Tao Zhang, Huide Fu, Jie Ji, Yuehong Su. An experimental study on a novel heat-pipe type photovoltaic/thermal system with and without a glass cover, International Journal of Green Energy, 2012, 10(1): 72-89.

[34] A.I.Streltsov. Theoretical and experimental investigation of optimum filling for heat pipes, Heat Transfer-Soviet Research, 1975, 7(1): 23-27. 
Click here to access/download RDM Data Profile XML DataProfile_4432146.xml 


\section{Conflict of interest statement}

We declare that we have no financial and personal relationships with other people or organizations that can inappropriately influence our work, there is no professional or other personal interest of any nature or kind in any product, service and/or company that could be construed as influencing the position presented in, or the review of, the manuscript entitled, "Droplet entrainment within the evaporator to the suitable volume-filling ratio of a vertical two-phase closed thermosyphon". 